\title{
Water in Albitic Glasses
}

\author{
by LYNN SILVER * AND EDWARD STOLPER
}

\author{
Division of Geological and Planetary Sciences, California Institute of Technology, Pasadena, \\ California 91125
}

(Received 18 September 1987; revised typescript accepted I September 1988)

\begin{abstract}
A BSTRACT
Infrared spectroscopy has been calibrated to provide a precise and accurate method for determining the concentrations of molecular water and hydroxyl groups in hydrous albitic glasses. At total water contents less than $4 \mathrm{wt} . \%$, most of the water is dissolved as hydroxyl groups; at higher total water contents, molecular water becomes the dominant species. For total water contents above $4 \mathrm{wt} \%$, the amount of water dissolved as hydroxyl groups is nearly constant at about $2 \mathrm{wt} . \%$ and additional water is incorporated as molecular water. These trends in the concentrations of the H-bearing species are similar to those observed in other silicate glasses using infrared and NMR spectroscopies. The ratio of molecular water to hydroxyl groups at a given total water content is independent of the pressure and only weakly dependent on the temperature of equilibration.

Molecular water and hydroxyl group concentrations in glasses provide constraints on the dissolution mechanisms of water in silicate liquids. Several mixing models involving homogeneous equilibria of the form $\mathrm{H}_{2} \mathrm{O}+\mathrm{O}^{2-}=2 \mathrm{OH}^{-}$among melt species in albitic melts have been developed. These models can account for the measured species concentrations if the effects of non-ideal behavior or mixing of polymerized units are included, or by allowing for several different anhydrous species.

We used two thermodynamic models of hydrous albitic melts to calculate phase equilibria. The first assumes that Henry's law holds for molecular water in albitic liquids; i.e. that the activity of molecular water in the melt is proportional to its mole fraction as determined by infrared spectroscopy. The second describes the speciation and thermodynamics of hydrous albitic melts using the formalism of a strictly regular solution. These models can account reasonably well for the position of the vaporsaturated solidus of high albite and the pressure and temperature dependence of the solubility of water in albitic melts. To the extent that these models are successful, our approach provides a direct link between measưred species concentrations in hydrous albitic glasses and the macroscopic thermodynamic properties of the $\mathrm{NaAlSi}_{3} \mathrm{O}_{8}-\mathrm{H}_{2} \mathrm{O}$ system.
\end{abstract}

\section{INTRODUCTION}

About fifty years have passed since Goranson first reported on the solubility of water in albitic melt at elevated pressure and on the influence of water pressure on the melting of crystalline albite (Goranson, 1936, 1938): Interest in these problems has not waned, however, as evidenced by the fact that in just the past few years there have been three new publications reporting the solubility of water in albitic melts (Blamart et al., 1986; Hamilton \& Oxtoby, 1986; Richet et al., 1986) and two on the melting of crystalline albite at elevated water pressure (Goldsmith \& Jenkins, 1985; Luth \& Boettcher, 1986). Goranson's pioneering studies have stood up to a remarkable degree, but it is not surprising that petrologists have returned again and again to investigate the effects of water on the physical and chemical properties of silicate melts given the abundant evidence of the importance of water in the evolution of terrestrial igneous systems.

Until recently, experimental investigations of water-bearing melts have, as did those first studies by Goranson, focused on their bulk, macroscopic properties; for example, measure- 
ments of water solubility and of the effects of water pressure on solid-liquid phase equilibria, or of the effects of dissolved water on transport properties such as viscosity, electrical conductivity, and diffusivities of water and other components in hydrous melts and glasses (e.g., Burnham, 1975, 1979; Takata et al., 1981; Watson, 1981; Karsten et al., 1982). Although they provide ample documentation of the influence of water on the properties of silicate melts and have been widely used to constrain thermodynamic models of hydrous silicate melts, these studies give few direct insights into the molecular level interactions that take place when water dissolves in molten silicates. In recent years, petrologists have turned increasingly to spectroscopic studies of hydrous glasses to provide such insights and to understand better how water affects the physical and chemical properties of magmas. Through such investigations, the H-bearing species in hydrous systems can be identified and their concentrations measured, their motional properties can be characterized, and the changes in the silicate framework accompanying the dissolution of water can be ascertained (Bartholomew et al., 1980; Bartholomew \& Schreurs, 1980; Mysen et al., 1980; Mysen \& Virgo, 1980, 1986a, b; Wu, 1980; Stolper, 1982a; McMillan et al., 1983, 1986; McMillan \& Remmele, 1986; Eckert et al., 1987, 1988; Farnan et al., 1987).

In this paper, we report the results of an investigation of the speciation of water* in hydrous albitic glasses quenched from melts equilibrated over a range of pressures and temperatures. We first determined the molar absorption coefficients of the infrared absorption bands in glasses due to the presence of dissolved molecules of water and hydroxyl groups. We then used this calibration to measure the concentrations of these species in hydrous albitic glasses synthesized under various conditions. These measurements were used to develop thermodynamic models of the homogeneous equilibria between the various melt species and of the heterogeneous equilibria between melt, vapor, and crystalline albite following the approach outlined in Stolper (1982b) and Silver \& Stolper (1985). The variations in the concentrations of water molecules and hydroxyl groups in silicate glasses as a function of the total dissolved water content and the thermodynamic models based on these measurements provide a basis for rationalizing the phase equilibria and physical properties of hydrous melts. To the extent that the approach we have taken in this study is successful, it provides a direct and quantitative link between measurements of microscopic molecular level characteristics of silicate melts - that is, of species concentrations - and descriptions of their macroscopic physical and chemical properties.

\section{EXPERIMENTAL METHODS}

Most of the starting materials used in this study were glasses prepared from crystalline Amelia albite or a synthetic oxide mixture of albite composition. Amelia albite was ground in agate to a powder under ethanol and then dried at $800^{\circ} \mathrm{C}$ in air for $24 \mathrm{~h}$ to remove any hydrocarbon residue; the powdered albite was melted in air at $1300^{\circ} \mathrm{C}$ and quenched to glass; the glass was then finely ground and heated at $800^{\circ} \mathrm{C}$ as described above. The synthetic oxide mixture was prepared by grinding approximate amounts of $\mathrm{Na}_{2} \mathrm{CO}_{3}$, $\mathrm{Al}_{2} \mathrm{O}_{3}$, and $\mathrm{SiO}_{2}$ (Johnson-Matthey SpecPure Reagents) in agate under ethanol for $6 \mathrm{~h}$; this mixture was then melted in air at $1200^{\circ} \mathrm{C}$ for $1 \mathrm{~h}$ and quenched to glass; the glass was ground under ethanol and heated as described above. Both batches of starting materials were stored over desiccant.

\footnotetext{
*Throughout this paper, we use 'water' to refer to total water content (i.e. water dissolved as hydroxyl groups plus that dissolved as water molecules) or to the component $\mathrm{H}_{2} \mathrm{O}$ in the system $\mathrm{NaAlSi}_{3} \mathrm{O}_{8}-\mathrm{H}_{2} \mathrm{O}$. Only when specifically indicated (e.g., 'molecular water', 'water molecules') will we be referring to the molecular species or its concentration.
} 
Major element concentrations were measured on selected glass samples by electron microprobe to assess glass homogeneity, to verify glass compositions, and to determine the extent of sodium loss during melting and drying. The glasses were analyzed with a JEOL 733 electron microprobe using an accelerating voltage of $15 \mathrm{kV}$, a beam current of $5 \mathrm{nA}$, and a $20-25 \mu \mathrm{m}$ spot size. The analyses are listed in Table 1 . Both starting materials are slightly non-stoichiometric, probably reflecting Na-loss during melting and/or contamination by silica during grinding. As discussed below, the effects of this non-stoichiometry on our results are thought to be negligible.

Hydrous glasses were synthesized by quenching from melts held at elevated pressure and temperature. Most of the glass samples were synthesized in a piston cylinder apparatus at Caltech. The powdered starting materials together with known amounts of triply distilled deionized $\mathrm{H}_{2} \mathrm{O}$ were weighed into $\mathrm{Pt}$ capsules, which were then sealed by arc-welding. These capsules were run in a $0.5 \mathrm{inh}$. solid-media piston cylinder apparatus using a $\mathrm{NaCl}$ or talc cell with a pyrex sleeve at pressures between 8 and $25 \mathrm{~kb}$ and temperatures between 1000 and $1600^{\circ} \mathrm{C}$ (see Fine \& Stolper, 1985, for experimental details). In all but one case, the capsules were held at constant pressure and temperature for the duration of the run; one experiment (ABC-34) was held at $13 \mathrm{~kb}, 1200^{\circ} \mathrm{C}$ for $0.5 \mathrm{~h}$, then the pressure was decreased to $8 \mathrm{~kb}$, and the sample was held at this lower pressure for $2 \mathrm{~h}$. At the end of most experiments, the power was shut off and the run cooled at a rate of $150-200^{\circ} \mathrm{C} / \mathrm{s}$ to $100^{\circ} \mathrm{C}$ (unless otherwise noted). Several runs were cooled at controlled cooling rates $\left(0 \cdot 3-2 \cdot 5^{\circ} \mathrm{C} / \mathrm{s}\right)$ using a Eurotherm Model 125 programmer. All of the run conditions are listed in Table 2 .

Two samples (JRH-1, JRH-2) were synthesized from a gel in a piston cylinder apparatus in Professor Holloway's laboratory at the Arizona State University and are described in McMillan et al. (1983). Several samples were synthesized in Professor Boettcher's laboratory at the University of California, Los Angeles, in a one inch piston cylinder apparatus, using a $\mathrm{NaCl}$ and boron nitride (BN) assembly (ALB-3378, ALB-3388, ALB-3399, ALB-3403, ABC$20, \mathrm{ABC}-21)$ or a $\mathrm{NaCl}$ and fired pyrophyllite assembly (ABC-26). The starting material for the ALB series was a fused natural albite supplied by Professor Boettcher; the ABC series used our fused Amelia albite as a starting material. Synthesis conditions for all of these samples are described in Table 2.

Several samples were synthesized in internally heated pressure vessels (IHPVs). Powdered starting materials were sealed in Pt or Au capsules with known amounts of triply distilled water and held at pressures between 1 and $7 \mathrm{~kb}$ and temperatures between 1000 and $1150^{\circ} \mathrm{C}$ in a $3 / 4$ in. bore IHPV at the Johnson Space Center, using a setup similar to that described

\section{TABLE 1}

Anhydrous glass compositions

\begin{tabular}{lccc}
\hline & $\begin{array}{c}\text { Amelia } \\
\text { albite } \\
\text { glass }\end{array}$ & $\begin{array}{c}\text { Synthetic } \\
\text { albite } \\
\text { glass }\end{array}$ & $\begin{array}{c}\text { Ideal } \\
\text { albite }\end{array}$ \\
\hline $\mathrm{SiO}_{2}$ & 68.05 & $70 \cdot 19$ & $68 \cdot 74$ \\
$\mathrm{Al}_{2} \mathrm{O}_{3}$ & 19.98 & $19 \cdot 18$ & $19 \cdot 44$ \\
$\mathrm{FeO}$ & 0.03 & 0 & 0 \\
$\mathrm{CaO}$ & 0.16 & 0 & 0 \\
$\mathrm{~K}_{2} \mathrm{O}$ & 0.18 & 0 & 0 \\
$\mathrm{Na}_{2} \mathrm{O}$ & 11.60 & 10.63 & 11.82 \\
\hline
\end{tabular}

Note: Reported values (given in weight percent) have been normalized to $100 \%$ and are based on averages of ten individual electron microprobe analyses per sample. 
TABLE 2

Hydrous albitic glasses: piston cylinder experiments

\begin{tabular}{|c|c|c|c|c|c|c|c|c|c|c|c|c|c|}
\hline \multirow[b]{2}{*}{ Sample } & \multirow{2}{*}{$\begin{array}{l}\text { Starting } \\
\text { material }\end{array}$} & \multirow{2}{*}{$\begin{array}{c}\mathrm{P} \\
(k b)\end{array}$} & \multirow{2}{*}{$\begin{array}{c}\mathrm{T} \\
\left({ }^{\circ} \mathrm{C}\right)\end{array}$} & \multirow{2}{*}{$\begin{array}{l}\text { Time } \\
(\mathrm{min})\end{array}$} & \multirow{2}{*}{$\begin{array}{l}\text { Density }{ }^{6} \\
(g / l)\end{array}$} & \multirow{2}{*}{$\begin{array}{l}\mathrm{H}_{2} \mathrm{O}, \mathrm{mol}^{1} \\
\quad w t . \%\end{array}$} & \multirow{2}{*}{$\begin{array}{l}O H^{1} \\
w t . \%\end{array}$} & \multirow{2}{*}{$\begin{array}{c}\mathrm{H}_{2} \mathrm{O}_{\mathrm{tot}}^{3} \\
\operatorname{Sum}(w t . \%)\end{array}$} & \multirow{2}{*}{$\begin{array}{l}\mathrm{H}_{2} \mathrm{O}_{\mathrm{tot}}^{2} \\
(w t . \%)\end{array}$} & \multirow[b]{2}{*}{ Remarks $^{4}$} & \multicolumn{3}{|c|}{ Mole fractions ${ }^{5}$} \\
\hline & & & & & & & & & & & $\mathrm{X}_{B}$ & $\mathrm{X}_{\mathrm{H}_{2} \mathrm{O}}$ & $\mathrm{X}_{O H}$ \\
\hline $\mathrm{ABC}-34$ & Am.ab & 8 & 1200 & 120 & 2400 e & $3 \cdot 23$ & $2 \cdot 04$ & $5 \cdot 27$ & & $\mathrm{c}, \mathrm{f}$ & 0.092 & $0 \cdot 056$ & $0 \cdot 071$ \\
\hline AVS-4 & syn.ab & 10 & 1000 & 130 & $2425 \mathrm{~h}$ & $0 \cdot 75$ & $1 \cdot 54$ & $2 \cdot 29$ & & f & 0.041 & 0.013 & 0.055 \\
\hline JRH-1 & syn.gel & 10 & 1200 & 240 & $2391 \mathrm{e}$ & $2 \cdot 29$ & 1.99 & $4 \cdot 29$ & & $\mathrm{a}, \mathrm{c}$ & 0.075 & $0 \cdot 040$ & 0.070 \\
\hline JRH-2 & syn.gel & 10 & 1200 & 240 & $2350 \mathrm{e}$ & $4 \cdot 38$ & 1.92 & $6 \cdot 30$ & & $\mathrm{a}, \mathrm{c}$ & $0 \cdot 109$ & 0.076 & $0 \cdot 066$ \\
\hline ALB-3378 & fused $a b$ & 15 & 1100 & 120 & $2410 \mathrm{~d}$ & 2.67 & 1.98 & $4 \cdot 65$ & $4 \cdot 76(0 \cdot 14), 4 \cdot 6(0 \cdot 23)$ & $b, f, u$ & 0.081 & 0.047 & 0.069 \\
\hline ALB-3403 & fused $a b$ & 15 & 1100 & 30 & $2320 \mathrm{e}$ & $4 \cdot 55$ & $2 \cdot 01$ & $6 \cdot 56$ & $6.86(0.34)$ & $\mathrm{b}, \mathrm{f}, \mathrm{u}$ & $0 \cdot 113$ & 0.079 & 0.069 \\
\hline LAS-26 & Am.ab & 15 & 1200 & 120 & $2385 \mathrm{~h}$ & $2 \cdot 45$ & $2 \cdot 02$ & $4 \cdot 47$ & & $\mathrm{f}$ & 0.079 & 0.043 & $0 \cdot 071$ \\
\hline ALB-3388 & fused $a b$ & 15 & 1225 & 120 & $2430 \mathrm{~d}$ & $1 \cdot 26$ & $1 \cdot 74$ & $3 \cdot 00$ & $2.97(0.06), 2.97(0.15)$ & $b, f, u$ & $0 \cdot 053$ & 0.022 & $0 \cdot 062$ \\
\hline ALB-3399 & fused $a b$ & 15 & 1350 & 30 & $2475 \mathrm{~d}$ & $0 \cdot 13$ & $0 \cdot 85$ & 0.98 & & $\mathrm{~b}, \mathrm{f}, \mathrm{u}$ & $0 \cdot 018$ & 0.002 & 0.031 \\
\hline LAS-27 & Am.ab & 15 & 1400 & 120 & $2490 \mathrm{~h}$ & $0 \cdot 00$ & $0 \cdot 10$ & $0 \cdot 10$ & & $\mathrm{c}, \mathrm{f}$ & 0.002 & 0.000 & $0 \cdot 004$ \\
\hline A1003 & syn.ab & 15 & 1400 & 130 & $2490 \mathrm{e}$ & 0.00 & $0 \cdot 10$ & $0 \cdot 10$ & & f & 0.002 & 0.000 & 0.004 \\
\hline A1009 & Am.ab & 15 & 1400 & 80 & $2425 \mathrm{~h}$ & $0 \cdot 71$ & $1 \cdot 50$ & $2 \cdot 22$ & & $\mathrm{c}, \mathrm{f}$ & 0.040 & 0.013 & 0.054 \\
\hline A1010 & Am.ab & 15 & 1400 & 75 & $2410 \mathrm{~h}$ & $1 \cdot 20$ & $1 \cdot 77$ & $2 \cdot 97$ & & $c, f$ & 0.053 & $0 \cdot 021$ & 0.063 \\
\hline LAS-19 & Am.ab & 15 & 1400 & 120 & $2410 \mathrm{~h}$ & 1.84 & 1.90 & 3.74 & & $c, x$ & 0.066 & 0.033 & 0.067 \\
\hline LAS- 20 & Am.ab & 15 & 1400 & 120 & $2400 \mathrm{e}$ & 1.99 & 1.96 & 3.95 & & $c, w$ & 0.070 & 0.035 & 0.069 \\
\hline LAS-11 & Am.ab & 15 & 1400 & 120 & $2400 \mathrm{~h}$ & 1.94 & $2 \cdot 05$ & : 3.99 & & $\mathrm{c}, \mathrm{f}$ & 0.070 & $0 \cdot 034$ & $0 \cdot 072$ \\
\hline LAS-9 & Am.ab & 15 & 1400 & 120 & $2400 \mathrm{e}$ & $2 \cdot 04$ & $2 \cdot 06$ & $4 \cdot 11$ & & $\mathrm{c}, \mathrm{z}$ & 0.072 & 0.036 & 0.073 \\
\hline LAS-18 & Am.ab & 15 & 1400 & 120 & $2385 \mathrm{~h}$ & $2 \cdot 33$ & $2 \cdot 14$ & $4 \cdot 48$ & & $f, c, y$ & 0.079 & $0 \cdot 041$ & 0.075 \\
\hline A1012 & Am.ab & 15 & 1400 & 120 & $2375 \mathrm{e}$ & $2 \cdot 66$ & $2 \cdot 02$ & $4 \cdot 68$ & & $\mathrm{c}$ & 0.082 & 0.047 & $0 \cdot 071$ \\
\hline A1008 & Am.ab & 15 & 1400 & 85 & $2367 \mathrm{~h}$ & $3 \cdot 59$ & $2 \cdot 08$ & $5 \cdot 67$ & & $\mathrm{c}, \mathrm{f}$ & 0.099 & 0.062 & 0.072 \\
\hline A1011 & Am.ab & 15 & 1400 & 153 & $2330 \mathrm{~h}$ & $4 \cdot 58$ & $2 \cdot 20$ & $6 \cdot 78$ & & f & $0 \cdot 117$ & 0.079 & 0.076 \\
\hline LAS-22 & Am.ab & 15 & 1400 & 120 & $2325 \mathrm{~h}$ & $4 \cdot 69$ & $2 \cdot 30$ & 6.99 & & f & $0 \cdot 120$ & 0.081 & 0.079 \\
\hline LAS-23 & Am.ab & 15 & 1400 & 120 & $2300 \mathrm{e}$ & 600 & $2 \cdot 40$ & $8 \cdot 41$ & & c & $0 \cdot 143$ & $0 \cdot 102$ & 0.082 \\
\hline LAS-21 & Am.ab & 15 & 1400 & 120 & $2280 \mathrm{e}$ & $7 \cdot 40$ & $2 \cdot 26$ & $9 \cdot 65$ & & c & $0 \cdot 163$ & 0.125 & 0.076 \\
\hline LAS-29 & Am.ab & 15 & 1600 & 45 & $2420 \mathrm{~h}$ & $1 \cdot 19$ & 1.71 & $2 \cdot 90$ & & f & $0 \cdot 052$ & 0.021 & $0 \cdot 061$ \\
\hline AVS-7 & syn.ab & 19 & 1000 & 130 & $2325 \mathrm{e}$ & $5 \cdot 11$ & $2 \cdot 35$ & $7 \cdot 46$ & & c & $0 \cdot 128$ & 0.088 & 0.081 \\
\hline $\mathrm{ABC}-22$ & Am.ab & 20 & 1400 & 180 & $2475 \mathrm{e}$ & 0.00 & 0.18 & $0 \cdot 18$ & & f & 0.003 & 0.000 & 0.006 \\
\hline
\end{tabular}




\begin{tabular}{|c|c|c|c|c|c|c|c|c|c|c|c|c|c|}
\hline ABC-12 & Am.ab & 20 & 1400 & 437 & $2475 \mathrm{~h}$ & 0.00 & $0 \cdot 21$ & $0 \cdot 21$ & & f & 0.004 & 0.000 & 0.008 \\
\hline ABC-10 & Am.ab & 20 & 1400 & 437 & $2475 \mathrm{~h}$ & 0.00 & $0 \cdot 27$ & $0 \cdot 27$ & & $\mathrm{c}, \mathrm{f}$ & 0.005 & 0.000 & 0.010 \\
\hline $\mathrm{ABC}-21$ & Am.ab & 20 & 1400 & 120 & $2475 \mathrm{~d}$ & 0.07 & 0.74 & 0.81 & $0.96(0.02), 1.05(0.05)$ & $\mathrm{b}, \mathrm{f}, \mathrm{u}$ & $0 \cdot 015$ & $0 \cdot 001$ & 0.027 \\
\hline CAB-1 & Am.ab & 20 & 1400 & 314 & $2456 \mathrm{~d}$ & $0 \cdot 15$ & $0 \cdot 84$ & 0.99 & & $\mathrm{c}$ & $0 \cdot 018$ & $0 \cdot 003$ & $0 \cdot 030$ \\
\hline CAB-5 & Am.ab & 20 & 1400 & 300 & $2490 \mathrm{~d}$ & $0 \cdot 16$ & 0.86 & 1.02 & $0.88(0.03)$ & $\mathrm{c}$ & 0.018 & 0.003 & 0.031 \\
\hline$A B C-26$ & Am.ab & 20 & 1400 & 120 & $2480 \mathrm{~d}$ & $0 \cdot 16$ & 0.90 & 1.06 & $1.04(0.02), 0.99(0.05)$ & $\mathrm{f}$ & $0 \cdot 019$ & 0.003 & 0.033 \\
\hline $\mathrm{ABC}-23$ & Am.ab & 20 & 1400 & 120 & $2465 \mathrm{e}$ & $0 \cdot 37$ & $1 \cdot 25$ & 1.62 & & $\mathrm{~b}, \mathrm{f}$ & 0.029 & 0.007 & 0.045 \\
\hline$A B C-20$ & Am.ab & 20 & 1400 & 120 & $2460 \mathrm{~h}$ & 0.85 & 1.56 & $2 \cdot 41$ & $2 \cdot 22(0 \cdot 11)$ & $\mathrm{b}, \mathrm{f}, \mathrm{u}$ & 0.043 & 0.015 & 0.056 \\
\hline ABC-13 & Am.ab & 20 & 1400 & 336 & $2435 \mathrm{~h}$ & 0.96 & 1.68 & $2 \cdot 64$ & $2.54(0.07)$ & $f$ & 0.047 & 0.017 & 0.060 \\
\hline CAB-2 & Am.ab & 20 & 1400 & 314 & $2454 \mathrm{~d}$ & 0.94 & $1 \cdot 71$ & $2 \cdot 65$ & & $c, f$ & 0.047 & $0 \cdot 017$ & 0.061 \\
\hline CAB-3 & Am.ab & 20 & 1400 & 314 & $2392 \mathrm{~d}$ & 1.59 & 1.97 & 3.55 & & $c, f$ & 0.063 & 0.028 & 0.070 \\
\hline CAB-4 & Am.ab & 20 & 1400 & 330 & $2419 \mathrm{~d}$ & 2.57 & 2.08 & $4 \cdot 65$ & & c, $\mathrm{f}$ & 0.082 & 0.045 & 0.073 \\
\hline $\mathrm{ABC}-11$ & Am.ab & 20 & 1400 & 336 & $2385 \mathrm{~h}$ & $2 \cdot 86$ & $2 \cdot 08$ & 4.94 & $4.93(0 \cdot 2)$ & $c, f$ & 0.086 & 0.050 & 0.073 \\
\hline A101 & syn.ab & 20 & 1400 & 275 & $2375 \mathrm{e}$ & 3.08 & 1.95 & 5.03 & & c & 0.088 & 0.054 & 0.068 \\
\hline ABC-9 & Am.ab & 20 & 1400 . & 365 & $2385 \mathrm{~h}$ & 3.00 & $2 \cdot 12$ & $5 \cdot 12$ & $4.94(0 \cdot 14)$ & f & $0 \cdot 089$ & 0.052 & 0.074 \\
\hline ABC-14 & Am.ab & 20 & 1400 & 390 & $2325 \mathrm{~h}$ & $4 \cdot 56$ & $2 \cdot 27$ & $6 \cdot 83$ & $6.90(0 \cdot 14)$ & $\mathrm{c}, \mathrm{f}$ & 0.118 & 0.079 & 0.078 \\
\hline CAB-6 & Am.ab & 20 & 1400 & 300 & $2328 \mathrm{~d}$ & $5 \cdot 10$ & $2 \cdot 23$ & $7 \cdot 34$ & & $\mathrm{c}, \mathrm{f}$ & $0 \cdot 126$ & 0.088 & 0.077 \\
\hline ABC-15 & Am.ab & 20 & 1500 & 240 & $2335 \mathrm{~h}$ & $4 \cdot 32$ & $2 \cdot 14$ & 6.47 & & f & $0 \cdot 112$ & 0.075 & 0.074 \\
\hline ABC- 17 & Am.ab & 20 & 1600 & 140 & $2460 \mathrm{~h}$ & 0.12 & 0.90 & 1.02 & & f & 0.018 & 0.002 & 0.032 \\
\hline A100 & syn.ab & 25 & 1400 & 240 & 2410 e & $2 \cdot 00$ & $2 \cdot 01$ & 4.01 & & c & 0.071 & 0.035 & 0.071 \\
\hline
\end{tabular}

Note: $\quad{ }^{1}$ Reported values for most samples are based on multiple spectra, often taken on several glass chips. OH concentration is reported as the amount of water dissolved as $\mathrm{OH}$.

2 Total $\mathrm{H}_{2} \mathrm{O}$ contents measured by $\mathrm{H}_{2}$ manometry listed on left side of column.

Total $\mathrm{H}_{2} \mathrm{O}$ contents measured by NMR listed on right side of column.

Numbers in parentheses indicate estimated uncertainties.

3 Total $\mathrm{H}_{2} \mathrm{O}$ contents determined from sum of molecular $\mathrm{H}_{2} \mathrm{O}$ and water dissolved as $\mathrm{OH}$

$4 \mathrm{a}=$ samples synthesized at ASU, $\mathrm{u}=$ samples synthesized at UCLA, b = used boron nitride assemblies. Infrared spectra taken with: $\mathrm{c}=$ Cary 17 spectrometer, $\mathrm{f}=$ Nicolet FTIR spectrometer.

Cooling rate $=150 \mathrm{deg} / \mathrm{s}$, unless indicated: $w=0.27 \mathrm{C} / \mathrm{s}, \mathrm{x}=0.54 \mathrm{C} / \mathrm{s}, \mathrm{y}=1.11 \mathrm{C} / \mathrm{s}, \mathrm{z}=2.5 \mathrm{C} / \mathrm{s}$.

5 Mole fractions calculated as follows:

$X_{\mathrm{B}}=$ mole fraction of $\mathrm{H}_{2} \mathrm{O}$, total $=\left(\right.$ wt. $\left.\% \mathrm{H}_{2} \mathrm{O} / 18\right) /\left(\right.$ wt. $\% \mathrm{H}_{2} \mathrm{O} / 18+\left(100\right.$-wt. $\left.\left.\% \mathrm{H}_{2} \mathrm{O}\right) / 32 \cdot 78\right)$.

$X_{\mathrm{H}_{2} \mathrm{O}}=$ mole fraction of molecular $\mathrm{H}_{2} \mathrm{O}=\left(\right.$ wt. $\left.\% \mathrm{H}_{2} \mathrm{O}, \mathrm{mol} / 18\right) /\left(\right.$ wt. $\left.\% \mathrm{H}_{2} \mathrm{O} / 18+\left(100-\mathrm{wt} . \% \mathrm{H}_{2} \mathrm{O}\right) / 32 \cdot 78\right)$

$X_{\mathrm{OH}}=$ mole fraction of hydroxyl $=2\left(X_{\mathrm{B}}-X_{\mathrm{H}_{2} \mathrm{O}, \mathrm{mol}}\right)$.

6 Density measurements: $h=$ heavy liquids; $d=$ Berman balance; $e=$ estimated. 
by Holloway (1971). The pressure medium was Ar gas and the temperature was controlled using a Pt-10\% Rh vs. Pt thermocouple. At the conclusion of the run, the power was shut off, and the run cooled isobarically at $3-4^{\circ} \mathrm{C} / \mathrm{s}$. The run conditions are listed in Table 3 . Sample A78-56 is from Dr. John Delaney (synthesized from a gel in an IHPV in Professor Holloway's laboratory) and has been previously reported on by Stolper (1982a).

Doubly polished thin sections of the run products were prepared for infrared spectroscopy (Newman et al., 1986). The sample thicknesses were measured using a digital dial indicator. In addition, pellets were prepared from selected samples by pressing $0.5 \mathrm{mg}$ finely ground glass mixed with $200 \mathrm{mg} \mathrm{KBr}$ into a disc; transmission spectra in the mid-infrared region were obtained on these pellets. For most samples, glass densities were measured on bubble-free glass fragments using a Berman balance and weighing in air and in toluene, or by a float-sink method using heavy liquids of known density. For samples that contained bubbles, densities were estimated by comparison with samples with similar water contents for which the densities had been measured.

Transmission infrared spectra were taken using either a Cary $17\left(2500-8000 \mathrm{~cm}^{-1}\right)$ or a Nicolet 60SX FTIR spectrophotometer $\left(400-8000 \mathrm{~cm}^{-1}\right)$. The Nicolet FTIR was used with a W source, $\mathrm{CaF}_{2}$ beamsplitter and an InSb detector $\left(1850-8000 \mathrm{~cm}^{-1}\right)$ or a Globar source, $\mathrm{KBr}$ beamsplitter and a $\mathrm{HgCdTe} \mathrm{C}_{2}$ detector $\left(400-5000 \mathrm{~cm}^{-1}\right)$, and operated at a resolution of $2-4 \mathrm{~cm}^{-1}$ with a mirror velocity of $1.57 \mathrm{~cm} / \mathrm{s}$. Typically, 512-2048 scans were collected for each spectrum.

Total water contents were determined by hydrogen manometry (Newman et al., 1986) for nine glasses and by nuclear magnetic resonance (NMR) spectroscopy (Eckert et al., 1988) for six glasses.

\section{INFRARED SPECTROSCOPY}

\section{Band assignments}

\section{Infrared spectra $\left(1500-3800 \mathrm{~cm}^{-1}\right)$}

Figure 1a shows the infrared absorption spectrum of a hydrous albitic glass $(5 \cdot 1 \mathrm{wt} . \%$ $\mathrm{H}_{2} \mathrm{O}^{*}$ ). The two bands of interest in this region peak at 1635 and $3530 \mathrm{~cm}^{-1}$. The band assignments were reviewed by Newman et al. (1986) for rhyolitic glasses: the band at $1635 \mathrm{~cm}^{-1}$ is the fundamental bending mode of $\mathrm{H}_{2} \mathrm{O}$ molecules; the broad band at $3530 \mathrm{~cm}^{-1}$ is due to fundamental $\mathrm{OH}$ stretching vibrations. The positions of these bands are displaced slightly in albitic glasses relative to rhyolitic glasses, which have absorption maxima at 1630 and $3570 \mathrm{~cm}^{-1}$ (Newman et al., 1986). The weak bands observed near 1800 and $1600 \mathrm{~cm}^{-1}$ in the anhydrous glass shown in Fig. 1a are uncorrelated with the hydrogen content, and we conclude that they are due to vibrations of the aluminosilicate network.

Figure $1 \mathrm{~b}$ shows the infrared spectra of five albitic glasses with water contents ranging from 0.1 to $5.1 \mathrm{wt} \%$. The breadth and asymmetry of the band at $3530 \mathrm{~cm}^{-1}$ reflects the distribution of hydrogen-bond strengths of the hydroxyl and $\mathrm{H}_{2} \mathrm{O}$ groups dissolved in the glasses (Scholze, 1959; Paterson, 1982). The intensity of this band increases with increasing water content with no significant change in band shape over this range of water contents. Although McMillan \& Remmele (1986) noted the presence of an additional component at $3450 \mathrm{~cm}^{-1}$ in the infrared spectra of silica glasses with high water contents, the infrared spectra (this work) and Raman spectra (McMillan et al., 1983; Mysen \& Virgo, 1986b) of

\footnotetext{
* Water contents reported in this section were determined by infrared spectroscopy as described below.
} 
Hydrous albitic glasses: IHPV experiments

\begin{tabular}{|c|c|c|c|c|c|c|c|c|c|c|c|c|}
\hline Sample & $\begin{array}{l}\text { Starting } \\
\text { material }\end{array}$ & $\underset{(k b)}{\mathrm{P}}$ & $\begin{array}{c}\mathrm{T} \\
\left({ }^{\circ} \mathrm{C}\right)\end{array}$ & $\begin{array}{c}\text { Time } \\
(h r)\end{array}$ & $\begin{array}{l}\text { Density } \\
\quad(g / l)\end{array}$ & $\begin{array}{l}\mathrm{H}_{2} \mathrm{O}, \mathrm{mol}^{7} \\
\quad(w t . \%)\end{array}$ & $\begin{array}{c}O H^{7} \\
(w t . \%)\end{array}$ & $\begin{array}{l}\mathrm{H}_{2} \mathrm{O}_{\text {tot }}^{2} \\
(w t . \%)\end{array}$ & Remarks $s^{3,4,5}$ & $\mathrm{X}_{B}$ & $\begin{array}{l}\text { le fracti } \\
\mathrm{X}_{\mathrm{H}_{2} \mathrm{O}}\end{array}$ & $\mathrm{X}_{\mathrm{OH}}$ \\
\hline G 1 & Am.ab & 0.99 & 1150 & 23 & $2475 \mathrm{e}$ & $0 \cdot 00$ & $0 \cdot 21$ & $0 \cdot 21$ & $\mathrm{c}, \mathrm{j}$, leaked, xtl & 0.004 & 0.000 & $0 \cdot 008$ \\
\hline G 2 & Am.ab & 0.99 & 1150 & 23 & $2410 \mathrm{~d}$ & $2 \cdot 49$ & 1.66 & $4 \cdot 15$ & $\mathrm{c}, \mathrm{j}, \mathrm{exv}$ & 0.073 & 0.044 & 0.057 \\
\hline $\mathrm{Ab} 12$ & Am.ab & $2 \cdot 00$ & 1150 & 144 & $2345 \mathrm{e}$ & $4 \cdot 33$ & 1.94 & $6 \cdot 28$ & $c, \mathrm{j}, \mathrm{bb}$-free & $0 \cdot 109$ & $0 \cdot 076$ & $0 \cdot 065$ \\
\hline $\mathrm{Ab} 12$ & Am.ab & $2 \cdot 00$ & 1150 & 144 & $2345 \mathrm{e}$ & $4 \cdot 46$ & 1.87 & $6 \cdot 33$ & $\mathrm{c}, \mathrm{j}, \mathrm{bb}$-rich & $0 \cdot 109$ & 0.078 & $0 \cdot 062$ \\
\hline G 3 & Am.ab & $2 \cdot 03$ & 1150 & 22 & $2435 \mathrm{e}$ & $1 \cdot 35$ & 1.57 & $2 \cdot 92$ & $\mathrm{c}, \mathrm{j}, \mathrm{exv}$ & 0.052 & 0.024 & 0.055 \\
\hline G 5 & Am.ab & $2 \cdot 28$ & 1150 & 19 & $2475 \mathrm{e}$ & 0.00 & $0 \cdot 13$ & $0 \cdot 13$ & $\mathrm{c}, \mathrm{j}, \mathrm{bb}$ & 0.002 & 0.000 & 0.005 \\
\hline G 4 & Am.ab & $2 \cdot 28$ & 1150 & 19 & $2410 \mathrm{e}$ & $2 \cdot 49$ & $1 \cdot 75$ & $4 \cdot 24$ & $\mathrm{c}, \mathrm{j}$, leaked, $\mathrm{xtl}$ & 0.075 & 0.044 & 0.060 \\
\hline G4 & Am.ab & $2 \cdot 28$ & 1150 & 19 & $2410 \mathrm{e}$ & $2 \cdot 70$ & 1.94 & $4 \cdot 64$ & $\mathrm{c}, \mathrm{j}$, leaked, xtl. & 0.081 & $0 \cdot 048$ & 0.066 \\
\hline A $78-56$ & syn. gel & 3.00 & 950 & & $2300 \mathrm{~h}$ & $4 \cdot 89$ & 1.98 & $6 \cdot 87$ & $\mathrm{c}, \mathrm{f}, \mathrm{a}$ & $0 \cdot 118$ & 0.085 & 0.066 \\
\hline G 6 & Am.ab & $3 \cdot 68$ & 1150 & 24 & $2290 \mathrm{e}$ & $6 \cdot 54$ & $2 \cdot 18$ & $8 \cdot 72$ & $c, j$, exv & $0 \cdot 148$ & $0 \cdot 113$ & $0 \cdot 070$ \\
\hline G7 & Am.ab & 3.68 & 1150 & 24 & $2264 \mathrm{~h}$ & $7 \cdot 34$ & $2 \cdot 11$ & $9 \cdot 45$ & $c, j$, exv, bb & $0 \cdot 160$ & $0 \cdot 126$ & 0.067 \\
\hline G 7 & Am.ab & $3 \cdot 68$ & 1150 & 24 & $2264 \mathrm{~h}$ & $7 \cdot 53$ & $2 \cdot 23$ & $9 \cdot 76$ & $c, \mathrm{j}$, exv, bb & $0 \cdot 164$ & $0 \cdot 129$ & 0.071 \\
\hline F 3 & syn.ab & 4.97 & 1000 & 5 & $2354 \mathrm{~d}$ & 1.63 & 1.91 & $3 \cdot 54$ & $\mathrm{c}, \mathrm{j}$ & 0.063 & 0.029 & 0.067 \\
\hline F 4 & syn.ab & 4.97 & 1000 & 6 & $2282 \mathrm{~d}$ & $5 \cdot 19$ & $2 \cdot 29$ & $7 \cdot 48$ & $\mathrm{c}, \mathrm{j}$, few bb & $0 \cdot 128$ & 0.091 & 0.075 \\
\hline G 8 & Am.ab & $5 \cdot 00$ & 1150 & 24 & $2415 \mathrm{e}$ & $2 \cdot 23$ & 1.92 & $4 \cdot 15$ & $\mathrm{c}, \mathrm{j}$, exv, few bb & 0.073 & 0.040 & 0.066 \\
\hline $\mathrm{Ab} 2$ & Am.ab & 5.00 & 1150 & 144 & $2410 \mathrm{e}$ & $2 \cdot 79$ & 1.75 & $4 \cdot 53$ & $\mathrm{c}, \mathrm{j}, \mathrm{bb}$-rich & $0 \cdot 080$ & $0 \cdot 050$ & $0 \cdot 060$ \\
\hline $\mathrm{Ab} 2$ & Am.ab & 5.00 & 1150 & 144 & 2410 e & $2 \cdot 80$ & 1.79 & $4 \cdot 59$ & $\mathrm{c}, \mathrm{j}, \mathrm{bb}$-free & $0 \cdot 080$ & $0 \cdot 050$ & $0 \cdot 061$ \\
\hline $\mathrm{Ab} 3$ & Am.ab & $5 \cdot 00$ & 1150 & 144 & $2365 \mathrm{e}$ & $4 \cdot 01$ & 1.79 & $5 \cdot 80$ & $\mathrm{c}, \mathrm{j}, \mathrm{bb}$-free & $0 \cdot 101$ & 0.071 & 0.060 \\
\hline Ab 6 & Am.ab & 5.00 & 1150 & 144 & $2300 \mathrm{e}$ & $6 \cdot 39$ & $1 \cdot 55$ & 7.94 & $\mathrm{c}, \mathrm{j}, \mathrm{bb}$-free & $0 \cdot 136$ & $0 \cdot 111$ & 0.050 \\
\hline $\mathrm{Ab} 5$ & Am.ab & 5.00 & 1150 & 144 & $2300 \mathrm{e}$ & $6 \cdot 27$ & $2 \cdot 00$ & $8 \cdot 27$ & $c, j$, few bb & $0 \cdot 141$ & $0 \cdot 109$ & 0.065 \\
\hline $\mathrm{Ab} 6$ & Am.ab & 5.00 & 1150 & 144 & $2300 \mathrm{e}$ & $7 \cdot 36$ & 1.43 & $8 \cdot 79$ & $\mathrm{c}, \mathrm{j}, \mathrm{bb}$-rich & $0 \cdot 149$ & $0 \cdot 126$ & $0 \cdot 046$ \\
\hline G $10 \mathrm{a}$ & Am.ab & 5.00 & 1150 & 24 & $2260 \mathrm{e}$ & $7 \cdot 90$ & 1.87 & $9 \cdot 77$ & $\mathrm{c}, \mathrm{j}$, bb-rich & $0 \cdot 165$ & $0 \cdot 135$ & 0.059 \\
\hline G $10 x$ & Am.ab & 5.00 & 1150 & 24 & $2260 \mathrm{e}$ & 7.99 & 2.05 & $10 \cdot 04$ & $\mathrm{c}, \mathrm{j}, \mathrm{xtl}$ & $0 \cdot 169$ & $0 \cdot 136$ & 0.065 \\
\hline F 8 & syn.ab & 5.03 & 1000 & 7 & $2300 \mathrm{~d}$ & $5 \cdot 60$ & $1 \cdot 86$ & $7 \cdot 46$ & $\mathrm{c}, \mathrm{j}$ & $0 \cdot 128$ & 0.097 & 0.061 \\
\hline F 8 & syn.ab & 5.03 & 1000 & 7 & $2301 \mathrm{~d}$ & $6 \cdot 40$ & 1.79 & $8 \cdot 19$ & $\mathrm{c}, \mathrm{j}$, bb-rich & $0 \cdot 140$ & $0 \cdot 111$ & 0.058 \\
\hline F 8 & syn.ab & 5.03 & 1000 & 7 & $2301 \mathrm{~d}$ & $6 \cdot 40$ & 1.86 & $8 \cdot 26$ & $c, j$, few bb & $0 \cdot 141$ & $0 \cdot 111$ & 0.060 \\
\hline F 8 & syn.ab & $5 \cdot 03$ & 1000 & 7 & $2301 \mathrm{~d}$ & $6 \cdot 60$ & 1.98 & $8 \cdot 58$ & $\mathrm{c}, \mathbf{j}$, bb-free & $0 \cdot 146$ & $0 \cdot 114$ & 0.064 \\
\hline G 11 & Am.ab & 7.00 & 1150 & 24 & $2260 \mathrm{e}$ & $8 \cdot 19$ & 1.95 & $10 \cdot 14$ & $\mathrm{c}, \mathrm{j}, \mathrm{exv}, \mathrm{bb}$ & $0 \cdot 170$ & $0 \cdot 140$ & 0.061 \\
\hline G9 & Am.ab & 7.00 & 1150 & 24 & $2260 \mathrm{e}$ & $8 \cdot 41$ & $2 \cdot 04$ & $10 \cdot 45$ & $\mathrm{c}, \mathrm{j}, \mathrm{exv}, \mathrm{xtl}, \mathrm{bb}$ & $0 \cdot 175$ & $0 \cdot 143$ & 0.064 \\
\hline G9 & Am.ab & $7 \cdot 00$ & 1150 & 24 & $2260 \mathrm{e}$ & 8.44 & $2 \cdot 77$ & $11 \cdot 21$ & $\mathrm{c}, \mathrm{j}, \mathrm{bb}$ & $0 \cdot 187$ & $0 \cdot 144$ & 0.086 \\
\hline
\end{tabular}

Notes: ${ }^{1}$ Density measurements: $\mathrm{h}=$ heavy liquids; $\mathrm{d}=$ Berman balance; $\mathrm{e}=$ estimated.

2 Total water contents determined from sum of molecular $\mathrm{H}_{2} \mathrm{O}$ and water dissolved as $\mathrm{OH}$.

${ }^{3}$ Infrared spectra taken using: $\mathrm{c}=$ Cary 17 spectrometer, $\mathrm{f}=$ FTIR spectrometer.

4 Samples synthesized at: $\mathrm{a}=\mathrm{ASU}, \mathrm{j}=$ Johnson Space Center.

$5 \mathrm{bb}=$ bubbles, exv = vapor escaped when charge opened, $\mathrm{xtl}=$ charge was partly crystalline.

6 See footnote 5 , Table 2

7 Reported values for most samples are based on multiple spectra, often taken on several glass chips. OH concentration is reported as the amount of water dissolved as $\mathrm{OH}$.

Multiple entries for the same sample indicate the sample was heterogeneous. 
hydrous albitic glasses do not show this feature. There is, however, a subtle change in the shape of the $3530 \mathrm{~cm}^{-1}$ band with increasing water content: the band becomes narrower in glasses with total water contents greater than $2 \mathrm{wt} . \%$. This feature is illustrated in Fig. 1c, which compares the shapes of the $3530 \mathrm{~cm}^{-1}$ bands of two samples containing $0 \cdot 1$ and
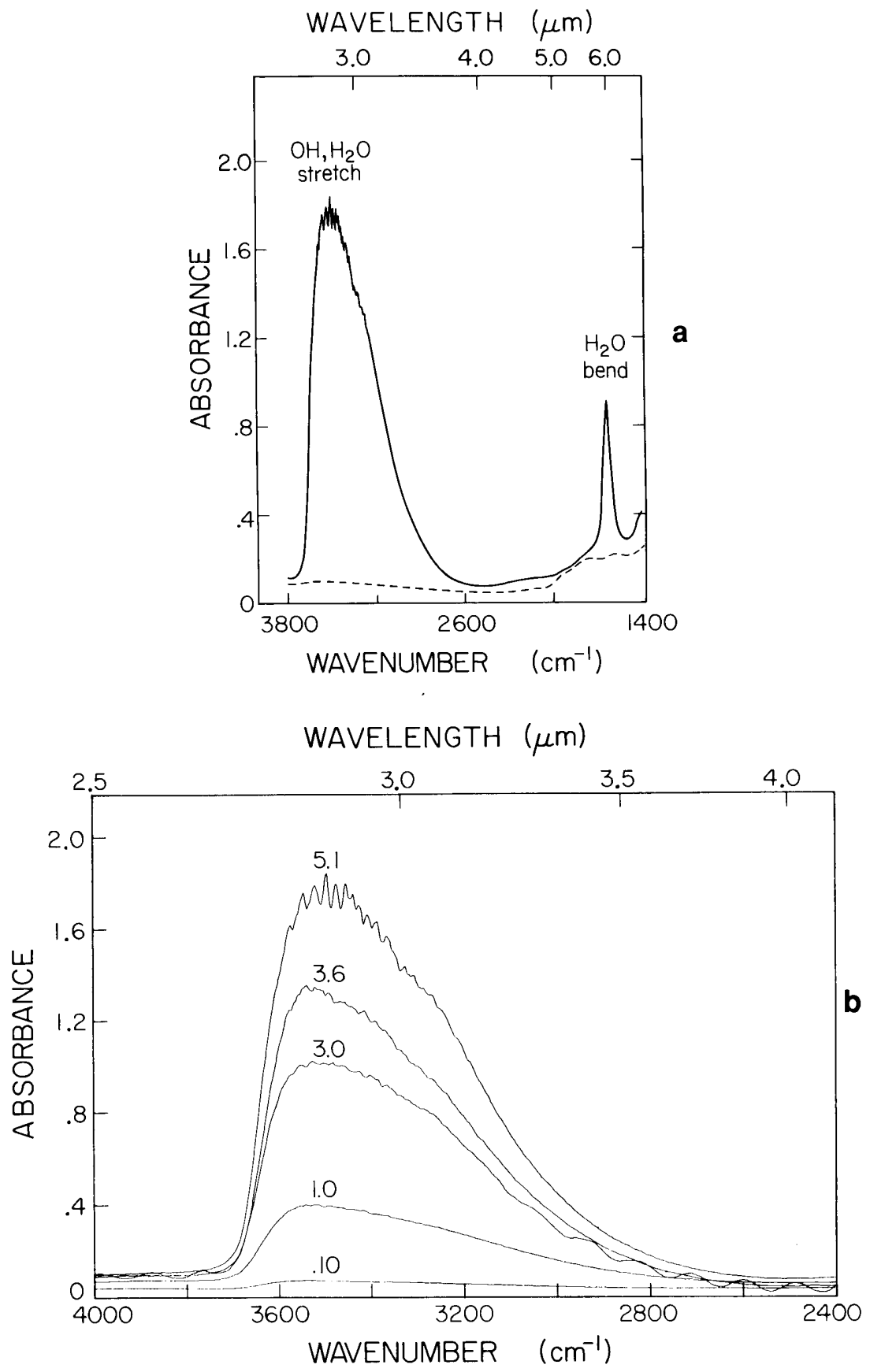

FIG. 1 


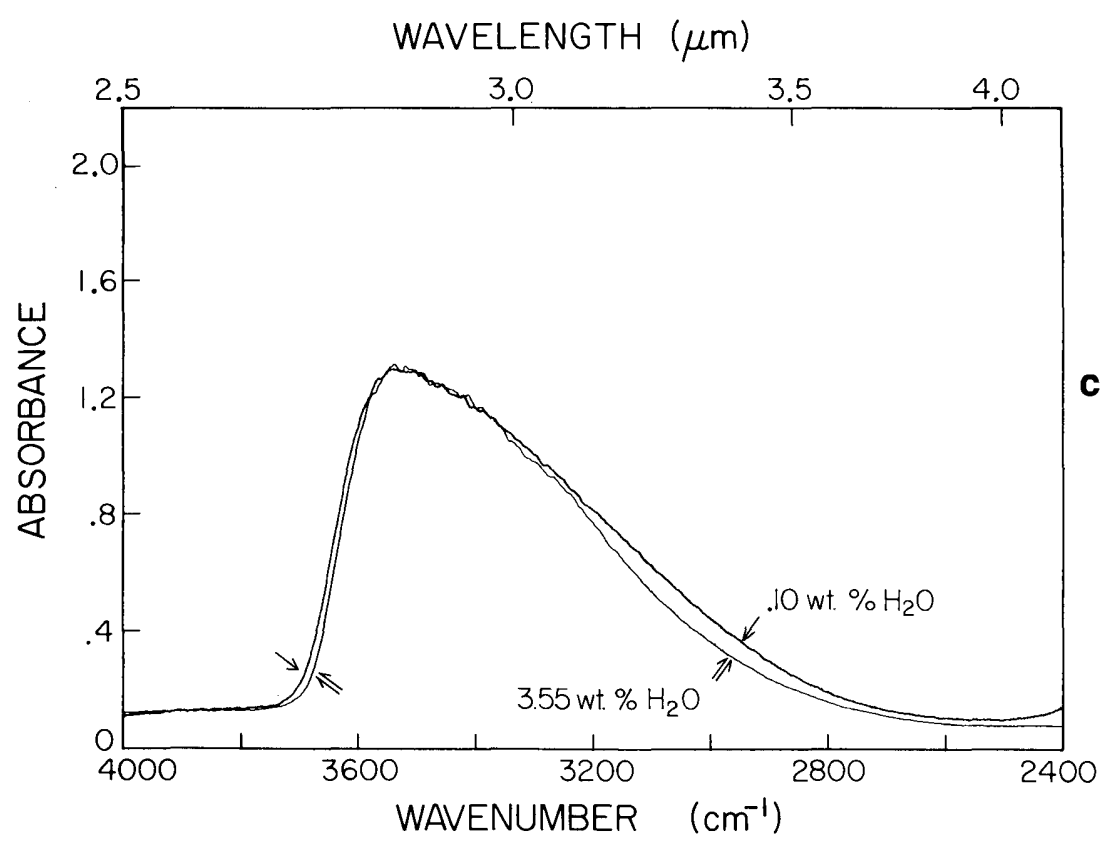

FIG. 1. Infrared absorption spectra of albitic glasses. (a) Sample ABC-9, with $5 \cdot 12 \mathrm{wt} . \% \mathrm{H}_{2} \mathrm{O}$. Sample thickness is $36 \mu \mathrm{m}$. The dashed line is the spectrum of anhydrous albite glass, scaled to $36 \mu \mathrm{m}$. (b) OH-stretch band for five albitic glasses spanning a range of total water contents. All the samples have been scaled to a constant thickness of $35 \mu \mathrm{m}$, and are arranged in order of increasing water content from bottom to top of the figure. Samples shown are LAS-27 (0.1 wt. \% $\left.\mathrm{H}_{2} \mathrm{O}\right)$, ABC-17 (1.02 wt. \% $\mathrm{H}_{2} \mathrm{O}$ ), LAS-29 (2.97 wt. \% $\left.\mathrm{H}_{2} \mathrm{O}\right)$, CAB-3 (3.55 wt. $\left.\% \mathrm{H}_{2} \mathrm{O}\right)$, and ABC-9 (5.12 wt.\% $\mathrm{H}_{2} \mathrm{O}$ ). (c) $\mathrm{OH}$-stretch band of two albitic glasses with 0.1 (LAS-27) and 3.55 (CAB-3) wt.\% $\mathrm{H}_{2} \mathrm{O}$. Both spectra have been scaled to the same height at maximum intensity. This band is narrower at both the low and high wavenumber regions in the sample with the higher total water content.

$3.55 \mathrm{wt} \% \mathrm{H}_{2} \mathrm{O}$, scaled to a constant height at maximum intensity. The band for the sample with the higher water content is narrower than the low water content sample in both the high and low wavenumber regions.

\section{Near-infrared spectra $\left(3800-7600 \mathrm{~cm}^{-1}\right)$}

There are four bands of interest in the near-infrared region (Fig. 2a). Band assignments are reviewed by Newman et al. (1986) for hydrous rhyolitic glasses. The absorption at $7030 \mathrm{~cm}^{-1}$ is the first overtone of the fundamental $\mathrm{OH}$ stretching vibration at $3530 \mathrm{~cm}^{-1}$. The band at $5218 \mathrm{~cm}^{-1}$ is a combination bend + stretch mode of $\mathrm{H}_{2} \mathrm{O}$ molecules. The absorption coefficient of this band is linearly correlated with that of the $1635 \mathrm{~cm}^{-1}$ band, with a correlation coefficient of 0.99 . The band at $4485 \mathrm{~cm}^{-1}$ is a combination mode for $\mathrm{Si}-\mathrm{OH}$ and $\mathrm{Al}-\mathrm{OH}$ groups, and other $\mathrm{X}-\mathrm{OH}$ species may also contribute here. The absorption at $4000 \mathrm{~cm}^{-1}$ correlates with total water content (Stolper, 1982a, fig. 8). Acocella et al. (1984) suggested that the absorption at $4000 \mathrm{~cm}^{-1}$ is correlated with the molecular water content (i.e. the intensity of the $\sim 5200 \mathrm{~cm}^{-1}$ band), but we have found that for hydrous albitic glasses in which only hydroxyl groups were detected, there is measurable intensity at $4000 \mathrm{~cm}^{-1}$. Thus, we prefer the interpretation of Stolper (1982a) that both molecular water and hydroxyl groups contribute to this absorption.

For hydrous albitic glasses with total water contents $<2 \mathrm{wt} . \%$ that were synthesized using furnace assemblies containing $\mathrm{BN}$, the spectra show absorptions at 4125 and $5030 \mathrm{~cm}^{-1}$. The assignment of the $5030 \mathrm{~cm}^{-1}$ band is unknown. The band at $4125 \mathrm{~cm}^{-1}$ 

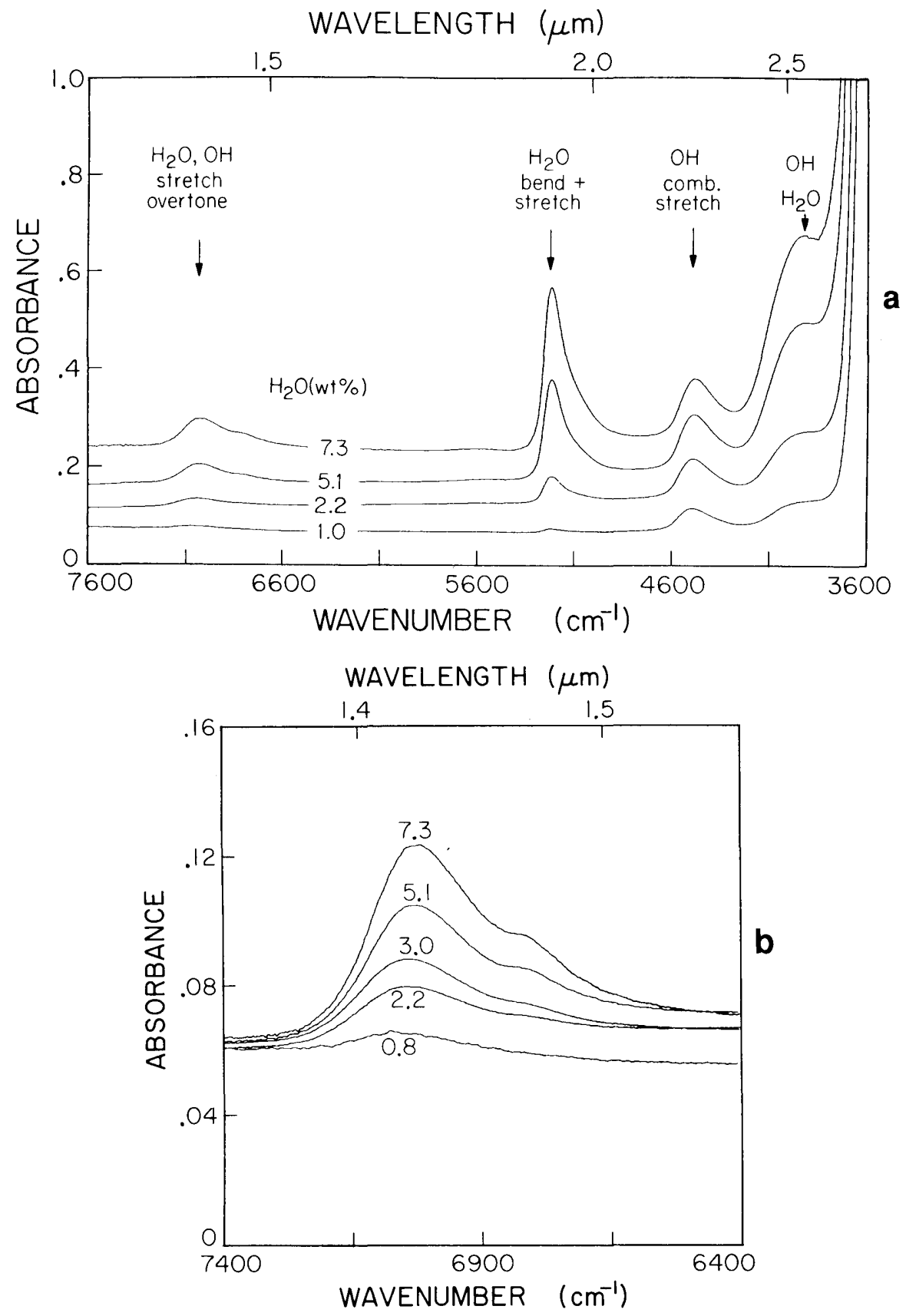

FIG. 2. Near-infrared spectra of albitic glasses. (a) Spectra of four albitic glasses with total water contents up to $7.3 \mathrm{wt} . \% \mathrm{H}_{2} \mathrm{O}$, all scaled to a thickness of $300 \mu \mathrm{m}$. The samples are arranged in order of increasing water content from bottom to top, and have been offset from each other by 0.04 absorbance units to avoid overlap. Note the continuous increases in intensities of the 5218 and $7030 \mathrm{~cm}^{-1}$ bands with increasing water content, whereas the intensity of the $4485 \mathrm{~cm}^{-1}$ band increases for water contents up to $4 \mathrm{wt} . \% \mathrm{H}_{2} \mathrm{O}$, and then remains constant. Samples shown are ABC-17 (1.02 wt. \% $\left.\mathrm{H}_{2} \mathrm{O}\right)$, A1009 (2.22 wt. \% $\left.\mathrm{H}_{2} \mathrm{O}\right)$, ABC-9 $\left(5.12\right.$ wt. $\left.\% \mathrm{H}_{2} \mathrm{O}\right)$, and CAB-6 (7.34 wt. $\% \mathrm{H}_{2} \mathrm{O}$ ). (b) The first overtone of the $\mathrm{OH}$-stretch band for five albitic glasses with total water contents between 0.8 and $7.3 \mathrm{wt} . \% \mathrm{H}_{2} \mathrm{O}$, scaled to a thickness of $300 \mu \mathrm{m}$. The samples are arranged in order of increasing water from bottom to top to illustrate the development of the shoulder near $6850 \mathrm{~cm}^{-1}$. Samples shown are ABC$21\left(0.81\right.$ wt. $\left.\% \mathrm{H}_{2} \mathrm{O}\right)$, A $1009\left(2.22\right.$ wt. $\left.\% \mathrm{H}_{2} \mathrm{O}\right)$, A1010 (2.97 wt. $\left.\% \mathrm{H}_{2} \mathrm{O}\right)$, ABC-9 $\left(5.12\right.$ wt. $\left.\% \mathrm{H}_{2} \mathrm{O}\right)$, and CAB-6 
may be due to dissolved molecular $\mathrm{H}_{2}$, which has a Raman-active fundamental stretching vibration at $4125 \mathrm{~cm}^{-1}$ that has been observed in $\mathrm{H}$-bearing albitic glasses by Raman spectroscopy (Luth et al., 1987). The ${ }^{11} \mathrm{~B} /{ }^{30} \mathrm{Si}$ ratio of sample ABC-21 was determined by ion-microprobe by Dr. I. Hutcheon and indicates a boron content of $\sim 0.3 \mathrm{wt} . \%$. In view of the enhanced boron content of this experiment, in which a single-walled Pt capsule was in direct contact with $\mathrm{BN}$, the results of syntheses in $\mathrm{BN}$-bearing assemblies in piston cylinder apparatus should be used with caution. Experiments that utilized $\mathrm{BN}$-bearing assemblies are indicated in Table 2.

The near-infrared bands in hydrous albitic glasses are displaced slightly relative to their positions in hydrous rhyolitic and silica glasses. In rhyolitic glasses, the band locations are at 4510,5240 , and $7080 \mathrm{~cm}^{-1}$ (Newman et al., 1986). In silica glass the combination mode for $\mathrm{Si}-\mathrm{OH}$ peaks at $4520 \mathrm{~cm}^{-1}$ (Stone \& Walrafen, 1982), shifted slightly relative to its position in albitic glasses. There is, however, significant overlap of the bands. The combination mode due to molecular water peaks at $5270 \mathrm{~cm}^{-1}$ (L. A. Silver, unpublished results) and the first overtone of the $\mathrm{OH}$ stretching fundamental peaks at $7260 \mathrm{~cm}^{-1}$ (Stone \& Walrafen, 1982) in silica glass; both of these modes are shifted to higher energies relative to their locations in albitic glass.

Figure 2a shows the near-infrared spectra of four albitic glasses with total water contents ranging from 1.02 to $7.34 \mathrm{wt} \%$. With increasing water content, the bands at 4000,5218 , and $7030 \mathrm{~cm}^{-1}$ all increase in intensity. The band at $4485 \mathrm{~cm}^{-1}$ increases in intensity with increasing water content up to $\sim 4 \mathrm{wt} . \%$ total $\mathrm{H}_{2} \mathrm{O}$ and then remains approximately constant in intensity at higher total water contents. A low-intensity band appears at high total water contents at $\sim 5600 \mathrm{~cm}^{-1}$ (not visible in Fig. 2a); its intensity appears to be correlated with that of the molecular water band at $5218 \mathrm{~cm}^{-1}$. The assignment of this band is unclear; however, a similar band occurs in the spectrum of liquid water at $5634 \mathrm{~cm}^{-1}$ (see Stolper, 1982a, fig. 12).

The $7030 \mathrm{~cm}^{-1}$ overtone of the $\mathrm{OH}$-stretching vibration changes shape with increasing water content. Figure $2 \mathrm{~b}$ shows the spectra of five albitic glasses arranged with increasing water contents up to $7.34 \mathrm{wt} \%$ in the region $6400-7400 \mathrm{~cm}^{-1}$. There is a distinct shoulder at $\sim 6850 \mathrm{~cm}^{-1}$ in glasses containing $\geq 2.5 \mathrm{wt} . \% \mathrm{H}_{2} \mathrm{O}$ that becomes more pronounced at higher water contents. There is no comparable feature at $\sim 3425 \mathrm{~cm}^{-1}$ (i.e. one-half the frequency of this shoulder). A similar feature in the spectra of opals has been attributed to clustering of water molecules (Langer \& Flörke, 1974). This feature may thus reflect a close proximity of some of the $\mathrm{H}_{2} \mathrm{O}$ molecules in the water-rich samples in which most of the water is present in molecular form.

The band at $7030 \mathrm{~cm}^{-1}$ is much narrower than twice the band width of the fundamental mode at $3530 \mathrm{~cm}^{-1}$; that is, little overtone intensity is contributed by the strongly hydrogenbonded $\mathrm{OH}$ groups with fundamental stretching frequencies between $\sim 2600$ and $3100 \mathrm{~cm}^{-1}$. This is not unexpected given the demonstration by Adams \& Douglas (1959) that in hydrous glasses and minerals of a wide variety of compositions, the overtone near $7100 \mathrm{~cm}^{-1}$ does not appear when there is strong association, i.e. strongly hydrogen-bonded $\mathrm{OH}$ groups.

\section{Mid-infrared spectra $\left(600-1500 \mathrm{~cm}^{-1}\right)$}

Figure 3 shows the powder infrared spectra of one anhydrous albitic glass and four hydrous albitic glasses embedded in $\mathrm{KBr}$. All of the spectra have been scaled to a constant height of the $1030 \mathrm{~cm}^{-1}$ band. It is difficult to use these spectra to obtain quantitative information because of the uncertainties associated with adsorbed water and variable particle size due to uneven grinding. However, in a qualitative way, these spectra permit the 


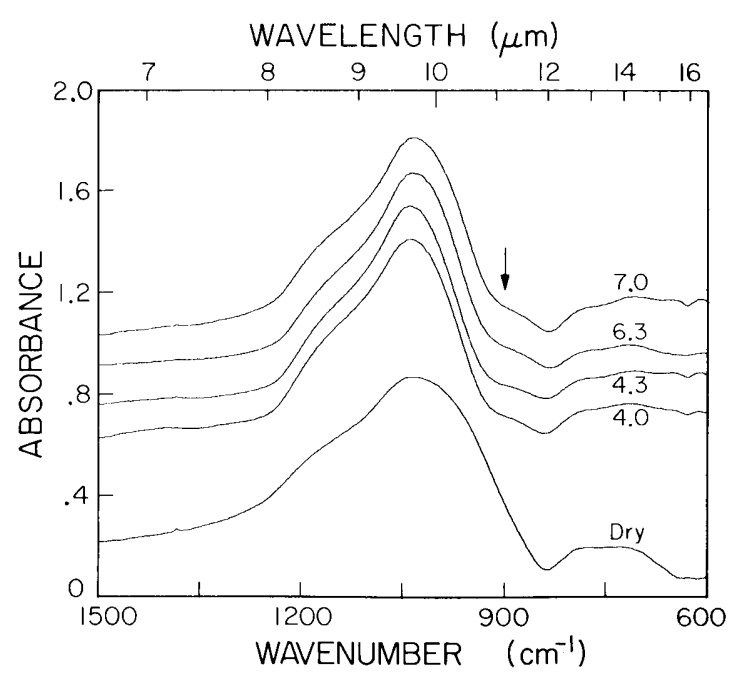

FIG. 3. Infrared spectra of one anhydrous albitic glass and four hydrous albitic glasses with total water contents ranging from 4 to $7 \mathrm{wt} \% \mathrm{H}_{2} \mathrm{O}$. Spectra were obtained on disks made by pressing $0.5 \mathrm{mg}$ of finely ground glass into $200 \mathrm{mg}$ of $\mathrm{KBr}$. All the spectra have been scaled to the same height of the $1030 \mathrm{~cm}^{-1}$ band, and have been offset by 0.1 absorbance units for clarity. The intensity of the shoulder at $900 \mathrm{~cm}^{-1}$ (noted by the arrow) remains approximately constant relative to that of the $\sim 1000 \mathrm{~cm}^{-1}$ band for the samples with total water contents $>4$ wt. $\%$. Samples shown are LAS-20 (3.95 wt. \% $\left.\mathrm{H}_{2} \mathrm{O}\right)$, JRH-1 (4.32 wt. \% $\left.\mathrm{H}_{2} \mathrm{O}\right), \mathrm{JRH}-2\left(6 \cdot 3\right.$ wt. $\left.\% \mathrm{H}_{2} \mathrm{O}\right)$, and LAS$22\left(6.99\right.$ wt. $\left.\% \mathrm{H}_{2} \mathrm{O}\right)$.

identification of important features in this region and are comparable to Raman spectra obtained for this region (McMillan et al., 1983).

All of the glasses show a group of broad bands between 850 and $1200 \mathrm{~cm}^{-1}$, with a maximum intensity at $1030-1040 \mathrm{~cm}^{-1}$. The bands in this region have been assigned based on Raman spectra to the symmetric stretching vibrations of tetrahedra associated with 1 to 4 nonbridging oxygens (McMillan et al., 1982) and may also include deformation vibrations of $\mathrm{Al}-\mathrm{OH}$ and $\mathrm{Si}-\mathrm{OH}$ groups near $1075 \mathrm{~cm}^{-1}$ (McMillan et al., 1983). There is a welldeveloped shoulder at $900 \mathrm{~cm}^{-1}$ that appears in the infrared spectra of hydrous albitic glasses, but it is absent from the spectra of dry albitic glass. This band might be due to $\mathrm{Si}$, $\mathrm{Al}-\mathrm{OH}$ vibrations and may be the mode that, in combination with the $\mathrm{OH}$ stretch at $\sim 3500 \mathrm{~cm}^{-1}$ is responsible for the $\mathrm{Si}, \mathrm{Al}-\mathrm{OH}$ mode at $4485 \mathrm{~cm}^{-1}$ (see above). The $900 \mathrm{~cm}^{-1}$ band has roughly a constant intensity relative to the height of the $1030 \mathrm{~cm}^{-1}$ band in the hydrous glass spectra illustrated in Fig. 6. As discussed above, the $4485 \mathrm{~cm}^{-1}$ band also has roughly a constant intensity for total water contents greater than about $4 \mathrm{wt}$.\%.

The assignment of the $900 \mathrm{~cm}^{-1}$ band is not well established. A similar band has been observed in Raman spectra of hydrous albitic glasses (Mysen et al., 1980; McMillan et al., 1983; Mysen \& Virgo, 1986b) and there are at least three different interpretations of it. In hydrous silica glass, there is a Raman and infrared band at $970 \mathrm{~cm}^{-1}$, assigned to $\mathrm{Si}-\mathrm{OH}$ stretching vibrations (Stolen \& Walrafen, 1976). The absence in hydrous albitic glass of a distinct band at $970 \mathrm{~cm}^{-1}$ (i.e. corresponding to $\mathrm{Si}-\mathrm{OH}$ groups) and the appearance of the band at $900 \mathrm{~cm}^{-1}$ led Remmele et al. (1986) to suggest that the latter band is due to $\mathrm{Al}-\mathrm{OH}$ groups and that most or all of the hydroxyls in albitic glass are $\mathrm{Al}-\mathrm{OH}$. Mysen et al. (1980) deconvolved Raman spectra of hydrous albitic glasses and assigned a band near $880 \mathrm{~cm}^{-1}$ to the symmetric $\mathrm{O}-\mathrm{Si}, \mathrm{Al}-\mathrm{O}$ stretching vibration and a band near $980 \mathrm{~cm}^{-1}$ to the $\mathrm{Si}-\mathrm{OH}$ stretch. No bands were assigned to Al-OH. Subsequently, Mysen \& Virgo (1986b) deconvolved the Raman spectra of hydrous albitic glasses into a second set of bands with 
locations and assignments differing from their earlier work. This time, no bands assigned to $\mathrm{Si}-\mathrm{OH}$ or $\mathrm{Al}-\mathrm{OH}$ vibrations were resolved, but they inferred the presence of $\mathrm{Al}-$ and $\mathrm{Na}-\mathrm{OH}$ groups in hydrous albitic glasses based on mass-balance considerations. We prefer the interpretation of Remmele et al. (1986), but conclude that, at present, the band assignments in this region of the spectra of hydrous albitic glasses are not well understood.

\section{Band intensities}

Band intensities (i.e. peak heights) were measured for the 4485,5218 , and $7030 \mathrm{~cm}^{-1}$ bands for most of the hydrous albitic glasses that were studied. For the 1635 and $3530 \mathrm{~cm}^{-1}$ bands, the band intensities are harder to measure unless the samples are very thin or the water concentrations are low, so only selected samples were measured at these frequencies. For the $1635 \mathrm{~cm}^{-1}$ band, the band intensities were measured after numerical subtraction of the spectrum of an anhydrous albite glass scaled to the thickness of the water-bearing glass. Integral absorbance measurements (i.e. the area under the absorption peak) were obtained by numerical integration after background subtraction. Backgrounds for the near-infrared and $3530 \mathrm{~cm}^{-1}$ bands were obtained either by estimating a baseline tangent to the spectrum between the minimum on either side of the absorbance band or by generating a computer-fit polynomial baseline. Both methods are arbitrary, but yield similar results and are reproducible. Selected band intensities and integral absorbance measurements are reported in Table 4. Precisions of band intensities are estimated to be on the order of a few percent based on repeated analyses of individual samples, similar to the results of Newman et al. (1986).

The validity of Lambert's law (i.e. that absorbance is proportional to sample thickness) for our samples was confirmed by measuring band intensities on several pieces of the same sample ground to different thicknesses. Figure 4 shows the absorbances of the 4485 and $5218 \mathrm{~cm}^{-1}$ bands as functions of sample thickness for three glasses with water contents ranging from 2.64 to $6.83 \mathrm{wt}$.\%. The close correspondence of the data shown in Fig. 4 to $45^{\circ}$ lines demonstrates that adsorbed water does not contribute significantly to the band intensities in our samples. Although not shown, a similar relationship holds for the $7030 \mathrm{~cm}^{-1}$ band. These bands can thus be used to determine quantitatively the concentrations of $\mathrm{OH}$ groups and molecular $\mathrm{H}_{2} \mathrm{O}$, provided the appropriate values for the molar absorption coefficients are used. Band intensities are reproducible on samples stored in laboratory air for over $5 \mathrm{y}$.

Either the peak height or the integral absorbance determinations can be used for quantitative analysis of the species concentrations. Absorbance is proportional to integral absorbance for both the 4485 and $5218 \mathrm{~cm}^{-1}$ bands, both with correlation coefficients $(r)$ of 0.999. Absorbance and integral absorbance are also proportional for the 7030, 1635, and $3530 \mathrm{~cm}^{-1}$ bands, with $r=0.998,0.999$, and 0.990 , respectively. Since there is no obvious advantage to using the integral absorbance measurements instead of peak heights, we have used peak heights for our quantitative work.

\section{Determination of molar absorption coefficients}

According to Beer's law, the concentration of a particular H-bearing species (given as the weight fraction of water that would be released from the sample if all of the hydrogen dissolved as this species were converted to $\mathrm{H}_{2} \mathrm{O}$ ) that gives rise to an infrared absorption is directly proportional to the intensity of that band (Abs) and inversely proportional to the 
TABLE 4

Selected spectroscopic data

\begin{tabular}{|c|c|c|c|c|c|c|c|c|c|c|c|c|c|}
\hline \multirow[b]{3}{*}{ Sample } & \multirow[b]{3}{*}{$\begin{array}{c}\text { Thickness } \\
(\mathrm{cm})\end{array}$} & \multicolumn{4}{|c|}{ Near-infrared bands } & \multicolumn{8}{|c|}{ Infrared bands } \\
\hline & & \multicolumn{2}{|c|}{$5218 \mathrm{~cm}^{-1}$} & \multicolumn{2}{|c|}{$4485 \mathrm{~cm}^{-1}$} & \multicolumn{2}{|c|}{$7030 \mathrm{~cm}^{-1}$} & \multicolumn{2}{|c|}{$3530 \mathrm{~cm}^{-1}$} & & \multicolumn{3}{|c|}{$1636 \mathrm{~cm}^{-1}$} \\
\hline & & $A b s$ & $\begin{array}{c}\text { Int- } A b s \\
\left(\mathrm{~cm}^{-1}\right)\end{array}$ & Abs & $\begin{array}{l}\text { Int- } A b s \\
\left(\mathrm{~cm}^{-1}\right)\end{array}$ & $A b s$ & $\begin{array}{l}\text { Int- } A b s \\
\left(\mathrm{~cm}^{-1}\right)\end{array}$ & $\begin{array}{l}\text { Thickness } \\
\quad(\mathrm{cm})\end{array}$ & $A b s$ & $\begin{array}{c}\text { Int- } A b s \\
\left(\mathrm{~cm}^{-1}\right)\end{array}$ & $\begin{array}{l}\text { Thickness } \\
(\mathrm{cm})\end{array}$ & Abs & $\begin{array}{c}\text { Int }-A b s \\
\left(\mathrm{~cm}^{-1}\right)\end{array}$ \\
\hline LAS-27 & $0 \cdot 0561$ & 0.000 & $0 \cdot 0$ & 0.009 & $1 \cdot 6$ & 0.001 & 0.65 & $0 \cdot 0561$ & 0.600 & 302 & & & \\
\hline A 1003 & $0 \cdot 1143$ & 0.000 & $0 \cdot 0$ & $0 \cdot 018$ & $3 \cdot 1$ & 0.002 & 0.88 & $0 \cdot 1143$ & $1 \cdot 134$ & 567 & & & \\
\hline $\mathrm{ABC}-12$ & 0.0317 & $0 \cdot 000$ & $0 \cdot 0$ & $0 \cdot 011$ & 1.5 & 0.002 & $0 \cdot 42$ & 0.0317 & 0.630 & 313 & & & \\
\hline ABC-10 & 0.0212 & 0.000 & & 0.009 & & & & 0.0212 & 0.638 & 319 & & & \\
\hline $\mathrm{ABC}-17$ & 0.0217 & 0.006 & $0 \cdot 7$ & 0.030 & $5 \cdot 4$ & 0.005 & $1 \cdot 23$ & 0.0088 & 0.832 & 423 & 0.0217 & $0 \cdot 158$ & 11.6 \\
\hline A 1009 & 0.0563 & 0.099 & $15 \cdot 0$ & 0.132 & $25 \cdot 0$ & 0.032 & $9 \cdot 34$ & & & & & & \\
\hline AVS-4 & 0.0118 & $0 \cdot 020$ & $2 \cdot 6$ & 0.027 & $4 \cdot 4$ & 0.007 & $2 \cdot 20$ & & & & 0.0118 & 0.550 & $31 \cdot 8$ \\
\hline ABC-13 & 0.0397 & 0.086 & $13 \cdot 1$ & $0 \cdot 101$ & $19 \cdot 5$ & $0 \cdot 026$ & $7 \cdot 70$ & & & & 0.0110 & $0 \cdot 688$ & $44 \cdot 1$ \\
\hline CAB-2 & 0.0074 & 0.017 & $2 \cdot 1$ & 0.019 & 3.0 & 0.004 & 1.58 & 0.0074 & $1 \cdot 720$ & 919 & 0.0074 & 0.460 & $24 \cdot 6$ \\
\hline LAS- 29 & 0.0238 & 0.063 & $9 \cdot 4$ & 0.062 & $10 \cdot 8$ & $0 \cdot 018$ & $5 \cdot 40$ & 0.0029 & $0 \cdot 784$ & 380 & 0.0029 & $0 \cdot 258$ & $15 \cdot 9$ \\
\hline A 1010 & $0 \cdot 1054$ & 0.287 & $45 \cdot 6$ & $0 \cdot 282$ & $55 \cdot 6$ & 0.087 & $25 \cdot 27$ & & & & & & \\
\hline CAB-3 & 0.0033 & 0.012 & & 0.009 & & 0.003 & & 0.0033 & $1 \cdot 195$ & 563 & 0.0033 & $0 \cdot 360$ & $2 \cdot 20$ \\
\hline LAS-11 & 0.0173 & 0.075 & $13 \cdot 0$ & 0.053 & $10 \cdot 8$ & $0 \cdot 016$ & $5 \cdot 62$ & & & & & & \\
\hline LAS- 18 & 0.0084 & 0.043 & 6.5 & 0.027 & $5 \cdot 6$ & 0.01 & $3 \cdot 10$ & & & & $0 \cdot 0084$ & 1.023 & $68 \cdot 4$ \\
\hline LAS-26 & $0 \cdot 1307$ & $0 \cdot 706$ & $112 \cdot 5$ & $0 \cdot 394$ & $76 \cdot 7$ & $0 \cdot 156$ & $45 \cdot 16$ & & & & & & \\
\hline CAB-4 & 0.0315 & $0 \cdot 181$ & $28 \cdot 7$ & 0.099 & $18 \cdot 9$ & 0.038 & $11 \cdot 31$ & & & & & & \\
\hline ABC- 11 & 0.0153 & 0.096 & 16.0 & 0.049 & $9 \cdot 7$ & 0.021 & 6.75 & & & & & & \\
\hline ABC-9 & 0.0320 & $0 \cdot 211$ & 33.9 & $0 \cdot 101$ & $20 \cdot 0$ & 0.041 & $12 \cdot 23$ & $0 \cdot 0036$ & 1.660 & 799 & $0 \cdot 0036$ & 0.66 & $42 \cdot 0$ \\
\hline A1008 & 0.0818 & $0 \cdot 642$ & $104 \cdot 5$ & $0 \cdot 252$ & $48 \cdot 7$ & $0 \cdot 123$ & $36 \cdot 60$ & & & & & & \\
\hline ABC- 15 & 0.0075 & 0.069 & $10 \cdot 9$ & 0.024 & 3.9 & $0 \cdot 012$ & 3.55 & & & & & & \\
\hline ABC-14 & 0.0295 & 0.288 & $47 \cdot 2$ & 0.095 & $18 \cdot 8$ & $0 \cdot 051$ & $15 \cdot 81$ & & & & & & \\
\hline A $78-56$ & 0.0233 & $0 \cdot 241$ & $38 \cdot 2$ & 0.066 & $12 \cdot 3$ & 0.044 & $11 \cdot 61$ & & & & 0.0025 & 0.813 & $51 \cdot 2$ \\
\hline LAS- 22 & 0.0192 & 0.194 & $31 \cdot 3$ & 0.064 & $12 \cdot 8$ & 0.028 & 8.00 & & & & & & \\
\hline CAB-6 & 0.0265 & 0.029 & $48 \cdot 3$ & 0.086 & $17 \cdot 0$ & 0.051 & $15 \cdot 32$ & & & & & & \\
\hline
\end{tabular}

Notes: Thickness $=$ the thickness of the plate of glass on which the spectrum was obtained.

Abs $=$ absorbance

Int-Abs = integral absorbance. 


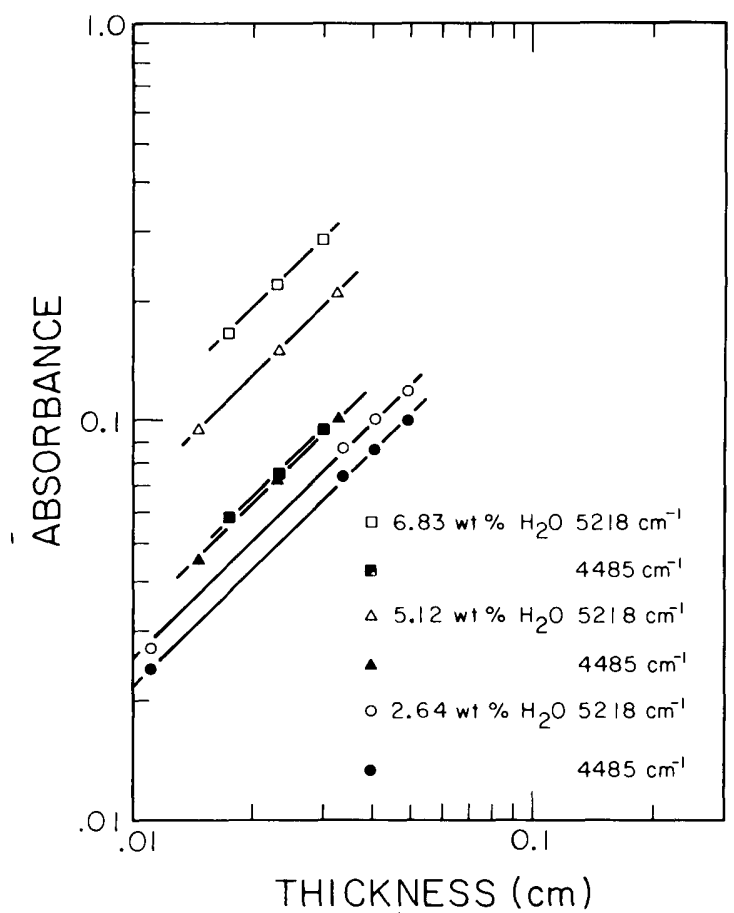

FIG. 4. Absorbances (peak height at maximum intensity) of the 4485 and $5218 \mathrm{~cm}^{-1}$ bands versus sample thickness (cm) for three albitic glasses with water contents between 2.64 and $6.83 \mathrm{wt} . \% \mathrm{H}_{2} \mathrm{O}$. The $45^{\circ}$ lines demonstrate that Lambert's law is valid up to 6.83 wt. $\% \mathrm{H}_{2} \mathrm{O}$ for these two bands. Samples shown are ABC-13 $\left(2.64\right.$ wt. $\left.\% \mathrm{H}_{2} \mathrm{O}\right)$, ABC-9 (5.12 wt. $\left.\% \mathrm{H}_{2} \mathrm{O}\right)$, and $\mathrm{ABC}-14$ (6.83 wt. $\left.\% \mathrm{H}_{2} \mathrm{O}\right)$.

sample thickness $(d)$ and the glass density $(\rho)$ :

$$
\text { concentration }=\frac{\mathrm{Abs} \times 18 \cdot 015}{d \times \rho \times \varepsilon},
$$

where $\varepsilon$ is the molar absorption coefficient, which is a function of composition and must be determined for each band of interest. We first determined values of the molar absorption coefficients for the 4485 and $5218 \mathrm{~cm}^{-1}$ bands for hydrous albitic glass following the method of Stolper (1982a) and Newman et al. (1986): The total dissolved water contents of a suite of glasses were determined by hydrogen manometry and/or ${ }^{1} \mathrm{HNMR}$ spectroscopy. The absorbances of the 4485 and $5218 \mathrm{~cm}^{-1}$ bands were measured on the same samples. A weighted linear least squares regression method was then used to solve for the molar absorption coefficients of these two infrared bands (Table 5). As described in Newman et al. (1986), the procedure assumes that the molar absorption coefficients do not vary over the range of water contents studied and that there were only two hydrogen-bearing species present in the glasses, such that the total water content of the glass can be obtained by summing the amount of molecular $\mathrm{H}_{2} \mathrm{O}$ (from the $5218 \mathrm{~cm}^{-1}$ band) and the amount of water dissolved as hydroxyl groups (from the $4485 \mathrm{~cm}^{-1}$ band).

Six samples were used for the calibration with water contents ranging from 1.02 to $6.83 \mathrm{wt} . \%$ and exactly the same glass fragments were used for the manometric, NMR and infrared measurements. Figure 5 shows the total water content determined by summing the amounts of $\mathrm{OH}$ groups (4485 $\mathrm{cm}^{-1}$ band) and molecular $\mathrm{H}_{2} \mathrm{O}\left(5218 \mathrm{~cm}^{-1}\right.$ band) calculated from the infrared measurements (based on our best-fit molar absorption coefficients) vs. the 
TABLE 5

Extinction coefficients

\begin{tabular}{llcc}
\hline Wavenumber $\left(\mathrm{cm}^{-1}\right)$ & Species & $\varepsilon(1 / \mathrm{mol}-\mathrm{cm})$ & $\varepsilon^{*}\left(\mathrm{l} / \mathrm{mol}-\mathrm{cm}^{2}\right)$ \\
\hline 4485 & $\mathrm{OH}$ & $1 \cdot 13 \pm 0 \cdot 04$ & $219 \pm 8$ \\
5218 & $\mathrm{H}_{2} \mathrm{O}$ & $1 \cdot 67 \pm 0 \cdot 06$ & $268 \pm 9$ \\
7030 & $\mathrm{OH}, \mathrm{H}_{2} \mathrm{O}$ & $0 \cdot 20 \pm 0 \cdot 002$ & $59 \pm 1$ \\
3530 & $\mathrm{OH}, \mathrm{H}_{2} \mathrm{O}$ & $70 \pm 2$ & $35000 \pm 500$ \\
1636 & $\mathrm{H}_{2} \mathrm{O}$ & $49 \pm 2$ & $3081 \pm 143$ \\
\hline
\end{tabular}

Note: $\varepsilon^{*}$ is the integral molar absorption coefficient.

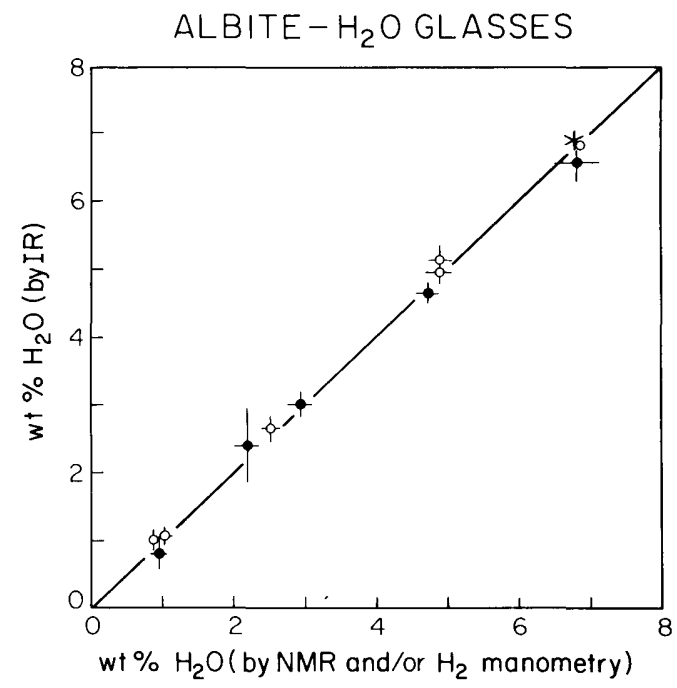

FIG. 5. Total water contents obtained by infrared spectroscopy by summing the concentrations of molecular $\mathrm{H}_{2} \mathrm{O}$ $\left(5218 \mathrm{~cm}^{-1}\right.$ band) and $\mathrm{OH}$ groups $\left(4485 \mathrm{~cm}^{-1}\right.$ band) vs. total water content determined by $\mathrm{H}_{2}$ manometry or NMR spectroscopy. Open symbols represent samples synthesized in BN-free assemblies and used in the least squares fit to determine molar absorption coefficients; filled symbols represent samples synthesized in BN-bearing assemblies; *represents sample A78-56 from Dr. J. Delaney. Estimated errors are indicated by error bars. Molar absorption coefficients are from Table 5. Synthesis conditions are listed in Table 2, except for A78-56 (Table 3). Samples shown are ABC-21, CAB-5, ABC-26, ABC-20, ABC-13, ALB-3388, ALB-3378, ABC-11, ABC-9, ALB-3403, A78-56, and ABC- 14 .

total water content determined by the manometric or NMR technique. The excellent correspondence between these methods suggests that our assumption of constant $\varepsilon$ is valid for this range of water contents. Also shown in Fig. 5 is sample A78-56 from Dr. J. Delaney for which the total water content $\left(6.85 \mathrm{wt} . \% \mathrm{H}_{2} \mathrm{O}\right)$ had been determined by $\mathrm{H}_{2}$ manometry by Professor P. Knauth. The water content we determined by infrared spectroscopy for this sample using our best-fit molar absorption coefficients $\left(6.87 \mathrm{wt} \% \mathrm{H}_{2} \mathrm{O}\right)$ reproduces Knauth's manometric result and provides an independent test of the validity of our methods.

Molar absorption coefficients were determined for the 1635,3530 , and $7030 \mathrm{~cm}^{-1}$ bands based on our values for the 4485 and $5218 \mathrm{~cm}^{-1}$ bands using the method described by Newman et at. (1986). Integral molar absorption coefficients were also determined for each band based on the best-fit ratio of area to peak height for each band. The values of all of the molar absorption coefficients determined in this study are listed in Table 5.

The molar absorption coefficient for the $5218 \mathrm{~cm}^{-1}$ band in hydrous albitic glasses is 
similar to the value determined for the equivalent absorption in hydrous rhyolitic glasses, whereas for the $4485 \mathrm{~cm}^{-1}$ band, the molar absorption coefficient for albitic glasses is smaller than its counterpart for rhyolitic glass.

The bands at 3530 and $7030 \mathrm{~cm}^{-1}$ have contributions from water dissolved as molecular water and hydroxyl groups. Consequently, the molar absorption coefficients may vary with total water content as the relative proportions of molecular $\mathrm{H}_{2} \mathrm{O}$ and $\mathrm{OH}$ change. We fit molar absorption coefficients for the $\mathrm{OH}$ and molecular $\mathrm{H}_{2} \mathrm{O}$ species separately for these bands following Newman et al. (1986). However, for each of these bands, the molar absorption coefficients for the $\mathrm{OH}$ and molecular $\mathrm{H}_{2} \mathrm{O}$ species are similar. Thus, we report only a single molar absorption coefficient for each of these bands in Table 5. This contrasts with the case for rhyolitic glasses, where, for both the 3550 and $7100 \mathrm{~cm}^{-1}$ bands, the molar absorption coefficient of the $\mathrm{OH}$ species is almost twice that of the molecular $\mathrm{H}_{2} \mathrm{O}$ species.

We noted above that the low-water glasses synthesized in BN-bearing assemblies have measurable intensity at $4125 \mathrm{~cm}^{-1}$. This could be due to the presence of molecular $\mathrm{H}_{2}$ or perhaps to a boron-bearing species. We determined the total water contents of six glasses that were synthesized in BN-bearing assemblies by NMR and/or $\mathrm{H}_{2}$ manometry and we also determined, by infrared spectroscopy, the amounts of water dissolved as hydroxyl and molecular water from the 4485 and $5218 \mathrm{~cm}^{-1}$ bands. We did not, however, include these samples in the calibration because of the possible existence of an additional $\mathrm{H}$-bearing species, but the best fit molar absorption coefficients for the 4485 and $5218 \mathrm{~cm}^{-1}$ bands are similar whether or not glasses showing this band are included in the regression. As shown in Fig. 5, for samples synthesized in BN-bearing assemblies, the calculated total water content determined from the sum of the molecular water and $\mathrm{OH}$ contents is sometimes low, but within $0.3 \mathrm{wt} . \%$ of the value determined for the same sample by hydrogen manometry or NMR spectroscopy. We thus conclude that if the band at $4125 \mathrm{~cm}^{-1}$ is in fact a $\mathrm{H}$-bearing species, its concentration is small, though perhaps not negligible.

Newman et al. (1986) calibrated the infrared technique for rhyolitic glasses with water contents up to about $2 \mathrm{wt} . \%$. In this study, we have demonstrated that infrared spectroscopy can be used quantitatively for determining total water contents and species concentrations in albitic glasses up to a total water content of at least $7 \mathrm{wt} . \%$. Over this concentration range, infrared spectroscopy offers a non-destructive method for measuring total water contents and hydrogen-bearing species concentrations in albitic glasses that is comparable to the most precise techniques currently available. With the FTIR spectrometer, spots on the order of a few tens of microns in diameter can be routinely analyzed, making the technique ideal for experimental studies.

\section{THE SPECIATION OF WATER IN ALBITIC GLASSES}

Using the calibrations described in the previous section, we have determined the concentrations of hydroxyl groups and molecular water dissolved in hydrous albitic glass synthesized at a variety of pressures and temperatures. Total dissolved water contents and species concentrations are listed in Tables 2 and 3. Figure 6 shows the concentrations of water dissolved as molecular $\mathrm{H}_{2} \mathrm{O}$ and $\mathrm{OH}$ as functions of total water content up to almost $10 \mathrm{wt} \%$ for samples quenched from melts equilibrated at $15-20 \mathrm{~kb}$ and $1350-1400^{\circ} \mathrm{C}$ (Fig. 6a) and for glasses quenched from melts equilibrated at other conditions in the range $8-25 \mathrm{~kb}$ and $1000-1600^{\circ} \mathrm{C}$ (Fig. 6b). Also shown is a best-fit to the data in Fig. $6 \mathrm{a}$ (see below for fitting procedure). All of the samples shown in Fig. 6 were synthesized in piston cylinder apparatus (Table 2). 


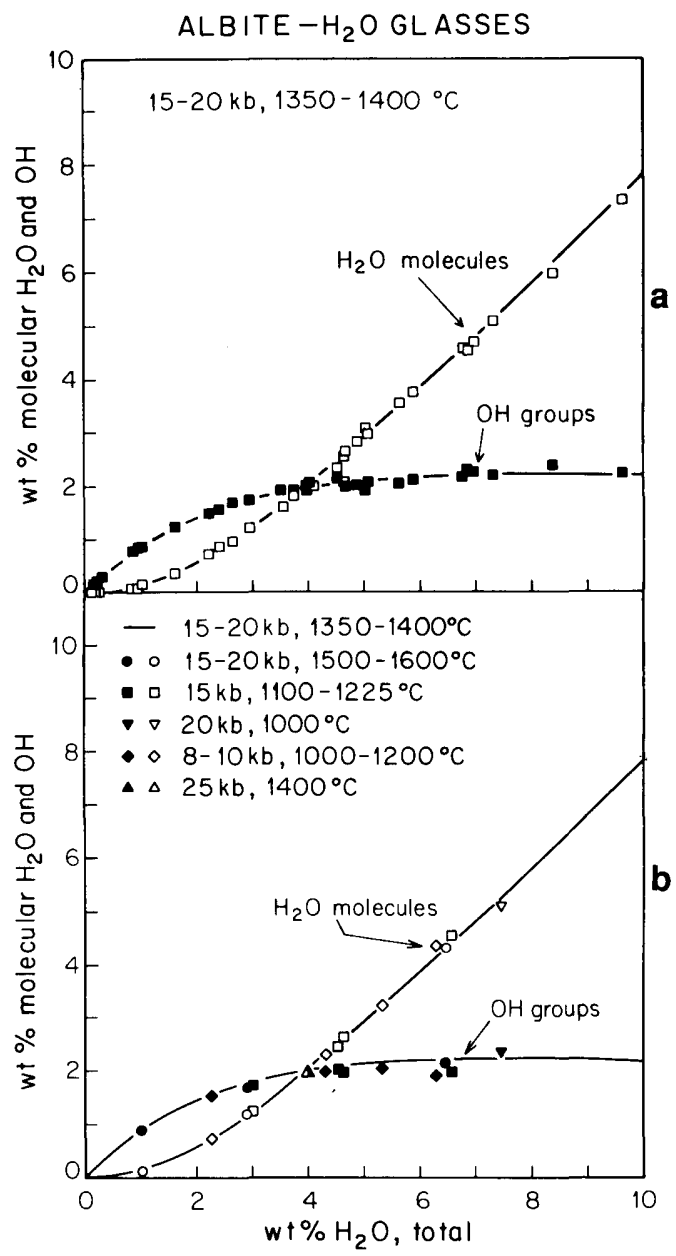

FIG. 6. The concentrations of water dissolved as molecules of water (open symbols) and as $\mathrm{OH}$ groups (filled symbols) as functions of total water content for albitic glasses. All samples were synthesized in piston cylinder apparatus. Run conditions are given in Table 2. Species concentrations and total water contents were determined by infrared spectroscopy based on the best-fit values for the molar absorption coefficients (Table 5). (a) Samples synthesized at $15-20 \mathrm{~kb}$ and $1350-1400^{\circ} \mathrm{C}$. The solid curves represent a best fit to this data based on the strictly regular solution model discussed in the text. (b) Samples synthesized at conditions other than $15-20 \mathrm{~kb}$ and $1350-1400^{\circ} \mathrm{C}$. Run conditions are noted in the legend. Solid curves show the best fit to data in (a).

At low total water contents, most of the water is dissolved as hydroxyl groups, but the amount of molecular water increases progressively as the total water content increases. At about $4 \mathrm{wt} . \%$ total water, equal amounts of water are dissolved as hydroxyl groups and as $\mathrm{H}_{2} \mathrm{O}$ molecules. At higher water contents, the $\mathrm{OH}$ concentration levels off and remains at approximately a constant value; i.e. beyond this point, essentially all additional water is incorporated as molecular $\mathrm{H}_{2} \mathrm{O}$. Although the position at which equal amounts of water are dissolved as $\mathrm{OH}$ groups and $\mathrm{H}_{2} \mathrm{O}$ groups differs from composition to composition, the trends for albitic glass are essentially identical to those for an alkali-, Zn-rich aluminosilicate glass (Bartholomew et al., 1980), Na-silicate glass (Acocella et al., 1984), rhyolitic glass (Newman et al., 1986, 1988), orthoclasic and jadeitic glasses, and glasses in the system silica-anorthite-wollastonite (Silver et al., 1989). We also note that the effects of bulk 
composition on speciation are sufficiently small that there are no detectable differences between results obtained on different batches of albite starting material, even though the various batches (fused natural and synthetic albite from our lab, gels from Professor Holloway, fused natural albite from Professor Boettcher) differ slightly in composition.

We also determined the speciation of water in albitic glass for glasses quenched from melts equilibrated in IHPV at $1-7 \mathrm{~kb}$ and $950-1150^{\circ} \mathrm{C}$. The species concentrations and total water contents were determined by infrared spectroscopy and are listed in Table 3. Figure 7 compares the concentrations of water dissolved as molecular water and $\mathrm{OH}$ groups as a function of total water up to about $11 \mathrm{wt} \%$ for these samples. The heavy solid curves show the fit to the data from the samples synthesized in piston cylinder apparatus at $1350-1400^{\circ} \mathrm{C}, 15-20 \mathrm{~kb}$ (Fig. 6a). Again, the $\mathrm{OH}$ concentration levels off with increasing total water content, but in comparison with the data from piston cylinder syntheses, there is more scatter and the $\mathrm{OH}$ concentration levels off at about $1.9 \mathrm{wt} . \%$ instead of $2.1 \mathrm{wt} . \%$ $\mathrm{H}_{2} \mathrm{O}$.

The well-defined trends in the concentrations of molecular $\mathrm{H}_{2} \mathrm{O}$ and $\mathrm{OH}$ groups as a function of total water content for all of these glasses, which were synthesized over a wide range of experimental conditions, illustrate the lack of a major dependence of the speciation of water on pressure and temperature. As discussed below and by Newman et al. (1988) for rhyolitic glasses, there is probably a minor increase in molecular water relative to hydroxyl groups with decreasing temperature, and this is probably responsible for the small differences between the results of the piston cylinder experiments and the generally lower temperature, slower quenching IHPV experiments.

Several of the albitic glasses have an absorption near $2350 \mathrm{~cm}^{-1}$, which is due to the fundamental bending mode of molecular $\mathrm{CO}_{2}$ (Fine \& Stolper, 1985) and is probably caused by adsorption of atmospheric $\mathrm{CO}_{2}$ onto the starting materials. The total amount of dissolved molecular $\mathrm{CO}_{2}$ is always $\leq 0.35 \mathrm{wt}$. \% based on the molar absorption coefficient for this band determined by Fine \& Stolper (1985). The molecular $\mathrm{H}_{2} \mathrm{O} / \mathrm{OH}$ ratios for

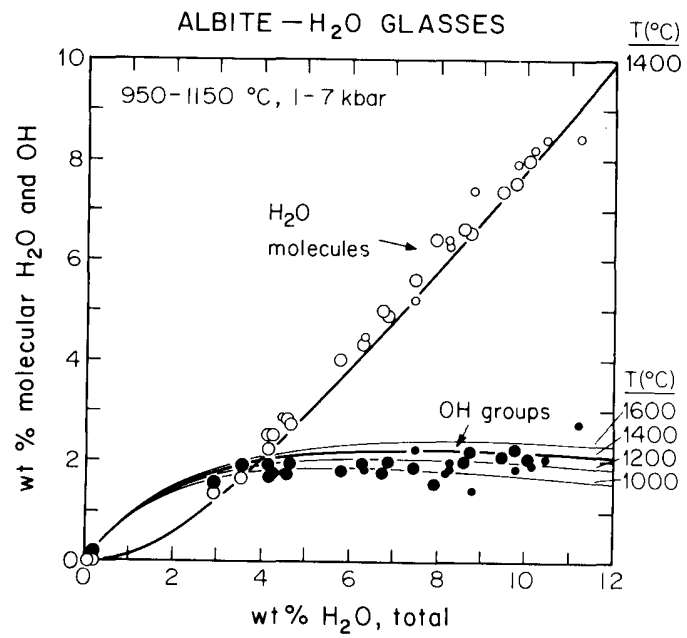

Fig. 7. The concentrations of water dissolved as molecules of $\mathrm{H}_{2} \mathrm{O}$ (open symbols) and as $\mathrm{OH}$ groups (filled symbols) versus total water content for glasses synthesized in IHPVs at $1-7 \mathrm{~kb}$ and $950-1150^{\circ} \mathrm{C}$. The smaller symbols represent those samples for which the infrared spectra were obtained on regions that contained bubbles. The curves show a best fit to the data in Figs. 6 and 7 based on a regular solution model incorporating the temperature dependence of speciation as discussed in the text. The dark solid curves are for $1400^{\circ} \mathrm{C}$ and are the same as those shown in Fig. 6. 
glasses with and without $\mathrm{CO}_{2}$ at a given total water content are indistinguishable, indicating that the presence of small amounts of $\mathrm{CO}_{2}$ does not have a significant effect on the speciatic of water.

\section{The effects of quenching}

The molecular water detected in these glasses is structurally bound-not in fluid inclusions or bubbles - based on several lines of evidence. The glasses synthesized in piston cylinder apparatus are optically clear and generally completely free of bubbles. In optically clear areas of glasses containing up to $7 \mathrm{wt} \%$ total water, no bubbles were seen with a scanning electron microscope, with a resolution of 10-20 nm. Professor J. Christie of the University of California, Los Angeles examined a glass with a total water content of $7 \mathrm{wt} . \%$ (LAS-22) by transmission electron microscopy with a resolution of $\sim 3 \mathrm{~nm}$ and detected no features indicating phase separation. Infrared spectra of optically clear hydrous glasses taken at liquid $\mathrm{N}_{2}$ temperatures do not show ice bands (Stolper, 1982a; L. A. Silver, unpublished results); ice bands are observed in the spectra of visibly bubbly samples when they are frozen (Stolper, 1982a). In rhyolitic glasses with up to $5 \mathrm{wt} \%$ total $\mathrm{D}_{2} \mathrm{O}$, NMR spectra confirm that very little of the water (if any) is present as a free fluid phase, i.e. in inclusions (Eckert et al., 1987). The ${ }^{1} \mathrm{H}$ NMR spectra of hydrous albitic glasses from this study and a variety of other bubble-free hydrous silicate glasses with up to $9 \mathrm{wt} \% \mathrm{H}_{2} \mathrm{O}$ lead to similar conclusions about the state of water in these in glasses (Eckert et al., 1988).

There can be little doubt that molecular water and hydroxyl groups coexist stably in hydrous silicate liquids and that the presence of molecular water in glasses is not an artifact of quenching or cooling. The fundamental bending mode of $\mathrm{H}_{2} \mathrm{O}$ molecules at $1630 \mathrm{~cm}^{-1}$ was observed in the high temperature $\left(850^{\circ} \mathrm{C}\right)$ spectrum of a rhyolitic obsidian (Aines et al., 1983). The intensity of this band showed a small inverse dependence on the temperature at which the spectrum was taken. The fact that molecular water persists in this rhyolite at temperatures above its glass transition indicates that its presence in glasses quenched from melts held at high temperatures and pressures is not simply a result of cooling. In addition, the reversible dependence of the concentrations of molecular $\mathrm{H}_{2} \mathrm{O}$ and $\mathrm{OH}$ groups on temperature whether observed in situ (Aines et al., 1983) or in glasses quenched from temperatures between 400 and $650^{\circ} \mathrm{C}$ (Stolper et al., 1983; Newman et al., 1988) is not readily reconcilable with quenching effects.

Since rhyolitic glasses exhibit a small, but measurable, temperature dependence of the relative concentrations of molecular $\mathrm{H}_{2} \mathrm{O}$ and $\mathrm{OH}$ at low temperatures, such that the $\mathrm{OH}$ content increases with increasing temperature, it is possible that the ratios of molecular $\mathrm{H}_{2} \mathrm{O}$ to $\mathrm{OH}$ of glasses synthesized from melts equilibrated at high temperatures increase as the melts are quenched to glasses. Without spectroscopic measurements in situ at elevated pressures and temperatures (as opposed to studies on glasses at room temperature and pressure), we cannot rule out the possibility that the species concentrations of all of our samples are altered to some degree on quenching. We have, however, examined the influence of quench rate on species concentrations so as to set limits on the possible magnitude of this effect. Several samples of albitic melt with $3 \cdot 7-4 \cdot 5 \mathrm{wt} . \%$ total $\mathrm{H}_{2} \mathrm{O}$ were held at $15 \mathrm{~kb}$ and $1400^{\circ} \mathrm{C}$ for $2 \mathrm{~h}$, and then cooled at rates of $0 \cdot 3-2 \cdot 5^{\circ} \mathrm{C} / \mathrm{s}$. For this range of cooling rates and water contents, the concentrations of $\mathrm{OH}$ groups and molecular $\mathrm{H}_{2} \mathrm{O}$ at a constant total water content are independent of cooling history and indistinguishable from glasses quenched as rapidly as possible (i.e. up to several hundred degrees per second). The IHPV experiments cooled more rapidly than $2.5^{\circ} \mathrm{C} / \mathrm{s}$, suggesting that the generally slightly higher ratios of molecular $\mathrm{H}_{2} \mathrm{O}$ to $\mathrm{OH}$ of glasses synthesized in IHPV compared to those 
synthesized in piston cylinder apparatus are not due to quenching effects, but instead, by analogy with the well-documented case for rhyolitic melts and glasses, reflect the typically lower equilibration temperatures of these experiments. The greater scatter of the results on the IHPV samples (Fig. 7 vs. Fig. 6), particularly for the most water-rich samples, may be due to the greater difficulty in obtaining spectra on these typically bubble-bearing samples or to a possibly greater tendency to reequilibrate during quenching of vapor-saturated or very water-rich samples.

\section{Comparison with other studies}

The trends in the speciation of water in hydrous albitic glasses presented in this work are similar to results obtained from infrared and NMR spectroscopic studies of albitic and other hydrous silicate glass compositions synthesized at various conditions (IR: Bartholomew et al., 1980; Stolper, 1982a; Acocella et al., 1984; Epel'baum, 1985; Stolper \& Silver, 1985; Silver et al., 1988; NMR: Bartholomew \& Schreurs, 1980; Eckert et al., 1987, 1988; Farnan et al., 1987). We note in particular that the ${ }^{1} \mathrm{H}$ MAS-NMR studies of Eckert et al. (1988) included some of the samples synthesized as part of this study, and yield results very similar to those we report based on a completely independent method. The exact value at which the $\mathrm{OH}$ content levels off as total water content increases varies with the bulk composition of the silicate (Stolper \& Silver, 1985; Silver et al., 1989), but the levelling off and the progressive increase in the ratio of molecular $\mathrm{H}_{2} \mathrm{O}$ to $\mathrm{OH}$ with total water content appear to be general phenomena.

In contrast to the consistency and reproducibility of the results based on infrared and NMR spectroscopies, Raman spectroscopic studies of hydrous glasses have yielded inconsistent results when results of different laboratories, or even successive reports from a single laboratory, are compared. The early studies on hydrous glasses using Raman spectroscopy failed to detect any intensity near $1600 \mathrm{~cm}^{-1}$ (Mysen et al., 1980; Mysen \& Virgo, 1980) and led to the conclusion, in contrast with previously published infrared results (Orlova, 1962; Ostrovskiy et al., 1964; Persikov, 1972; Ernsberger, 1977), that water dissolves in silicate melts only as $\mathrm{OH}$ groups. Later, McMillan et al. (1983) observed a small band near $1600 \mathrm{~cm}^{-1}$ in the Raman spectra of hydrous albitic glasses that they assigned to molecular $\mathrm{H}_{2} \mathrm{O}$, confirming the results of the previous infrared studies; recently, Mysen \& Virgo (1986a) confirmed the results of McMillan et al. (1983).

Detection of molecular water in glasses by Raman spectroscopy is difficult because of the low Raman cross-section of molecular water; this is the reason that water is commonly used as a solvent for the Raman study of other molecules. Given this difficulty, it is not surprising that Raman spectroscopy is not the optimum technique for quantitative measurement of the concentration of water molecules in glass.

Other factors also make quantitative measurements of species concentrations in glasses by Raman spectroscopy difficult. Foremost among them is the difficulty in normalizing band intensities. In the case of the infrared measurements reported in this paper, we measure the intensity of a band and normalize it to the thickness of our sample. Provided that Beer's law is obeyed, we can be confident that if the intensity per thickness (the 'absorption coefficient') in one sample is twice that of another, then the concentration of the absorbing species in the first glass is twice that in the second. For the Raman spectra of glasses, there is typically no such convenient normalization procedure. Ideally, one band due to a major species whose concentration is invariant over the range of samples studied could be used for normalization (i.e. all other band intensities would be scaled to the intensity of this band). However, in silicate glasses covering a substantial compositional range, it is generally not possible to 
identify such an invariant band, and in any case, band assignments are so poorly known that even if a species could be postulated to be invariant, it would be difficult to confidently associate it with a specific band. Consequently, normalization procedures that have been adopted are necessarily ad hoc (Seifert et al, 1981; Mysen et al., 1982). Also, in contrast to the infrared studies reported here, where bands are well separated from each other, deconvolution procedures are required in the Raman studies to obtain band intensities and these involve a variety of assumptions about band shapes, location, and number that diminish the precision of the results.

Despite these difficulties, Mysen \& Virgo (1986a) attempted to use Raman spectroscopy to measure quantitatively the concentrations of molecular water and hydroxyl groups in hydrous silica glass. They concluded that hydroxyl groups are the dominant species of dissolved water for total water contents up to $10 \mathrm{wt} . \%$, that the ratio of molecular water to hydroxyl groups decreases with increasing water content in the 4-10 wt.\% water range, and that molecular water (not hydroxyl) group concentrations are approximately constant over this concentration range. These conclusions are quite different from those reached in this study for albitic glass and by others for silicate glasses, including silica, based on infrared and NMR spectroscopies. Recently, Farnan et al. (1987) used cross-polarization NMR to determine the concentration of hydroxyl groups as a function of total water content for hydrous silica glasses with 2.5 and $8.7 \mathrm{wt} . \% \mathrm{H}_{2} \mathrm{O}$. They found that molecular water is the dominant species at high total water contents and that the molecular $\mathrm{H}_{2} \mathrm{O}$ to $\mathrm{OH}$ ratio increases with total water content, in agreement with the data presented here for albitic glasses. In addition, preliminary work by us on silica glasses with up to $10 \mathrm{wt}$. \% water, based on the infrared intensities of the 4520 and $5270 \mathrm{~cm}^{-1}$ bands, also indicates a behavior for silica that is similar to that observed for all other glasses studied by infrared spectroscopy.

It is not possible to be certain of the cause of the discrepancies between the conclusions based on infrared and NMR spectroscopies versus those based on Raman spectroscopy. However, in our view, it is clearly an analytical problem and not, as suggested by Mysen \& Virgo (1986a), related in some way to the techniques by which the glasses were prepared. Their samples and ours were synthesized by identical techniques, and we have demonstrated that equilibration temperature and pressure have, at most, minor effects on the results. We have demonstrated here and elsewhere (Newman et al., 1986; Silver et al., 1989) that infrared spectroscopy can yield precise and accurate measurements of total water content when properly calibrated. These demonstrations give us confidence in our technique and quantitative results. In contrast, the Raman technique is not, at this point, as internally consistent or quantitatively successful. Until Raman spectroscopy can be demonstrated against independent techniques to be truly quantitative, infrared and NMR spectroscopies will remain the methods of choice for measuring species concentrations in hydrous glasses.

\section{THERMODYNAMICS OF HYDROUS ALBITIC MELTS}

In the preceding sections, we demonstrated that infrared spectroscopy can be used to measure the concentrations of molecular water, hydroxyl groups and total dissolved water in hydrous albitic glasses over a wide range of water contents. As we stated in the Introduction, one of our goals is to use our spectroscopic data to link the molecular level characteristics of hydrous glasses to the macroscopic thermodynamic properties of silicate melts. For the remainder of this paper, we will assume that the concentrations of hydrous species in albitic glasses formed by quenching of melts from high temperature and pressure accurately preserve the concentrations of these species in the melts. The observed variations in species concentrations are thus assumed to reflect the molecular level 
interactions between water and silicate melt and to provide insights into the dissolution mechanisms of water. In the following section, we illustrate mixing models involving homogeneous equilibria among melt species that can account for the spectroscopically determined molecular water and hydroxyl group concentrations. Then, in the final section, we use the measured species concentrations as the basis for thermodynamic models of hydrous albitic melts and demonstrate that such models can account for phase equilibria in the $\mathrm{NaAlSi}_{3} \mathrm{O}_{8}-\mathrm{H}_{2} \mathrm{O}$ system.

\section{Mixing models for silicate- $\mathrm{H}_{2} \mathrm{O}$ systems}

If we were to inject water molecules into albitic melt, they would react with the silicate portions of the glass to generate hydroxyl groups. These reactions would tend to proceed until the concentrations of water molecules, hydroxyl groups, and the various anhydrous species present in the glass are in equilibrium. Such reactions can be represented in the following way:

$$
\mathrm{H}_{2} \mathrm{O} \text {, molecular (melt) }+\mathrm{O}^{2-}(\text { melt })=2 \mathrm{OH}^{-} \text {(melt). }
$$

Many such reactions may take place in the melt, depending on the different types of oxygens available for reaction with the water molecules (e.g., non-bridging vs. bridging, Al-O-Si vs. $\mathrm{Si}-\mathrm{O}-\mathrm{Si}$ bridges), and the measured concentrations of molecular water and hydroxyl groups will reflect simultaneous achievement of all of these equilibria. One of the goals of our study of the concentrations of water molecules and hydroxyl groups is to see if they can be rationalized in terms of such homogeneous equilibria and, if so, do they yield insights into the thermodynamics of hydrous silicate melts.

\section{Ideal mixing of $\mathrm{H}_{2} \mathrm{O}, \mathrm{OH}$, and oxygen in hydrous silicate melt}

In our previous treatments of this problem (Stolper, 1982b; Silver \& Stolper, 1985), we pursued the simplest possible model of homogeneous equilibria in hydrous silicate melts. The melt is modelled as an ideal mixture of water molecules, hydroxyl groups, and oxygens. These three species are related through reaction (2) and their activities $\left(a^{\mathrm{m}}\right)$ and mole fractions $\left(X^{\mathrm{m}}\right.$, defined in Silver \& Stolper, 1985, and in Table 2, note 5) are related through the following equilibrium constant:

$$
K_{1}=\frac{\left(a_{\mathrm{OH}}^{\mathrm{m}}\right)^{2}}{\left(a_{\mathrm{H}_{2} \mathrm{O}, \mathrm{mol}}^{\mathrm{m}}\right)\left(a_{\mathrm{O}}^{\mathrm{m}}\right)}=\frac{\left(X_{\mathrm{OH}}^{\mathrm{m}}\right)^{2}}{\left(X_{\mathrm{H}_{2} \mathrm{O}, \mathrm{mol}}^{\mathrm{m}}\right)\left(X_{\mathrm{O}}^{\mathrm{m}}\right)},
$$

where the superscript $m$ refers to the melt phase, and the subscript refers to the species. At any pressure and temperature, $K_{1}$ is a constant and the concentrations of the three species can be calculated as functions of total water content and $K_{1}$ using the expressions given in Silver \& Stolper (1985). This treatment is basically an extension of the treatment developed by Wasserburg (1957) for modelling the thermodynamic properties of silicate melts.

Figure 8 compares the measured concentrations of hydroxyl groups and molecules of water in albitic glasses (plotted in terms of their mole fractions; Table 2) with the concentrations expected for a value of $K_{1}=0.17$ given that the melt species mix ideally. The shapes of the model and actual species concentration curves are grossly similar in that the molecular water concentration is concave up when plotted against total water content and the hydroxyl group content is concave down. The agreement between the model and actual concentrations is best at low $(<2 \mathrm{wt} . \%)$ water contents. At high water contents, however, the model diverges progressively from the measured concentrations as the measured hydroxyl group concentration levels off more sharply than does the model calculation. 


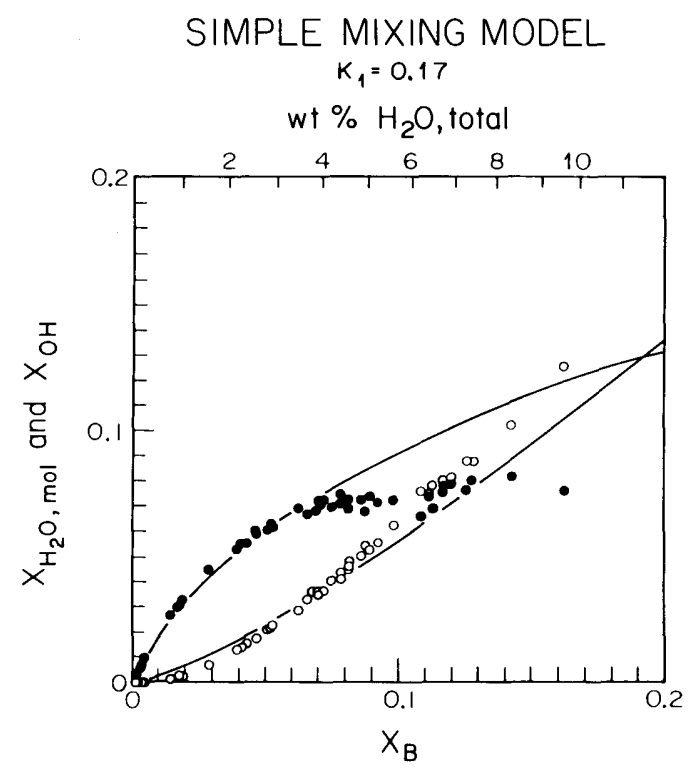

FIG. 8. Mole fractions of molecular $\mathrm{H}_{2} \mathrm{O}$ and $\mathrm{OH}$ groups in albitic melt as functions of the mole fraction of total water, $X_{\mathrm{B}}$, based on the ideal mixing model. The solid curve shows the calculated species concentrations for $K_{1}$ $=0 \cdot 17$ (eqn 3). Shown for comparison are the mole fractions of hydrous species determined by IR spectroscopy for the samples in Fig. 6. Open symbols are molecular water. Filled symbols are hydroxyl groups.

The general correspondence between observed species concentrations and those calculated using the simplest ideal mixing model suggests that it is a useful starting point for development of more complex and realistic models of the homogeneous equilibria of hydrous albitic melts. The ideal mixing model involves several simplifying assumptions, each of which will be relaxed in subsequent sections as we illustrate how more complex models can account in detail for the observed species concentrations. The first assumption is that the mixing between species is ideal; i.e. that all possible configurations of water molecules, hydroxyl groups, and oxygen atoms are energetically identical. This assumption can be relaxed by including non-ideal interactions between the three species. The second assumption is that the entropy of mixing of the melt can be modelled by counting all possible configurations of water molecules, hydroxyl groups, and oxygen atoms assuming that each of these species occupies a single 'lattice site' in the sense of quasi-crystalline models of melt structure (Guggenheim, 1952). This assumption can be relaxed by recognizing that polymeric units exist in silicate melts and modelling the configurational entropy accordingly. The final assumption in the simple ideal mixing model is that all of the oxygens in the melt are indistinguishable and equally reactive with water molecules to produce hydroxyl groups; i.e. that only one reaction such as (2) needs to be considered. It is more likely that different types of oxygens (e.g., bridging vs. non-bridging vs. free; oxygens between two Albearing tetrahedra, two Si-bearing tetrahedra, etc.) react to differing degrees with water molecules and should be distinguished. This assumption can be relaxed by considering several different, coupled reactions such as (2) each describing interactions with distinguishable oxygen (and/or hydroxyl) types.

Non-ideal mixing of $\mathrm{H}_{2} \mathrm{O}$, hydroxyl, and oxygen units

We have chosen to model possible non-ideal interactions between water molecules, hydroxyls, and oxygens using the formalism of a strictly regular ternary solution. This is 
analogous to the extension by Shaw (1964) of Wasserburg's (1957) model of silicate-water mixtures as ideal mixtures of water molecules and oxygen atoms to include non-ideal behavior. In this treatment, the entropy of mixing is taken to be identical to that in an ideal mixture, but all possible configurations of the three species over the quasi-crystalline lattice sites are not energetically identical. It can be shown that the activities of the three species given these restrictions are (Guggenheim, 1952; Prigogine \& Defay, 1954, equation 16.90):

$$
\begin{aligned}
a_{\mathrm{H}_{2} \mathrm{O}, \mathrm{mol}}^{\mathrm{m}}= & X_{\mathrm{H}_{2} \mathrm{O}, \mathrm{mol}}^{\mathrm{m}} \exp \left\{\frac { 1 } { R T } \left(X_{\mathrm{O}}^{\mathrm{m}} X_{\mathrm{OH}}^{\mathrm{m}}\left(W_{\mathrm{H}_{2} \mathrm{O}, \mathrm{mol}-\mathrm{o}}-W_{\mathrm{O}-\mathrm{OH}}+W_{\mathrm{H}_{2} \mathrm{O}, \mathrm{mol}-\mathrm{OH}}\right)\right.\right. \\
& \left.\left.+X_{\mathrm{O}}^{\mathrm{m}_{2}} W_{\mathrm{H}_{2} \mathrm{O}, \mathrm{mol}-\mathrm{O}}+X_{\mathrm{OH}}^{\mathrm{m}_{2}} W_{\mathrm{H}_{2} \mathrm{O}, \mathrm{mol}-\mathrm{OH}}\right)\right\}, \\
a_{\mathrm{O}}^{\mathrm{m}}= & X_{\mathrm{O}}^{\mathrm{m}} \exp \left\{\frac { 1 } { R T } \left(X_{\mathrm{H}_{2} \mathrm{O}, \mathrm{mol}}^{\mathrm{m}} X_{\mathrm{OH}}^{\mathrm{m}}\left(W_{\mathrm{O}-\mathrm{OH}}-W_{\mathrm{H}_{2} \mathrm{O}, \mathrm{mol}-\mathrm{OH}}+W_{\mathrm{H}_{2} \mathrm{O}, \mathrm{mol}-\mathrm{o}}\right)\right.\right. \\
& \left.\left.+X_{\mathrm{H}_{2} \mathrm{O}, \mathrm{mol}}^{\mathrm{m}_{2}} W_{\mathrm{H}_{2} \mathrm{O}, \mathrm{mol}-\mathrm{o}}+X_{\mathrm{OH}}^{\mathrm{m}_{2}} W_{\mathrm{O}-\mathrm{OH}}\right)\right\}, \\
a_{\mathrm{OH}}^{\mathrm{m}}= & X_{\mathrm{OH}_{\mathrm{H}}}^{\mathrm{m}} \exp \left\{\frac { 1 } { R T } \left(X_{\mathrm{H}_{2} \mathrm{O}, \mathrm{mol}}^{\mathrm{m}} X_{\mathrm{O}}^{\mathrm{m}_{2}}\left(W_{\mathrm{H}_{2} \mathrm{O}, \mathrm{mol}-\mathrm{OH}}-W_{\mathrm{H}_{2} \mathrm{O}, \mathrm{mol}-\mathrm{O}}+W_{\mathrm{O}-\mathrm{OH}}\right)\right.\right. \\
& \left.\left.+X_{\mathrm{H}_{2} \mathrm{O}, \mathrm{mol}}^{\mathrm{m}_{2}} W_{\mathrm{H}_{2} \mathrm{O}, \mathrm{mol}-\mathrm{OH}}+X_{\mathrm{O}}^{\mathrm{m}_{2}} W_{\mathrm{O}-\mathrm{OH}}\right)\right\},
\end{aligned}
$$

where the $W_{\mathrm{ij}}$ are binary interaction parameters, have units of energy, and are independent of temperature and pressure. If $W_{i j}$ is positive, species $i$ and $j$ will tend to be separated (i.e. $i$ and $j$ atoms will tend to cluster with like atoms) in the mixture compared to the random distribution of an ideal solution; if $W_{i j}$ is negative, $i$ and $j$ atoms will tend to be associated in the mixture compared with an ideal solution.

By substituting the activity expressions given above into the definition of $K_{1}$ (eqn 3) and rearranging, we obtain the following expressions:

$$
-\ln \left[\frac{\left(X_{\mathrm{OH}}^{\mathrm{m}}\right)^{2}}{\left(X_{\mathrm{H}_{2} \mathrm{O}, \mathrm{mol}}^{\mathrm{m}}\right)\left(1-X_{\mathrm{OH}}^{\mathrm{m}}-X_{\mathrm{H}_{2} \mathrm{O}, \mathrm{mol}}^{\mathrm{m}}\right)}\right]=\mathrm{A}^{\prime}+\mathrm{B}^{\prime} X_{\mathrm{OH}}^{\mathrm{m}}+\mathrm{C}^{\prime} X_{\mathrm{H}_{2} \mathrm{O}, \mathrm{mol}}^{\mathrm{m}},
$$

where

$$
\begin{gathered}
\mathrm{A}^{\prime}=-\ln K_{1}+\left(2 W_{\mathrm{O}-\mathrm{OH}}-W_{\mathrm{H}_{2} \mathrm{O}, \mathrm{mol}-\mathrm{o}}\right) / R T, \\
\mathrm{~B}^{\prime}=\left(W_{\mathrm{H}_{2} \mathrm{O}, \mathrm{mol}-\mathrm{o}}-3 W_{\mathrm{O}-\mathrm{OH}}-W_{\mathrm{H}_{2} \mathrm{O}, \mathrm{mol}-\mathrm{OH}}\right) / R T, \\
\mathrm{C}^{\prime}=2\left(W_{\mathrm{H}_{2} \mathrm{O}, \mathrm{mol}-\mathrm{o}}-W_{\mathrm{O}-\mathrm{OH}}\right) / R T .
\end{gathered}
$$

Given values of these coefficients, which are constants at any given pressure and temperature, eqn (5) can be solved iteratively to give $X_{\mathrm{OH}}^{\mathrm{m}}$ as a function of $X_{\mathrm{H}_{2} \mathrm{O} \text {, mol }}^{\mathrm{m}}$. Equation (5) thus specifies the form of the relationship between species concentrations given a strictly regular solution model. Note that eqn (5) can be readily transformed into equivalent expressions between any two of the variables $X_{\mathrm{O}}^{\mathrm{m}}, X_{\mathrm{B}}$ (the mole fraction of total dissolved water; Stolper, 1982b), $X_{\mathrm{H}_{2} \mathrm{O} \text {, mol }}^{\mathrm{m}}$, and $X_{\mathrm{OH}}^{\mathrm{m}}$ using the relationships between them given as eqns (A.6) and (A.7) in Silver et al. (1989).

A least squares fit to eqn (5) using our measurements of species concentrations for samples synthesized at $1350-1400^{\circ} \mathrm{C}$ as constraints resulted in best fit values of $\mathrm{A}^{\prime}=0 \cdot 403, \mathrm{~B}^{\prime}$ $=15.333$, and $C^{\prime}=10 \cdot 894$. The relationships between total water content and the mole 
fractions of molecular water and hydroxyl groups calculated from these parameters are shown in Fig. 9. Figure 9 (and Fig. 6, which shows the same fit in terms of weight percents) demonstrates that this treatment can indeed account for the observed species concentrations of hydrous albitic glasses.

Values for the three parameters $\mathrm{A}^{\prime}, \mathrm{B}^{\prime}$, and $\mathrm{C}^{\prime}$ are sufficient to specify the relationship between the concentrations of hydrous species in hydrous albitic melt. As defined in equations (4.1)-(4.3), $\mathrm{A}^{\prime}, \mathrm{B}^{\prime}$, and $\mathrm{C}^{\prime}$ are linear combinations of the four parameters in the thermodynamic formulation of the strictly regular solution $\left(K_{1}, W_{\mathrm{O}-\mathrm{OH}}, W_{\mathrm{H}_{2} \mathrm{O} \text {, mol-OH }}\right.$, and $\left.W_{\mathrm{H}_{2} \mathrm{O} \text {, mol-OH }}\right)$. An additional relationship among these four parameters must be specified before their values can be determined. We arbitrarily take $W_{\mathrm{H}_{2} \mathrm{O} \text {,mol-o }}=0$, with the result that $a_{\mathrm{H}_{2} \mathrm{O}, \mathrm{mol}}^{\mathrm{m}} \rightarrow X_{\mathrm{H}_{2} \mathrm{O} \text {, mol }}^{\mathrm{m}}$ as $X_{\mathrm{B}} \rightarrow 0$ (see eqn (4.1)). Given $W_{\mathrm{H}_{2} \mathrm{O}, \text { mol }-\mathrm{O}}=0$, we have used equations (6.1)-(6.3) to determine values for $K_{1}$ and the other two interaction parameters from our best fit values of $\mathrm{A}^{\prime}, \mathrm{B}^{\prime}$, and $\mathrm{C}^{\prime}: \ln \left(K_{1}[1673 \mathrm{~K}]\right)=-10 \cdot 793 ; W_{\mathrm{H}_{2} \mathrm{O}, \mathrm{mol}-\mathrm{OH}}=838 \mathrm{cal} / \mathrm{mole} ; W_{\mathrm{O}-\mathrm{OH}}$ $=-17271 \mathrm{cal} / \mathrm{mole}$. In the context of this model, the fact that the interaction parameters have values that are either close to zero or very negative would indicate that the species do not tend to cluster preferentially with like molecules. This is consistent with the ${ }^{1} \mathrm{H}$ NMR results of Eckert et al. (1988), who found no evidence for clustering of $\mathrm{OH}$ groups or water molecules.

The small temperature dependence of species concentrations that we suggest is responsible for the slightly lower hydroxyl group contents of albitic glasses synthesized in IHPV (Fig. 7) can also be incorporated into the regular solution formulation. Using the values of the interaction parameters given in the previous paragraph, a value of $\ln \left(K_{1}[T]\right)$ for each glass for which species concentrations have been measured has been calculated from the following expression, obtained by rearrangement of equations (5) and (6.1)-(6.3)

$$
\begin{aligned}
& \ln K_{1}=\ln \left[\frac{\left(X_{\mathrm{OH}}^{\mathrm{m}}\right)^{2}}{\left(X_{\mathrm{H}_{2} \mathrm{O}, \mathrm{mol}}^{\mathrm{m}}\right)\left(1-X_{\mathrm{OH}}^{\mathrm{m}}-X_{\mathrm{H}_{2} \mathrm{O}, \mathrm{mol}}^{\mathrm{m}}\right)}\right]+\frac{W_{\mathrm{H}_{2} \mathrm{O}, \mathrm{mol}-\mathrm{O}}}{R T}\left(X_{\mathrm{OH}}^{\mathrm{m}}-1\right) \\
& +\frac{2 W_{\mathrm{O}-\mathrm{OH}}}{R T}\left(1-X_{\mathrm{H}_{2} \mathrm{O}, \mathrm{mol}}^{\mathrm{m}}-\frac{3}{2} X_{\mathrm{OH}}^{\mathrm{m}}\right)+\frac{2 W_{\mathrm{H}_{2} \mathrm{O}, \mathrm{mol}-\mathrm{OH}}}{R T}\left(X_{\mathrm{H}_{2} \mathrm{O}, \mathrm{mol}}^{\mathrm{m}}-\frac{1}{2} X_{\mathrm{OH}}^{\mathrm{m}}\right) .
\end{aligned}
$$

Figure 10 shows $\ln \left(K_{1}[T]\right)$ vs. $1 / T$ for the albitic glasses from this study. The relationsnip between $\ln \left(K_{1}\right)$ and $1 / T$ was fit to a straight line constrained to pass through $\ln \left(K_{1}[1673 K]\right)=-10 \cdot 793$. The best fit line is

$$
\ln K_{1}=\frac{-17167}{T}-0 \cdot 532 \text {. }
$$

Note that

$$
\left.\frac{\partial\left(\ln K_{1}\right)}{\partial(1 / T)}\right|_{P}=\frac{\Delta H_{\mathrm{r}}^{\mathrm{o}}}{R}
$$

so $\Delta H_{\mathrm{r}}^{\circ}$ (i.e. the standard state enthalpy change for reaction (2)) for the regular solution model is $34 \cdot 1 \mathrm{kcal} / \mathrm{mol}$.

Using the temperature dependence of $K_{1}$ given by eqn (8) and the values of the interaction parameters given above, species concentrations at any temperature can be determined by solution of eqn (5). Figure 7 shows the resulting temperature dependence of speciation. As required by the data, the calculated temperature dependence of speciation is small, although the regular solution model predicts that it will become larger at lower temperatures. This fit also predicts that a downturn in the hydroxyl content with increasing water content will become pronounced at lower temperatures, with the maximum in the hydroxyl content 

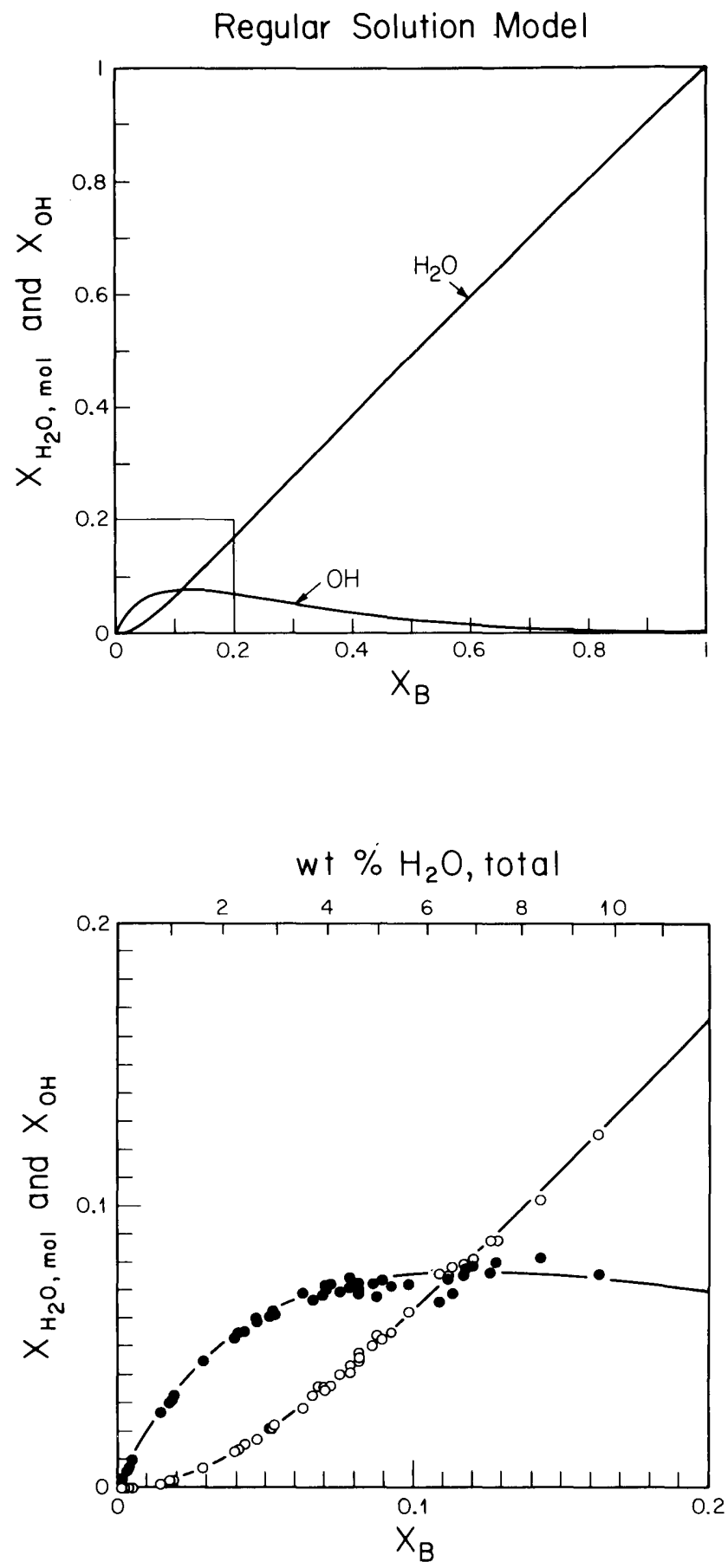

FIG. 9. Mole fractions of molecular $\mathrm{H}_{2} \mathrm{O}$ and $\mathrm{OH}$ groups (solid curves) in albitic melt as functions of the mole fraction of total water, $X_{\mathrm{B}}$, based on the regular solution model discussed in the text $\left(T=1400^{\circ} \mathrm{C}\right)$. These best fit curves are reproduced in Figs. 6 and 7. Shown for comparison are the mole fractions of molecular water (open symbols) and $\mathrm{OH}$ groups (filled symbols) determined by IR spectroscopy for the samples shown in Fig. 6 . 


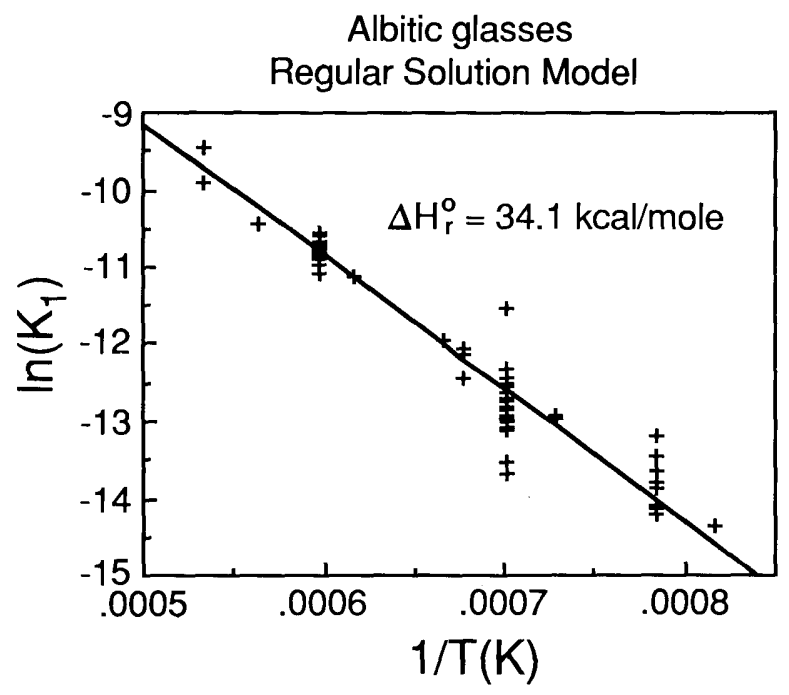

FIG. 10. $\ln \left(K_{1}\right)$ vs. $1 / T(K)$ for hydrous albitic glasses based on the regular solution model discussed in the text. For each sample listed in Tables 2 and $3, \ln \left(K_{1}\right)$ was calculated using eqn (7). The line is a best fit, constrained to pass through $\ln \left(K_{1}\right)=-10 \cdot 793$ at $1673 \mathrm{~K}$.

occurring at progressively lower total water contents as temperature is decreased. Interestingly, such a maximum has been observed by Bartholomew et al. (1980) in silicate glasses hydrated at low temperatures and by Silver et al. (1989) in glasses in the system $\mathrm{CaAl}_{2} \mathrm{Si}_{2} \mathrm{O}_{8}-\mathrm{SiO}_{2}-\mathrm{H}_{2} \mathrm{O}$.

The expected effects of pressure on the concentration of hydrous species in albitic melt can also be evaluated using the regular solution model. The variation in $K_{1}$ with pressure is related to $\Delta V_{\mathrm{r}}^{\mathrm{o}}$, the standard state volume change of reaction (2):

$$
\left.\frac{\partial\left(\ln K_{1}\right)}{\partial P}\right|_{T}=-\frac{\Delta V_{\mathrm{r}}^{\mathrm{o}}}{R T}
$$

By varying $K_{1}$ with pressure according to eqn (10) and substituting into eqn (6.1) to obtain a new value of $A^{\prime}$ at each pressure, eqn (5) can be used to determine the variation in speciation with pressure. Given that we have not detected any pressure dependence of speciation between 8 and $25 \mathrm{~kb}$, we conclude that the reaction of water molecules with the silicate framework to produce hydroxyl groups in albitic glass results in a negligible volume change over this pressure range. Likewise, inspection of the data from IHPV syntheses (Fig. 7 and Table 3), which cover the pressure range from 1 to $7 \mathrm{~kb}$, reveals no systematic trends with pressure. Analysis of the density and speciation data presented by Acocella et al. (1984) for hydrous Na-silicate glasses leads to a value for the volume change of reaction (2) of about $-3.4 \mathrm{~cm}^{3} / \mathrm{mol}$ at $1 \mathrm{~atm} ., 25^{\circ} \mathrm{C}$. Given a volume change of $-3 \mathrm{~cm}^{3} / \mathrm{mol}$ and a melt with $5.8 \mathrm{wt} . \%$ water of which $2.0 \mathrm{wt} . \%$ is dissolved as hydroxyl groups at $10 \mathrm{~kb}$ and $1400^{\circ} \mathrm{C}$, a change in pressure of $10 \mathrm{~kb}$ would change the hydroxyl content by only $0.14 \mathrm{wt} . \%$. This is a small, barely detectable change. We conclude that the standard state volume change for reaction (2) in albitic melt is less than about $-3 \mathrm{~cm}^{3} / \mathrm{mol}$. There is no support for the suggestion of Mysen \& Virgo (1986a) that the volume change is as large as $-6 \mathrm{~cm}^{3} / \mathrm{mol}$.

\footnotetext{
*Acocella et al. (1984) obtained a similar result if the partial molar volumes they determined are expressed on the same single oxygen basis we have used.
} 


\section{Polymer mixing models}

In both the ideal and non-ideal mixing models developed above, the entropy of mixing is evaluated by counting the number of possible configurations of $\mathrm{H}_{2} \mathrm{O}, \mathrm{OH}$, and oxygens distributed over the sites of a quasi-crystalline lattice. We know, however, that in anhydrous albitic melt, oxygen atoms are arranged in linked tetrahedra, and a more realistic treatment of the entropy of hydrous melts would consider the mixing units as polymers of various sizes and shapes. In this section, we develop a schematic model that includes the effects of polymerization on the mixing properties of hydrous melts.

We consider the anhydrous melt to be composed of chain polymers each consisting of loxygen atoms. A chain of oxygens can react with a water molecule to produce two smaller chains of length $(l+1) / 2$, each of which is terminated by a hydroxyl group. The hydrous melt is thus modelled as a mixture of anhydrous polymers of length $l$, hydroxyl-bearing polymers of length $(l+1) / 2$, and water molecules. Using Flory's approximation for the entropy of mixing of such polymers and assuming that the enthalpy of mixing is zero leads to the following expressions for the activities of each of these polymer species (Guggenheim, 1952; Flory, 1953, eqs XIII-12, 13, 14):

$$
\begin{gathered}
a_{\mathrm{H}_{2} \mathrm{O}, \mathrm{mol}}=v_{\mathrm{H}_{2} \mathrm{O}, \mathrm{mol}} \exp \left\{\left(1-v_{\mathrm{H}_{2} \mathrm{O}, \mathrm{mol}}\right)-\frac{1}{l} v_{l \mathrm{O}}-\left(\frac{2}{l+1}\right) v_{\left.\left(\begin{array}{c}
l+1 \\
2
\end{array}\right)_{\mathrm{OH}}\right\},}\right. \\
a_{l \mathrm{O}}=v_{l \mathrm{O}} \exp \left\{\left(1-v_{l \mathrm{O}}\right)-l_{\mathrm{H}_{2} \mathrm{O}, \mathrm{mol}}-\left(\frac{2 l}{l+1}\right) v_{\left(\frac{l+1}{2}\right) \mathrm{OH}}\right\}, \\
a_{\left(\frac{l+1}{2}\right)_{\mathrm{OH}}}=v_{\left(\frac{l+1}{2}\right)_{\mathrm{OH}}} \exp \left\{\left(1-v_{\left(\frac{l+1}{2}\right) \mathrm{OH}}\right)-\left(\frac{l+1}{2}\right) v_{\mathrm{H}_{2} \mathrm{O}, \mathrm{mol}}-\left(\frac{l+1}{2 l}\right) v_{l \mathrm{O}}\right\},
\end{gathered}
$$

where $v_{\mathrm{H}_{2} \mathrm{O}, \mathrm{mol}}, v_{l \mathrm{O}}$ and $v_{\left(\frac{1+1}{2}\right)}$ are the volume fractions of the three polymers. These can be expressed in terms of the number of lattice sites each polymer occupies:

$$
\begin{gathered}
v_{\mathrm{H}_{2} \mathrm{O}, \mathrm{mol}}=\frac{n_{\mathrm{H}_{2} \mathrm{O}, \mathrm{mol}}}{N_{\mathrm{s}}}, \\
v_{\left(\frac{l+1}{2}\right)_{\mathrm{OH}}}=\frac{\left(\frac{l+1}{2}\right) n_{\mathrm{OH}}}{N_{\mathrm{s}}}, \\
v_{l \mathrm{O}}=\frac{n_{\mathrm{O}}-\left(\frac{l-1}{2}\right) n_{\mathrm{OH}}}{N_{\mathrm{s}}},
\end{gathered}
$$

where $N_{\mathrm{S}}=$ total number of oxygens or lattice sites $=n_{\mathrm{O}}+n_{\mathrm{OH}}+n_{\mathrm{H}_{2} \mathrm{O}, \mathrm{mol}}$, and $n_{\mathrm{O}}, n_{\mathrm{OH}}$, and $n_{\mathrm{H}_{2} \mathrm{O} \text {, mol }}$ are the numbers of moles of the unpolymerized species in the ideal mixing model described above and in Silver \& Stolper (1985). The polymer units interact through the following reactions:

anhydrous polymer $(l$ oxygens in length $)+\mathrm{H}_{2} \mathrm{O}$, molecules $=$

H-bearing polymer $\left(\frac{l+1}{2}\right.$ oxygens in length $)$, 
with an equilibrium constant given by

$$
K_{\mathrm{p}}=\frac{\left.\left(a_{(1+1}\right)_{\mathrm{OH}}\right)^{2}}{\left(a_{\mathrm{H}_{2} \mathrm{O}, \mathrm{mol}}\right)\left(a_{l \mathrm{O}}\right)} .
$$

Substitution of the activity and volume fraction expressions from equations (11) and (12) into this equation for $K_{\mathrm{p}}$ yields, after some manipulation, the following relation:

$$
K_{\mathrm{p}}=\frac{\left(\begin{array}{c}
v_{(}+1 \\
-2
\end{array}\right){ }_{\mathrm{OH}}}{\left(v_{\mathrm{H}_{2} \mathrm{O}, \mathrm{mol}}\right)\left(v_{l \mathrm{O}}\right)}=\left(\frac{l+1}{2}\right)^{2} \frac{\left(n_{\mathrm{OH}}\right)^{2}}{\left(n_{\mathrm{H}_{2} \mathrm{O}, \mathrm{mol}}\right)\left(n_{\mathrm{O}}-\left(\frac{l-1}{2}\right) n_{\mathrm{OH}}\right)}
$$

For a given value of $K_{\mathrm{p}}$, eqn (15) can be solved at a given total water content for the equilibrium concentrations of the dissolved species. As shown in Fig. 11, for values of $l \sim 20$, the model species concentrations are similar to the values we have measured.

We emphasize that this treatment is highly schematic. The compromises implicit in the use of Flory's approximation and the neglect of the effect of polymer shape are discussed in detail in Guggenheim (1952) and Flory (1953), but it appears that to first order the simple treatment is adequate. We also note that a range of polymer sizes would probably exist in silicate melts and that a more realistic treatment would consider the distribution of these polymers and the possibility that hydroxyl-bearing polymers can have more than one hydroxyl group; such models would be analogous to the polymer models of silicate melts such as those reviewed by Masson (1977). We have also explored models involving equilibria between silicate tetrahedra with four bridging oxygens, $\mathrm{H}_{2} \mathrm{O}$ molecules and silicate units

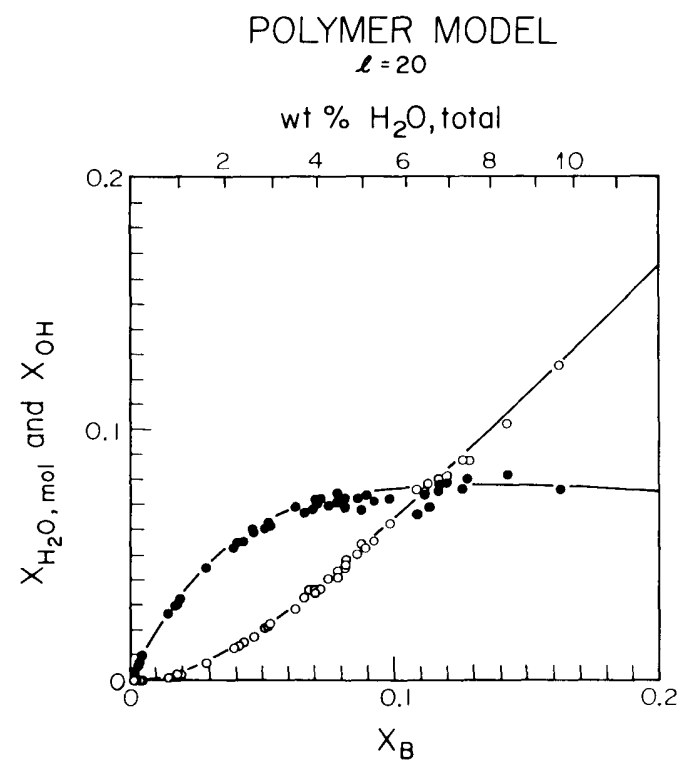

FIG. 11. Hydrous species concentrations in albitic melt as a function of the mole fraction of total water, $X_{\mathrm{B}}$, for a model based on mixing of molecules of different sizes (eqn 15). The solid curves represent the calculated species concentrations for $K_{\mathrm{p}}=60$ and $l=20$, where $l=$ length of polymer chain. Shown for comparison are the mole fractions of molecular water (open symbols) and $\mathrm{OH}$ groups (filled symbols) determined by IR spectroscopy for the samples shown in Fig. 6. 
with one to four $\mathrm{OH}$ groups; e.g., $\mathrm{SiO}_{3}(\mathrm{OH}), \mathrm{Si}(\mathrm{OH})_{4}$. This type of model can also account for the observed species concentrations as long as the hydrous silicate units do not have too many OH groups, consistent with the results of Farnan et al. (1987) for hydrous silica glass. At this point, however, given the success of the simple model in retrieving the measured species concentrations and the lack of detailed structural information for hydrous melts, we feel that the introduction of further complexities is unwarranted.

\section{Mixing models with several types of distinguishable oxygens and hydroxyls}

The models discussed thus far include the assumption that all of the anhydrous oxygens are indistinguishable and equally reactive with water molecules to produce hydroxyl groups; i.e. a single reaction such as equation (2) suffices to describe the homogeneous equilibria between water molecules, hydroxyl groups, and oxygens. This is clearly unrealistic. It has, for example, long been inferred by glass scientists that bridging oxygens and non-bridging oxygens react to different extents with water to form hydroxyl groups (e.g., Uys \& King, 1963). In aluminosilicate compositions such as albite, it is likely that oxygens bridging two Si-bearing tetrahedra are not as reactive with water molecules as those attached to Albearing tetrahedra (McMillan et al., 1983; Remmele et al., 1986) and this may explain the lower solubility of water in silica than in aluminosilicate melts. Phase relations in the system albite-orthoclase-silica-water have been used to infer that Na-bearing units are more reactive than K-bearing units, which are more reactive than alkali-free species (e.g., Pichavant \& Ramboz, 1985). The levelling off of hydroxyl group concentrations at high total water contents could indicate that one kind of oxygen species is much more reactive than others and it has been essentially entirely consumed when the hydroxyl concentration saturates.

It is simple in principle to relax the assumption that all of the oxygen atoms are indistinguishable. We need only to specify all of the species of interest and write a complete, linearly independent set of reactions such as eqn (2) among these species and formulate the equilibrium constant for each reaction. Assuming ideal mixing (or any other mixing law that gives activity expressions that can be substituted into the equilibrium constant expressions), we can then determine the equilibrium species concentrations for any bulk composition and values of the equilibrium constants by solving a simultaneous set of equations made up of the independent equilibrium constant expressions plus mass balance constraints. The equilibrium constants can then be adjusted until the molecular water and total hydroxyl contents match the measured values. The difficulty is deciding on the species to be included in the model. There is always a temptation to include a larger number of species, but the problem then becomes poorly constrained because given enough species, it will almost always be possible to approximate the macroscopic thermodynamic properties of a solution, or in our case, to get a close approximation to the molecular water and hydroxyl group concentrations.

To illustrate how the simple ideal mixing model can be readily extended to include more than one type of oxygen and hydroxyl in the melt, we have used it to approximate the cation exchange model developed by Burnham (1975). Although albitic melts probably contain many types of oxygens (e.g., $\mathrm{Si}-\mathrm{O}-\mathrm{Si}, \mathrm{Al}-\mathrm{O}-\mathrm{Al}, \mathrm{Si}-\mathrm{O}-\mathrm{Al}$ ), the model proposed by Burnham (1975) assumes that only $\mathrm{Si}-\mathrm{O}-\mathrm{Si}$ bridges ('SiOSi') and $\mathrm{Si}-\mathrm{O}-\mathrm{Al}$ bridges charge balanced by $\mathrm{Na}$ ions ('SiOAlNa') are present in anhydrous albitic melt. The interaction between the silicate melt and $\mathrm{H}_{2} \mathrm{O}$ is illustrated schematically in Fig. 12. These coupled equilibria can be expressed as

$$
\mathrm{H}_{2} \mathrm{O} \text {, molecular (melt) }+\mathrm{SiOSi} \text { (melt) }=2 \mathrm{SiOH} \text { (melt), }
$$

$\mathrm{SiOH}($ melt $)+\mathrm{SiOAINa}($ melt $)=\mathrm{SiONa}($ melt $)+\mathrm{SiOAlH}($ melt $)$. 


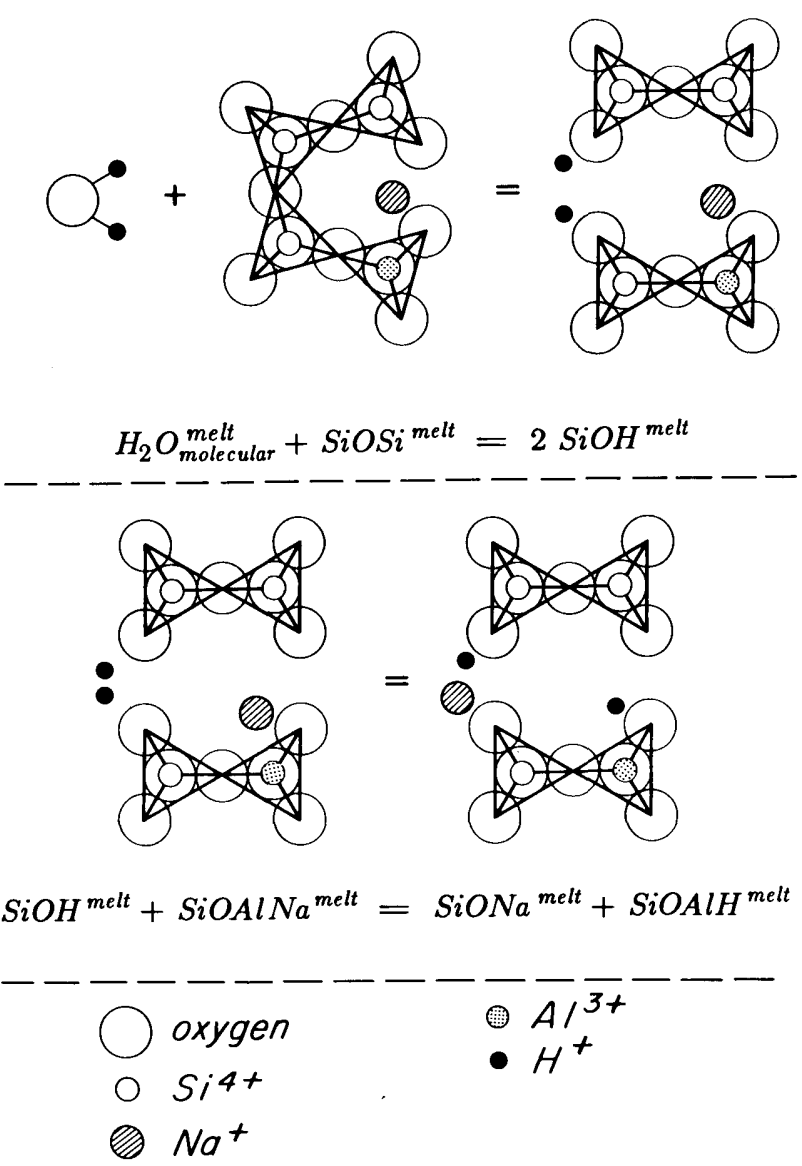

FIG. 12. Schematic representation of the coupled exchange reactions given in eqns (16.1) and (16.2), illustrating the interaction of water with albitic melt. After Burnham (1975, 1979).

Reaction (16.1) describes the breaking of $\mathrm{Si}-\mathrm{O}-\mathrm{Si}$ bridges by reaction with water molecules to form non-bridging oxygens charge balanced by protons ('SiOH'). Reaction (16.2) describes the exchange of $\mathrm{Na}$ and $\mathrm{H}$ atoms between $\mathrm{SiOH}$ groups and SiOAINa bridges to generate non-bridging oxygens charge balanced by $\mathrm{Na}$ ('SiONa') and $\mathrm{Si}-\mathrm{O}-\mathrm{Al}$ bridges charge balanced by a proton ('SiOAlH'). These equilibria are governed by equilibrium constants:

$$
\begin{gathered}
K_{17 \cdot 1} \equiv \frac{\left(a_{\text {SiOH }}^{\mathrm{m}}\right)^{2}}{\left(a_{\text {SiOSi }}^{\mathrm{m}}\right)\left(a_{\mathrm{H}_{2} \mathrm{O}, \mathrm{mol}}^{\mathrm{m}}\right)}=\frac{\left(X_{\text {SiOH }}^{\mathrm{m}}\right)^{2}}{\left(X_{\text {SiOSi }}^{\mathrm{m}}\right)\left(X_{\mathrm{H}_{2} \mathrm{O}, \mathrm{mol}}^{\mathrm{m}}\right)}, \\
K_{17 \cdot 2} \equiv \frac{\left(a_{\text {SiONa }}^{\mathrm{m}}\right)\left(a_{\text {SiOAIH }}^{\mathrm{m}}\right)}{\left(a_{\text {SiOH }}^{\mathrm{m}}\right)\left(a_{\text {SiOAINa }}^{\mathrm{m}}\right)}=\frac{\left(X_{\text {SiONa }}^{\mathrm{m}}\right)\left(X_{\text {SiOAIH }}^{\mathrm{m}}\right)}{\left(X_{\text {SiOH }}^{\mathrm{m}}\right)\left(X_{\text {SiOAINa }}^{\mathrm{m}}\right)},
\end{gathered}
$$

assuming ideal mixing of the species. For any bulk composition and values of $K_{17 \cdot 1}$ and $K_{17 \cdot 2}$, we can solve for the species concentrations in the melt. The magnitudes of $K_{17.1}$ and $K_{17.2}$ define the reactivities of the different oxygen units; with appropriate choices of these equilibrium constants, it is possible to reproduce the measured species concentrations. Figure 13 shows the results of the model calculation for $K_{17 \cdot 1}=0.003$ and $K_{17 \cdot 2}=10$. The 


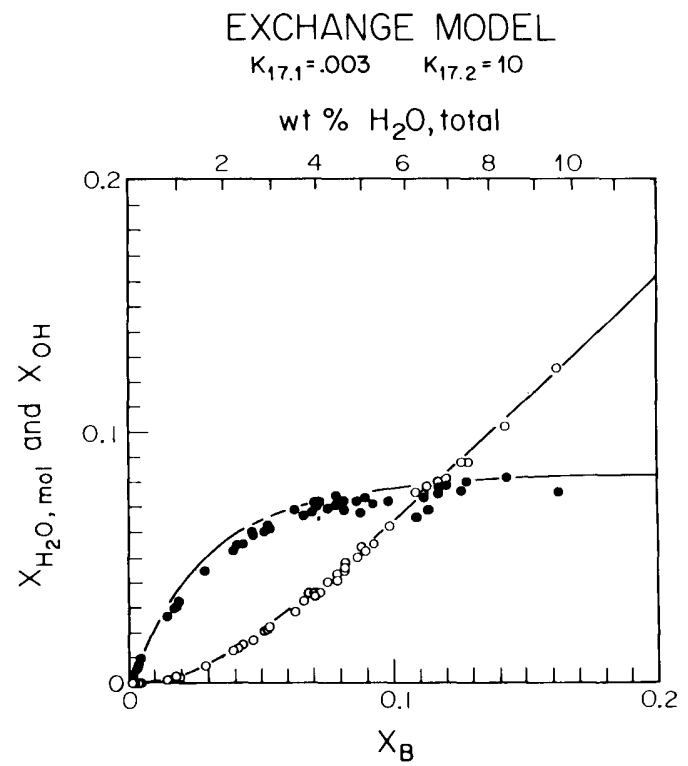

FIG. 13. Mole fractions of molecular water and $\mathrm{OH}$ groups in albitic melt as functions of the mole fraction of total water, $X_{\mathrm{B}}$, based on the proton-exchange model (reactions $16 \cdot 1$ and 16.2). Solid curves represent the calculated species concentrations for $K_{17 \cdot 1}=0.003$ and $K_{17 \cdot 2}=10$. Shown for comparison are the mole fractions of molecular water (open symbols) and $\mathrm{OH}$ groups (filled symbols) determined by IR spectroscopy for the samples shown in

Fig. 6.

calculated species concentrations are consistent with the spectroscopic measurements and demonstrate that this type of behavior could be important in controlling the dissolution of water in albitic melts. In addition, this model predicts that at a given total water content hydrous silica glass will have a much higher molecular $\mathrm{H}_{2} \mathrm{O}$ to $\mathrm{OH}$ ratio than albitic glass and that the $\mathrm{OH}$ content of silica glass will level off more gradually with increasing total water content than it does in albitic melt. It will be interesting to compare the speciation of water in silica glass to that of albitic glasses when systematic infrared or NMR spectroscopic data become available.

\section{Summary of mixing models}

It is clear from the preceding discussion that the simple mixing model developed by Stolper (1982b) and Silver \& Stolper (1985) can be used as a starting point for the development of more complex models that can account in detail for the measured concentrations of water molecules and hydroxyl groups in albitic glasses. Individually, inclusion in our models of non-ideal interactions, of the mixing properties of polymeric groups, and of a range of distinguishable types of oxygens in the melt can lead to models that successfully account for the observed species concentrations. Models that combine these three modifications would also be successful.

There is thus a range of mixing models for hydrous albitic melt that could retrieve our species measurements, but we have no basis for choosing between them. It should be possible, however, to test these models and to discriminate between them with more measurements on albitic glass and other compositions. For example, the multiple oxygen species model that we have considered makes specific predictions about the saturation concentration of hydroxyl groups and about the solubility of water along the $\mathrm{NaAlO}_{2}-\mathrm{SiO}_{2}$ 
join that are grossly consistent with experimental data (i.e. the lower solubility of water in silica glass than in albite) and could be tested in detail by extending our measurements along this join. It will be particularly important to determine if silica glass also shows a saturation in its hydroxyl group concentration that is less gradual than that predicted by the simple ideal mixing model; if so, it will suggest that this feature is not dependent on the availability of an exchangeable cation (or some other reactive species) that is nearly exhausted at high hydroxyl concentrations. Reliable quantitative measurements of the concentrations of distinguishable hydroxyl units (e.g., $\mathrm{SiOH}, \mathrm{AlOH}, \mathrm{NaOH}$ ) and oxygen species (e.g., bridging vs. non-bridging, $\mathrm{Al}-\mathrm{O}-\mathrm{Al}, \mathrm{Al}-\mathrm{O}-\mathrm{Si}$ ) would also be useful in developing more accurate models of the dissolution mechanisms of water in silicate melts.

\section{Phase equilibria}

Thermodynamic models of silicate melts such as those described in the preceding section can be used in conjunction with descriptions of the thermodynamic properties of vapor and crystals to calculate crystal-liquid-vapor phase equilibria. In this section, we illustrate these types of calculations using two different assumptions about the relationship between melt chemistry and the activity of water in hydrous albitic melt. The first assumption is that Henry's law holds for molecular water; i.e. $a_{\mathrm{H}_{2} \mathrm{O}}^{\mathrm{m}}=a_{\mathrm{H}_{2} \mathrm{O} \text {, mol }}^{\mathrm{m}} \propto X_{\mathrm{H}_{2} \mathrm{O} \text {, mol }}^{\mathrm{m}}{ }^{*}$ Although somewhat arbitrary, this approximation will be valid for all ideal mixtures in all concentration ranges no matter how many species are involved in the solution. Moreover, it is the traditional starting point for thermodynamic modelling of liquid solutions and is likely to be valid in the dilute limit for most solutions. The second assumption is that hydrous albitic melt can be treated as a strictly regular solution and that activities of melt species as functions of their concentrations can be described by eqns (4.1)-(4.3). For both approximations, the activities are defined relative to standard states of the pure melt species at pressure and temperature.

The goal of this final section of the paper is to evaluate the extent to which these two descriptions of the thermodynamics of hydrous albitic melt, both of which are based on our spectroscopic measurements, are consistent with the macroscopic properties of the system $\mathrm{NaAlSi}{ }_{3} \mathrm{O}_{8}-\mathrm{H}_{2} \mathrm{O}$. We first examine how well they can account for measurements of the solubility of water in albitic melt over a range of pressures and temperatures, and then compare freezing point depressions calculated based on these activity-composition relationships and thermochemical data with experimental determinations.

\section{The solubility of water in albitic melt}

The activity of water in vapor-saturated melt as a function of pressure $(P)$ and temperature $(T)$ is given by

$$
\begin{aligned}
a_{\mathrm{H}_{2} \mathrm{O}}^{\mathrm{m}}(T, P)= & a_{\mathrm{H}_{2} \mathrm{O}}^{\mathrm{m}}\left(T_{\mathrm{r}}, P_{\mathrm{r}}\right) \frac{f_{\mathrm{H}_{2} \mathrm{O}}^{\mathrm{o}}(T, P)}{f_{\mathrm{H}_{2} \mathrm{O}}^{\mathrm{o}}\left(T_{\mathrm{r}}, P_{\mathrm{r}}\right)} \exp \left\{-\int_{P_{\mathrm{r}}}^{P} \frac{V_{\mathrm{H}_{2} \mathrm{O}}^{\mathrm{o}, \mathrm{m}}\left(T, P^{\prime}\right)}{R T} \mathrm{~d} P^{\prime}\right. \\
& \left.+\int_{T_{\mathrm{r}}}^{T} \frac{\Delta H_{\mathrm{H}_{2} \mathrm{O}}^{\mathrm{o}}\left(T^{\prime}, P_{\mathrm{r}}\right)}{R T^{\prime 2}} \mathrm{~d} T^{\prime}\right\}
\end{aligned}
$$

where $P_{\mathrm{r}}$ and $T_{\mathrm{r}}$ refer to a reference pressure and temperature; $a_{\mathrm{H}_{2} \mathrm{O}}^{\mathrm{m}}\left(T_{\mathrm{r}}, P_{\mathrm{r}}\right)$ is the activity of water in vapor-saturated albite melt at $T_{\mathrm{r}}$ and $P_{\mathrm{r}} ; f_{\mathrm{H}_{2} \mathrm{O}}^{\mathrm{o}}(T, P)$ and $f_{\mathrm{H}_{2} \mathrm{O}}^{\mathrm{O}}\left(T_{\mathrm{r}}, P_{\mathrm{r}}\right)$ are the

\footnotetext{
* Provided that the standard states for water (where "water" refers to the bulk component, defined macroscopically without regard to its speciation) and molecular water are taken to be the same and the water molecules behave as monomers, then $a_{\mathrm{H}_{2} \mathrm{O}}^{\mathrm{m}}=a_{\mathrm{H}_{2} \mathrm{O} \text {.mol }}^{\mathrm{m}}$ (Prigogine \& Defay, 1954, p. 411, eqn. 26.7).
} 
fugacities of pure water vapor at $T, P$ and $T_{\mathrm{r}}, P_{\mathrm{r}}$ calculated using a modified Redlich-K wong equation-of-state for $\mathrm{H}_{2} \mathrm{O}$ (Holloway, 1977); $V_{\mathrm{H}_{2} \mathrm{O}}^{\mathrm{o}} \mathrm{m}(T, P)$ is the molar volume of water in the melt in its standard state; $\Delta H_{\mathrm{H}_{2} \mathrm{O}}^{\mathrm{o}}=H_{\mathrm{H}_{2} \mathrm{O}}^{\mathrm{o}, \mathrm{m}}-H_{\mathrm{H}_{2} \mathrm{O}}^{\mathrm{o}, \mathrm{v}}$, where $H_{\mathrm{H}_{2} \mathrm{O}}^{\mathrm{o}, \mathrm{v}}$ is the molar enthalpy of water vapor at $T$ at a pressure low enough for the vapor phase to be ideal and $H_{\mathrm{H}_{2} \mathrm{O}}^{\text {o,m }}$ is the enthalpy per mole of water in the melt in its standard state at $T$ and $P_{\mathrm{r}}$. Equation (18) is based on the assumption that the vapor in equilibrium with melt is pure water. Given expressions for $V_{\mathrm{H}_{2} \mathrm{O}}^{\mathrm{o}, \mathrm{m}}(T, P), \Delta H_{\mathrm{H}_{2} \mathrm{O}}^{\mathrm{o}}\left(T, P_{\mathrm{r}}\right)$, and a value for $a_{\mathrm{H}_{2} \mathrm{O}}^{\mathrm{m}}\left(T_{\mathrm{r}}, P_{\mathrm{r}}\right)$, we can calculate the variation in water activity as a function of $T$ and $P$ using eqn (18).

The question we want to address is how well eqn (18) can account for the measured solubility of water in albitic melts given our spectroscopically constrained expressions for $a_{\mathrm{H}_{2} \mathrm{O}}^{\mathrm{m}}$. To answer this, we used the recent determinations of water solubility in albitic melt of Hamilton \& Oxtoby (1986) in the following way. At the conditions of each of their experiments, which covered a wide range of $P(560-8000 \mathrm{~b})$ and $T\left(750-1375^{\circ} \mathrm{C}\right)$, we used values of $\mathrm{A}^{\prime}, \mathrm{B}^{\prime}, \mathrm{C}^{\prime}$, and $K_{1}$ calculated from eqns (6.1)-(6.3) and (8) and an equivalent of eqn (5) relating $X_{\mathrm{B}}$ and $X_{\mathrm{OH}}^{\mathrm{m}}$ to calculate $X_{\mathrm{OH}}^{\mathrm{m}}$ for the water solubility they reported. Values of $X_{\mathrm{H}_{2} \mathrm{O} \text {, mol }}^{\mathrm{m}}$ and $X_{\mathrm{O}}^{\mathrm{m}}$ were calculated using the relationships between them and $X_{\mathrm{B}}$ and $X_{\mathrm{OH}}^{\mathrm{m}}$ given in Silver et al. (1989).

For the first case, in which Henry's law was assumed, $a_{\mathbf{H}_{2} \mathrm{O}}^{\mathbf{m}}$ in eqn (18) was replaced with $X_{\mathrm{H}_{2} \mathrm{O} \text {, mol }}^{\mathrm{m}}$. Given this substitution, the values of $X_{\mathrm{H}_{2} \mathrm{O} \text {, mol }}^{\mathrm{m}}, P$, and $T$ determined as described in the previous paragraph for all of the experiments of Hamilton \& Oxtoby (1986) were fit by least squares to eqn (18), giving best fit values of $X_{\mathrm{H}_{2} \mathrm{O}, \mathrm{mol}}^{\mathrm{m}}\left(T_{\mathrm{r}}, P_{\mathrm{r}}\right)=0 \cdot 1298$ and $\Delta \bar{H}_{\mathrm{H}_{2} \mathrm{O}}^{\mathrm{o}}\left(T, P_{\mathrm{r}}\right)$ $=-2986 \mathrm{cal} / \mathrm{mol}$, with $P_{\mathrm{r}}=5000 \mathrm{~b}, T_{\mathrm{r}}=745^{\circ} \mathrm{C}$. The volume function $\left[\bar{V}_{\mathrm{H}_{2} \mathrm{O}}^{\mathrm{o}, \mathrm{m}}(T, P)\right]$ was taken to be described by the polynomial fit to the partial molar volume of water in albitic melts given by Burnham \& Davis (1971). For the second case, in which the regular solution model was assumed to be valid, a value of $a_{\mathrm{H}_{2} \mathrm{O}}^{\mathrm{m}}\left(=a_{\mathrm{H}_{2} \mathrm{O} \text {, mol }}^{\mathrm{m}}\right)$ was calculated for each experiment using eqn (4.1). A least squares fit to eqn (18) using the Burnham \& Davis (1971) volume function gives best fit values of $a_{\mathrm{H}_{2} \mathrm{O}}^{\mathrm{m}}\left(T_{\mathrm{r}}, P_{\mathrm{r}}\right)=0.1830$ and $\Delta \bar{H}_{\mathrm{H}_{2} \mathrm{O}}^{\mathrm{o}}\left(T, P_{\mathrm{r}}\right)$ $=-2816 \mathrm{cal} / \mathrm{mol}$.

Figure 14 compares, over three temperature ranges, all measurements of water solubility of which we are aware with calculated solubility based on the best fits to the data of Hamilton \& Oxtoby (1986) described in the previous paragraphs. It is clear that both of our approximations to $a_{\mathrm{H}_{2} \mathrm{O}}^{\mathrm{m}}$ account well for the available data on water solubility in albitic melt.

Several features of Fig. 14 deserve comment:

(1) There is considerable scatter in measurements of water solubility in albitic melt. Above $8 \mathrm{~kb}$, we consider the solubility to be essentially unconstrained. There continues to be a need for careful, modern measurements of water solubility in silicate melts.

(2) The pressure derivative of water solubility basically reflects the volume function used in eqn (18). Burnham \& Davis (1971) had data only between 3 and $8.5 \mathrm{~kb}$, and thus outside of this range, particularly above $8.5 \mathrm{~kb}$, the curves shown in Fig. 14 are uncertain extrapolations.

(3) There must be a problem, either with the solubility data of Hamilton \& Oxtoby (1986) at pressures approaching $8 \mathrm{~kb}$, or with the volume function of Burnham \& Davis (1971) in this pressure range. This is demonstrated by the fact that according to Hamilton \& Oxtoby (1986), solubility essentially levels off at $P=7-8 \mathrm{~kb}$ (i.e. the partial molar volume of water in the melt is nearly identical to the volume of water in the vapor), whereas the data of Burnham \& Davis (1971) indicate that at this pressure, the volume of the vapor is still much larger (by several $\mathrm{cm}^{3} / \mathrm{mol}$ ) than the partial molar volume of water in the melt (this leads to the positive slopes of the calculated solubility curves in Fig. 14, which incorporate the volume function of Burnham \& Davis, 1971). The cause of this discrepancy is unknown, but 
Water solubility in albitic melt

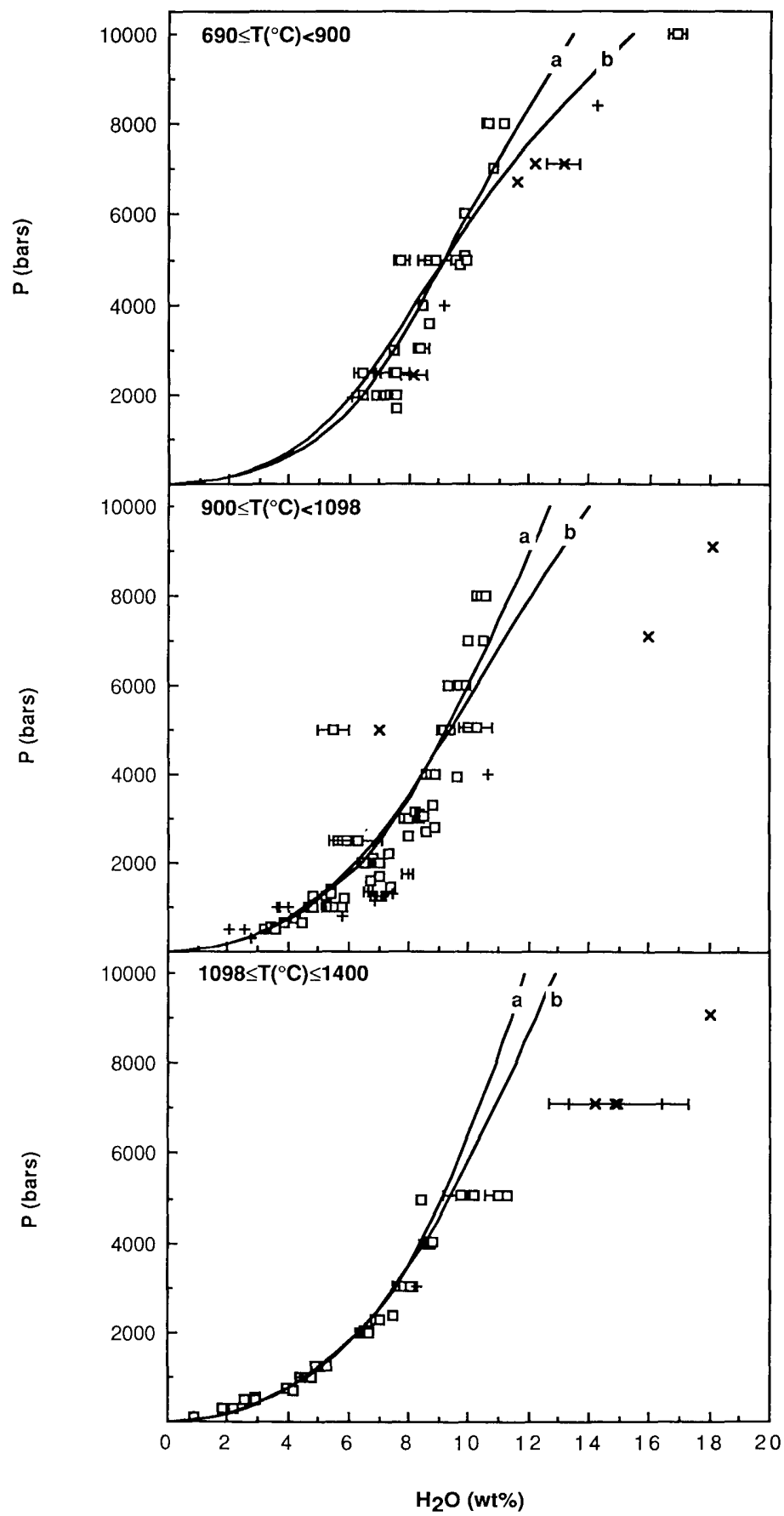

FIG. 14. Comparison of calculated and measured water solubility in albitic melts in three temperature ranges. Solid curves are based on best fits to the data of Hamilton \& Oxtoby (1986) to eqn (18) as discussed in the text. Curves labelled 'a' assume Henry's law holds for molecular water; curves labelled ' $b$ ' assume the activity formulations of the regular solution model discussed in the text. From top to bottom, curves represent solubilities calculated at 800 , 1000 , and $1200^{\circ} \mathrm{C}$. Experimental data are from Goranson (1936, 1938), Tuttle \& Bowen (1958), Burnham \& Jahns 
no reasonable choice of a relationship between activity of water and melt composition will resolve it. Resolution will require additional solubility or volumetric measurements.

(4) A final uncertainty in the calculated curves shown in Fig. 14 is that the vapor is assumed to be pure water. Although this is thought to be a good approximation at low pressures, it becomes progressively worse at higher pressures. Inclusion of this effect would lower the calculated water solubility.

\section{The vapor-saturated solidus of high albite}

Calculation of the position of the wet solidus of albite (i.e. the locus of points in $P-T$ space at which albite, melt, and vapor coexist) requires the solution of two simultaneous equations in $T$ and $X_{\mathrm{H}_{2} \mathrm{O} \text {, mol }}^{\mathrm{m}}$ (or $X_{\mathrm{B}}$ ) at each pressure: the equation for the position of the albite liquidus (i.e. the locus of liquid compositions saturated with crystalline albite) and the equation for the solubility of water in albitic melt.

Given a relationship between melt chemistry and the activity of albite in the NaAlSi ${ }_{3} \mathrm{O}_{8}-\mathrm{H}_{2} \mathrm{O}$ system $\left(a_{\mathrm{ab}}^{\mathrm{m}}\right.$, defined relative to the standard state of liquid albite at $P$ and $T$, where the albite component is defined as $\mathrm{Na}_{1 / 8} \mathrm{Al}_{1 / 8} \mathrm{Si}_{3 / 8} \mathrm{O}$ ), the composition of melt in equilibrium with crystalline albite at a given $P$ and $T$ can be determined from eqn (12) in Silver \& Stolper (1985), which gives $a_{\mathrm{ab}}^{\mathrm{m}}$ in albite-saturated liquids as a function of $P$ and $T$. This equation requires the entropy of fusion of albite as a function of $P$ and $T$ (taken from table 1 of Silver \& Stolper, 1985) and the temperature of the dry solidus of albite at each pressure (taken from Kress et al., 1988; fig. 4a, $K^{\prime}=4$ ). Given the assumption of Henry's law (i.e. $a_{\mathrm{H}_{2} \mathrm{O}}^{\mathrm{m}} \propto X_{\mathrm{H}_{2} \mathrm{O} \text {, mol }}^{\mathrm{m}}$ ), the relationship between $a_{\mathrm{ab}}^{\mathrm{m}}$ and melt chemistry can be obtained by Gibbs-Duhem integration. The appropriate Gibbs-Duhem relation is

$$
\left(1-X_{\mathrm{B}}\right) \mathrm{d}\left(\ln a_{\mathrm{ab}}^{\mathrm{m}}\right)=-X_{\mathrm{B}} \mathrm{d}\left(\ln X_{\mathrm{H}_{2} \mathrm{O}, \mathrm{mol}}^{\mathrm{m}}\right) .
$$

Given the assumption of a regular solution, $a_{\mathrm{ab}}^{\mathrm{m}}$ is equal to $a_{\mathrm{O}}^{\mathrm{m}}$, the expression for which is given by eqn (4.2). The relationship between $a_{\mathrm{ab}}^{\mathrm{m}}$ and melt chemistry in this case is determined by solving eqns (4.2), (5), and $\left(X_{\mathrm{O}}^{\mathrm{m}}+X_{\mathrm{H}_{2} \mathrm{O} \text {, mol }}^{\mathrm{m}}+X_{\mathrm{OH}}^{\mathrm{m}}=1\right)$ simultaneously for $X_{\mathrm{O}}^{\mathrm{m}}, X_{\mathrm{OH}}^{\mathrm{m}}$, and $X_{\mathbf{H}_{2} \mathrm{O} \text {, mol }}^{\mathrm{m}}$ for given values of $T$ and $a_{\mathrm{O}}^{\mathrm{m}}$.

Calculation of the solubility of water in albitic melt was described above. For the Henrian case, $X_{\mathrm{H}_{2} \mathrm{O} \text {, mol }}^{\mathrm{m}}$ can be calculated directly from eqn (18) at any $T$ and $P$, given the substitution of $X_{\mathrm{H}_{2} \mathrm{O} \text {, mol }}^{\mathrm{m}}$ for $a_{\mathrm{H}_{2} \mathrm{O}}^{\mathrm{m}}$. For the regular solution, this requires simultaneous solution of eqns (4.1), (5), (18), and $\left(X_{\mathrm{O}}^{\mathrm{m}}+X_{\mathrm{H}_{2} \mathrm{O}, \mathrm{mol}}^{\mathrm{m}}+X_{\mathrm{OH}}^{\mathrm{m}}=1\right)$. For both cases, the best fit values given above for $\Delta H_{\mathrm{H}_{2} \mathrm{O}}^{\mathrm{o}}\left(T_{\mathrm{r}}, P_{\mathrm{r}}\right)$ and $a_{\mathrm{H}_{2} \mathrm{O}}^{\mathrm{m}}\left(T_{\mathrm{r}}, P_{\mathrm{r}}\right)$ based on the data of Hamilton \& Oxtoby (1986) and the volume function of Burnham \& Davis (1971) were used in eqn (18).

For both the Henrian and regular solution assumptions, the temperature of the vaporsaturated solidus was determined at several pressures by calculating, as described in the previous paragraphs, the relationships between $T$ and $X_{\mathrm{H}_{2} \mathrm{O} \text {, mol }}^{\mathrm{m}}$ for the albite liquidus and for vapor-saturated liquids, and then graphically determining the $T$ at which they intersected

Figure 15 compares the calculated wet solidus of high albite with all of the experimental determinations of which we are aware. Except at pressures above $10 \mathrm{~kb}$, the Henrian and regular solution approximations are essentially identical. Given the uncertainties that went into these calculations (e.g., in the solubility of water in albitic melt, the entropy of fusion of

(1962), Orlova (1962), Khitarov et ai. (1963), Kadik \& Lebedev (1968), Voigt et al. (1981), Fenn (1973) reported in Day \& Fenn (1982), Blamart et al. (1986), Hamilton \& Oxtoby (1986), and Richet et al. (1986). Most data are shown as ' $\square$ ' and are the reported values of solubility from these sources; ' + ' are data described in these publications as upper limits to the solubility; ' $x$ ' are data described as lower limits. Uncertainties are shown where available. 


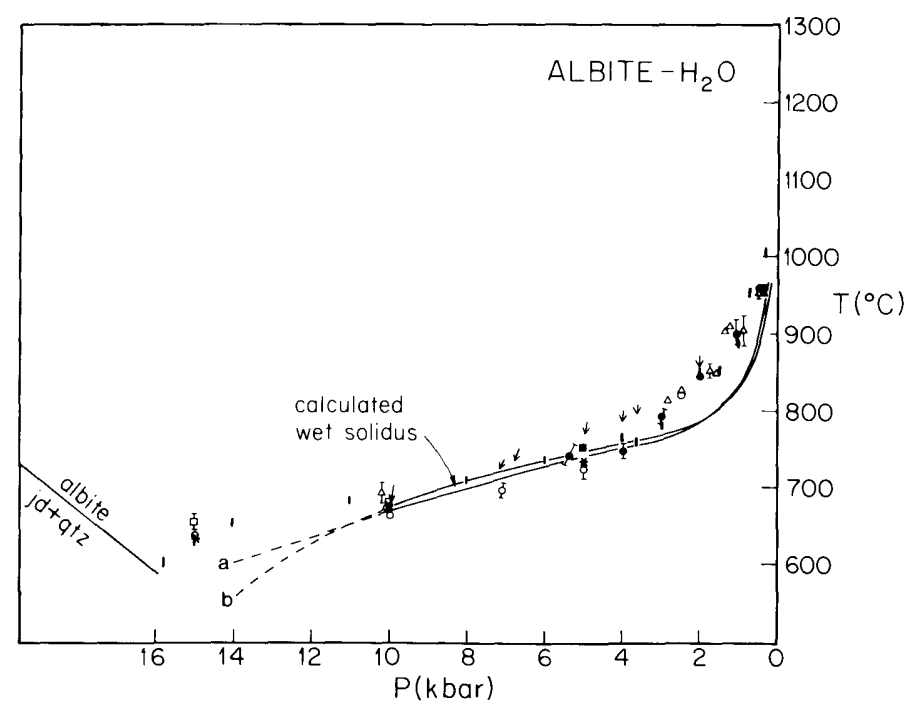

FIG. 15. The position of the water-vapor-saturated solidus for high albite. The curves are calculated as discussed in the text and utilize activity-composition relations for hydrous albitic melts constrained by our measurements of hydrous species concentrations in albitic glasses. The curve labelled 'a' assumes Henry's law holds for molecular water; the curve labelled 'b' assumes the activity formulations of the regular solution model discussed in the text. The symbols represent experimental determinations of the melting point of high albite in the presence of water vapor (with uncertainties, where available) from $\triangle$ Goranson (1938); - Tuttle \& Bowen (1958); $\Delta$ Luth et al. (1964), corrected by Luth (1976); $\square$ Boettcher \& Wyllie (1969); $\square$ Morse (1970); $\bigcirc$ Bohlen et al. (1982); |Goldsmith \& Jenkins (1985); and * Luth \& Boettcher (1986). Arrows are upper temperature limits from Burnham \& Jahns (1962).

albite, the position of the dry solidus) and the uncertainties in the experimental determinations of the wet solidus, we consider the correspondence between the calculated and experimental positions of the wet solidus to be excellent.

Several features of Fig. 15 deserve comment:

(1) The uncertainty in the solubility of water in albitic melt at pressures above $8 \mathrm{~kb}$, the necessity to extrapolate the partial molar volume of water determined by Burnham $\&$ Davis (1971) at pressures beyond $8.5 \mathrm{~kb}$, and the likely breakdown of the assumption that the coexisting vapor is pure water under these conditions make extrapolations beyond $8 \mathrm{~kb}$ uncertain.

(2) The greatest mismatch between the calculated and experimental solidi is at pressures below $3 \mathrm{~kb}$, where the calculated freezing point depression is as much as $50^{\circ} \mathrm{C}$ greater than that observed experimentally. The partial molar volume of water in melts would have to be lower at these pressures than it is at higher pressures in order to bring the calculated curve into perfect correspondence with the experimental curve. Since this pressure range is lower than that explored experimentally by Burnham \& Davis (1971), there are no constraints on the partial molar volume of water under these conditions. It is interesting, however, that low partial molar volumes at low pressures are also suggested by water solubility measurements on rhyolitic melts when the data are analyzed using the Henrian approximation (Silver et al., 1989). Further work will be required to determine whether the partial molar volume of water at low pressures really is lower than at high pressures, or if this is an artifact of the Henrian approximation or of imperfect data.

(3) The curves in Fig. 16 show the variations in the solubility of water along the wet solidus that would be required, given our two approximations to the thermodynamic 


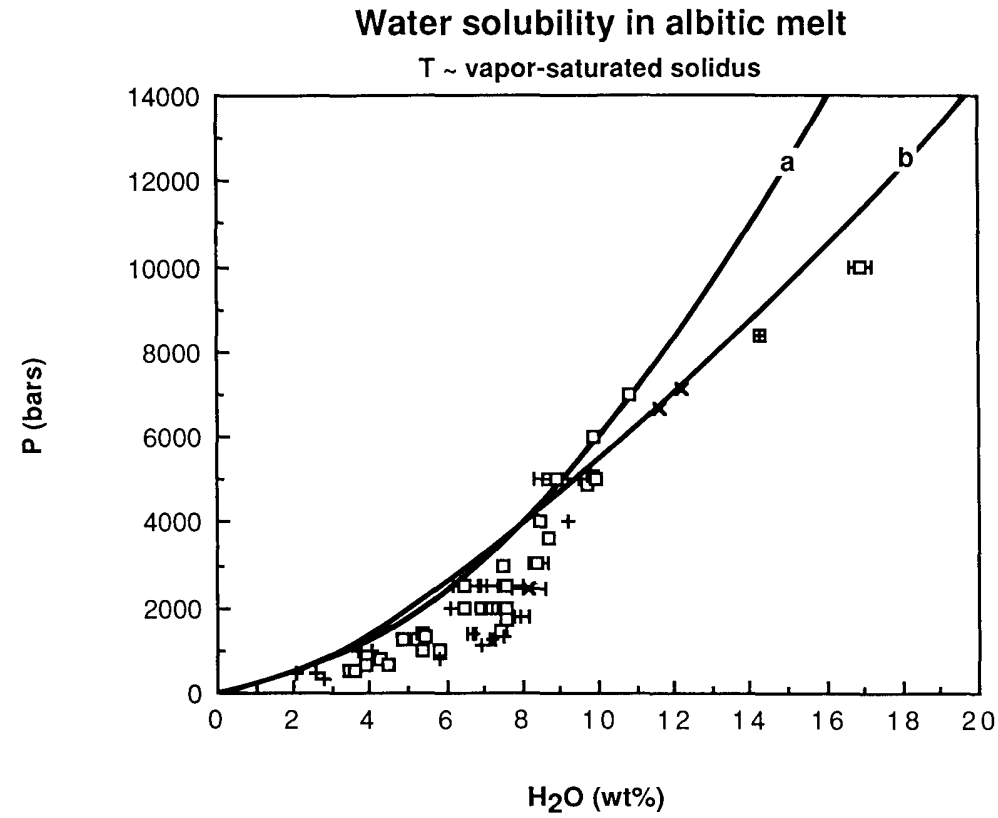

FIG. 16. Comparison of measured solubility of water in albitic melts at temperatures within $50^{\circ} \mathrm{C}$ of the wet solidus (symbols and data sources as in Fig. 14) with the solubility required to obtain a perfect match between the calculated and experimentally determined positions of the wet solidus using the models discussed in the text. The curve labelled ' $a$ ' assumes Henry's law holds for molecular water; the curve labelled 'b' assumes the activity formulations of the strictly regular solution model discussed in the text.

properties of hydrous albitic melts, to get a perfect match between the calculated and experimentally determined wet solidus. These curves are compared with measurements of water solubility at temperatures within $50^{\circ} \mathrm{C}$ of the wet solidus. The required solubility basically skirts the lower limit of available solubility measurements. That the lowest reported measurements of solubility may be the most reliable is not unreasonable, given that most problems with measurements of water solubility tend to lead to overestimates.

(4) The wet solidi for high and low albite curve downward towards lower temperatures at pressures greater than $14 \mathrm{~kb}$ (Goldsmith \& Jenkins, 1985). ${ }^{*}$ It has been suggested that this downturn could partly reflect structural changes occurring in albitic melts as the albite $=$ jadeite + quartz reaction is approached from the low pressure side (Goldsmith $\&$ Jenkins, 1985). Infrared spectra of glasses quenched from melts synthesized at pressures and temperatures near the albite-breakdown curve (samples MAb-10, 16, 34, 105 from Goldsmith \& Jenkins, 1985) do not show any systematic changes that indicate a major change in coordination of $\mathrm{Al}^{3+}$ (L. A. Silver, unpublished results). Although such a coordination change could contribute to the observed downturn of the solidus, we note that our regular solution model, with its simple, continuous volume function and a pressure independent activity-composition relation for water also generates such a feature. Such downturns in temperature with increasing pressure along water-saturated solidi in silicate

\footnotetext{
*At pressures below $4 \mathrm{~kb}$, the assemblage high albite + water + melt is metastable relative to low albite + water. Above $16( \pm 1) \mathrm{kb}$, the assemblage high albite + water + melt is metastable relative to the jadeite-bearing assemblages (Boettcher \& Wyllie, 1969). Thus, the solidus shown in Fig. 15 is metastable at both the high and low pressure ends.
} 
systems have long been known (Morey \& Fenner, 1917), and they are not always in th vicinity of solid-solid phase transformations. Indeed, the wet solidi in many systems actuall go through pressure maxima (i.e. $\mathrm{d} P / \mathrm{d} T=0$ ), and these, too, appear unrelated to solid-soli reactions. These phenomena can be readily understood without recourse to changes in melt structure and are more likely related to the high solubility of water and its negative temperature dependence in certain systems (Morey \& Fenner, 1917; Morey, 1924, 1957).

\section{Summary of phase equilibrium calculations}

In this section, we illustrated an approach to modelling the thermodynamic properties of hydrous albitic melts based on direct measurements of hydrous species in albitic glasses. Two different relationships between water content and the activity of water in the melt based on our spectroscopic measurements were employed, one assuming Henrian behavior for molecular water and the other utilizing the formalism of a strictly regular solution developed in a previous section of this paper. The resulting thermodynamic models can account reasonably well for the pressure and temperature dependence of water solubility and the position of the water-saturated solidus of high albite. Similar success was had in modelling the thermodynamics of $\mathrm{CO}_{2}$-bearing albitic melt using the assumption that $a_{\mathrm{CO}_{2}}^{\mathrm{m}}=X_{\mathrm{CO}_{2} \text {, mol }}^{\mathrm{m}}$ (Stolper $e$ al., 1987). Although these models may be useful for modelling phase equilibria in this system, this was not the primary goal. Our principal intent was to demonstrate the potential of spectroscopic measurements of species concentrations for modelling the thermodynamic properties of silicate melts, and we believe this has been amply demonstrated.

\section{CONCLUSIONS}

(1) $\mathrm{H}_{2}$ manometry and NMR spectroscopy have been used to calibrate an infrared spectroscopic method for measuring the concentrations of molecular $\mathrm{H}_{2} \mathrm{O}$ and hydroxyl in albitic glasses. This technique offers a precise, accurate, and non-destructive method for measuring species concentrations and total water contents in hydrous glasses.

(2) Infrared spectroscopy has been used to determine the speciation of water in albitic glasses for total water contents up to about $11 \mathrm{wt} . \%$. At low total water contents, hydroxyl groups are the dominant form of dissolved water; at total water contents greater than $4 \mathrm{wt} . \%$, molecular water becomes the dominant hydrous species and the hydroxyl group concentration levels off. These results are consistent with the species concentrations in albitic glasses determined using NMR spectroscopy and the trends for albitic glasses are similar to those observed in other silicate glass compositions using infrared and NMR spectroscopies.

(3) The proportions of molecular $\mathrm{H}_{2} \mathrm{O}$ and $\mathrm{OH}$ in glasses quenched from melts equilibrated at temperatures in the range $950-1600^{\circ} \mathrm{C}$ and pressures between 1 and $25 \mathrm{~kb}$ are independent of the pressure of equilibration. The ratio of molecular water to hydroxyl groups decreases a small amount with increasing temperature over this temperature range.

(4) We have explored several models of the homogeneous equilibria between melt species in albitic melts. All are based on simple equilibria of the form $\mathrm{H}_{2} \mathrm{O}+\mathrm{O}^{2-}=2 \mathrm{OH}^{-}$. Although simple ideal mixing of these three species cannot account for the saturation of the hydroxy' group concentration for total water contents greater than about $4 \mathrm{wt} . \%$, this feature can be reproduced if the effects of non-ideal mixing of melt species, of polymerization, or of several distinguishable types of anhydrous melt species are considered. We cannot distinguish between these and other possible models of homogeneous equilibria in hydrous melts, but extension of our measurements to other compositions on the $\mathrm{SiO}_{2}-\mathrm{NaAlO}_{2}-\mathrm{H}_{2} \mathrm{O}$ join would provide important constraints. 
(5) We have developed two models of the thermodynamics of hydrous albitic melts. The first assumes that Henry's law holds; i.e. that the activity of water is proportional to the mole fraction of molecular water. The second describes the speciation and thermodynamics of hydrous albitic melts using the formalism of a strictly regular solution. These models can account reasonably well for the pressure and temperature dependence of water solubility in albitic melts and the position of the water-saturated solidus of high albite. The most important feature of this treatment is the connection between spectroscopic measurements and thermodynamics.

\section{ACKNOWLEDGEMENTS}

We thank: Dr. H. Eckert for the NMR spectroscopic analyses; Prof. J. Christie and Dr. I. Hutcheon for the TEM and ion-probe analyses; Dr. P. Dobson and Dr. S. Newman for assistance with the hydrogen extraction procedure; Prof. A. L. Boettcher, Prof. S. Epstein, and Dr. G. Lofgren for opening their laboratories to us; Prof. A. L. Boettcher, Prof. J. R. Holloway, Prof. P. McMillan, and Dr. J. Delaney for synthesis of various samples; and Dr. K. Burke of the Lunar and Planetary Institute for financial assistance to support work done at the Johnson Space Center. Reviews from A. L. Boettcher, Y. Bottinga, R. Fogel, and J. Nicholls led to important improvements to the manuscript. This work was supported by NSF Grants EAR-8212765, EAR-8417434 and EAR-8618229 and by the donors of the Petroleum Research Fund, administered by the American Chemical Society (Grant 17737AC2). Caltech Division of Geological and Planetary Sciences Contribution 4509.

\section{REFERENCES}

Acocella, J., Tomozawa, M., \& Watson, E. B., 1984. The nature of dissolved water in sodium silicate glasses and its effect on various properties. J. Non-Crystalline Solids 65, 175-83.

Adams, R. V., \& Douglas, R. W., 1959. Infra-red studies of various samples of fused silica with special reference to the bands due to water. J. Soc. Glass Technol. 43, 147-58 T.

Aines, R. D., Silver, L. A., Rossman, G. R., Stolper, E. M., \& Holloway, J. R., 1983. Direct observation of water speciation in rhyolite at temperatures up to $850^{\circ} \mathrm{C}$. Geol. Soc. Am. Abstr. Prog. 15, 512.

Bartholomew, R. F., Butler, B. L., Hoover, H. L., \& Wu, C. K., 1980. Infrared spectra of a water-containing glass. $J$. Am. ceram. Soc. 63, 481-5.

Schreurs, J. W. H., 1980. Wide-line NMR study of protons in hydrosilicate glasses of different water content. $J$. Non-Crystalline Solids 38/39, 679-84.

Blamart, D., Graham, C. M., \& Sheppard, S. M. F., 1986. The system $\mathrm{NaAlSi}_{3} \mathrm{O}_{8}$ (melt)- $\mathrm{H}_{2} \mathrm{O}$-sea water: Solubility of water and hydrogen isotope fractionation factor at 3,5 and $8 \mathrm{~kb}$. Intl. Symp. Exp. Miner. Geochem. Abstr. 23-4.

Boettcher, A. L., \& Wyllie, P. J., 1969. Phase relationships in the system $\mathrm{NaAlSiO}_{4}-\mathrm{SiO}_{2}-\mathrm{H}_{2} \mathrm{O}$ to 35 kilobars pressure. Am. J. Sci. 267, 875-909.

Bohlen, S. R., Boettcher, A. L., \& Wall, V. J., 1982. The system albite- $\mathrm{H}_{2} \mathrm{O}-\mathrm{CO}_{2}$ : A model for melting and activities of water at high pressures. Am. Miner. 67, 451-62.

Burnham, C. W., 91975. Water and magmas: A mixing model. Geochim. Cosmochim. Acta 39, $1077-84$.

_ 1979. The importance of volatile constituents. In: Yoder, H. S. Jr. (ed.) The Evolution of the Igneous Rocks. Princeton University Press, 439-82.

- Davis, N. F., 1971. The role of $\mathrm{H}_{2} \mathrm{O}$ in silicate melts: I. $P-V-T$ relations in the system $\mathrm{NaAlSi}_{3} \mathrm{O}_{8}-\mathrm{H}_{2} \mathrm{O}$ to 1 kilobars and $1000^{\circ}$ C. Am. J.Sci. 270, 54-79.

_ Jahns, R. H., 1962. A method for determining the solubility of water in silicate melts. Am. J. Sci. 260, $721-45$.

Day, H. W., \& Fenn, P. M., 1982. Estimating the $P-T-X_{\mathrm{H}_{2} \mathrm{O}}$ conditions during crystallization of low-calcium granites. J. Geol. 90, 485-507.

Eckert, H., Yesinowski, J. P., Stolper, E. M., Stanton, T. R., \& Holloway, J., 1987. The state of water in rhyolitic glasses: A deuterium NMR study. J. Non-Crystalline Solids 93, 93-114.

Silver, L. A., \& Stolper, E. M., 1988. Water in silicate glasses: Quantitation and structural studies by ${ }^{1} \mathrm{H}$ solid echo and MAS-NMR methods. J. phys. Chem. 92, 2055-64.

Epel'baum, M. B., 1985. The structure and properties of hydrous granitic melts. Geologica Carpathica 36, $491-8$.

Ernsberger, F. M., 1977. Molecular water in glass. J. Am. ceram. Soc. 60, 91-2. 
Farnan, I., Kohn, S. C., \& Dupree, R., 1987. A study of the structural role of water in hydrous silica glass using crosspolarization magic angle spinning NMR. Geochim. Cosmochim. Acta 51, 2869-73.

Fenn, P. M., 1973. Nucleation and growth of alkali feldspars from melts in the system $\mathrm{NaAlSi}_{3} \mathrm{O}_{8}-\mathrm{KAlSi}_{3} \mathrm{O}_{8}-\mathrm{H}_{2} \mathrm{O}$. Ph.D. thesis, Stanferd University.

Fine, G., \& Stolper, E., 1985. The speciation of carbon dioxide in fodium aluminosilicate glasses. Contr. Miner Petrol. 91, 105-21.

Flory, P. J., 1953. Principles of Polymer Chemistry. New York: Cornell University Press, 672 pp.

Goldsmith, J. R., \& Jenkins, D. M., 1985. The hydrothermal melting and low and high albite. Am. Miner. 70, 924-33.

Goranson, R. W., 1936. Silicate-water systems: The solubility of water in albite-melt. Trans. Am. Geophys. Union 17, 257-9.

- 1938. Silicate-water systems: Phase equilibria in the $\mathrm{NaAlSi}_{3} \mathrm{O}_{8}-\mathrm{H}_{2} \mathrm{O}$ and $\mathrm{KAlSi} \mathrm{O}_{8}-\mathrm{H}_{2} \mathrm{O}$ systems at high temperatures and pressures. Am. J. Sci. 35A, 71-91.

Guggenheim, E. A., 1952. Mixtures. Oxford University Press, $270 \mathrm{pp}$.

Hamilton, D. L., \& Oxtoby, S., 1986. Solubility of water in albite-melt determined by the weight-loss method. $J$. Geol. 94, 626-30.

Holloway, J. R., 1971. Internally-heated pressure vessels. In: Ulmer, G. C. (ed.) Research Techniques for High Pressure and High Temperature. New York: Springer-Verlag, 217-58.

1977. Fugacity and activity of molecular species in supercritical fluids. In: Fraser, D. (ed.) Thermodynamics in Geology. Boston: D. Reidel, 161-81.

Kadik, A. A., \& Lebedev, Ye. B., 1968. Temperature dependence of the solubility of water in an albite melt at high pressures. Geokhimiya 12, 1444-55.

Karsten, J. L., Holloway, J. R., \& Delaney, J. R., 1982. Ion microprobe studies of water in silicate melts: Temperature-dependent water diffusion in obsidian. Earth planet. Sci. Lett. 59, 420-8.

Khitarov, N. I., Kadik, A. S., \& Lebedev, E. B., 1963. Estimate of the thermal effect of the separation of water from felsic melts based on data for the system albite-water. Geokhimiya 7, 637-49.

Kress, V. C., Williams, Q., \& Carmichael, I. S. E., 1988. Ultrasonic investigation of melts in the system $\mathrm{Na}_{2} \mathrm{O}-\mathrm{Al}_{2} \mathrm{O}_{3}-\mathrm{SiO}_{2}$. Geochim. Cosmochim. Acta 52, 283-93.

Langer, K., \& Flörke, O. W., 1974. Near infrared absorption spectra $\left(4000-9000 \mathrm{~cm}^{-1}\right)$ of opals and the role of 'water' in these $\mathrm{SiO}_{2} \cdot \mathrm{nH}_{2} \mathrm{O}$ minerals. Fortsch. Miner. 52, 17-51.

Luth, R. W., \& Boettcher, A. L., 1986. Hydrogen and the melting of silicates. Am. Miner. 71, $264-76$. Mysen, B. O., \& Virgo, D., 1987. Hydrogen in silicate liquids: Solution mechanisms of hydrogen in liquids in the system $\mathrm{Na}_{2} \mathrm{O}-\mathrm{Al}_{2} \mathrm{O}_{3}-\mathrm{SiO}_{2}-\mathrm{H}_{2}$. Am. Miner. 72, $481-6$.

Luth, W. C., 1976. Experimental petrology: Igneous rocks. In: Bailey, D. K., \& MacDonald, R. (eds.) The Evolution of the Crystalline Rocks. New York: Academic Press, 333-417.

Jahns, R. H., \& Tuttle, O. F., 1964. The granite system at pressures of 4 to 10 kb. J.geophys. Res. 69, 759-73.

Masson, C. R., 1977. Anionic constitution of glass-forming melts. J. Non-Crystalline Solids 25, 1-41.

McMillan, P. F., Jakobsson, S., Holloway, J. R., \& Silver, L. A., 1983. A note on the Raman spectra of water-bearing albite glasses. Geochim. Cosmochim. Acta 47, 1937-43.

- Peraudeau, G., Holloway, J., \& Coutures, J.-P., 1986. Water solubility in a calcium aluminosilicate melt. Contr. Miner. Petrol. 94, 178-82.

_- Piriou, B., \& Navrotsky, A., 1982. A Raman spectroscopic study of glasses along the joins silica-calcium aluminate, silica-sodium aluminate, and silica-potassium aluminate. Geochim. Cosmochim. Acta 46, 2021-38.

Remmele, R. R., Jr., 1986. Hydroxyl sites in $\mathrm{SiO}_{2}$ glass: A note on infrared and Raman Spectra. Am. Miner. 71, $772-8$.

Morey, G. W., 1924. Relation of crystallization to the water content and vapor pressure of water in a cooling magma. J. Geol. 32, 291-5.

1957. The solubility of solids in gases. Econ. Geol. 52, 225-51.

Fenner, C. N., 1917. The ternary system $\mathrm{H}_{2} \mathrm{O}-\mathrm{K}_{2} \mathrm{SiO}_{3}-\mathrm{SiO}_{2}$. J. Am. chem. Soc. 39, 1173-229.

Morse, S. A., 1970. Alkali feldspars with water at $5 \mathrm{~kb}$ pressure. J. Petrology 11, 221-51.

Mysen, B. O., Finger, L. W., Seifert, F. A., \& Virgo, D., 1982. Curve-fitting of Raman spectra of amorphous materials. Am. Miner. 67, 686-96.

- Virgo, D., 1980. Solubility mechanisms of water in basalt melt at high pressures and temperatures: $\mathrm{NaCaAlSi}{ }_{2} \mathrm{O}_{7}-\mathrm{H}_{2} \mathrm{O}$ as a model. Ibid. 65, 1176-84.

$1986 \mathrm{a}$. Volatiles in silicate melts at high pressure and temperature. 1. Interaction between $\mathrm{OH}$ groups and $\mathrm{Si}^{4+}, \mathrm{Al}^{3+}, \mathrm{Ca}^{2+}, \mathrm{Na}^{+}$and $\mathrm{H}^{+}$. Chem. Geol. 57, 303-331.

$1986 \mathrm{~b}$. Volatiles in silicate melts at high pressure and temperature. 2. Water in melts along the join $\mathrm{NaAlO}_{2}-\mathrm{SiO}_{2}$ and a comparison of solubility mechanisms of water and fluorine. Ibid. 57, 333-58.

Harrison, W. J., \& Scarfe, C. M., 1980. Solubility mechanisms of $\mathrm{H}_{2} \mathrm{O}$ in silicate melts at high pressures and temperatures: A Raman spectroscopic study. Am. Miner. 65, 900-914.

Newman, S., Epstein, S., Stolper, E. M., 1988. Water, carbon dioxide, and hydrogen isotopes in glasses from the ca. 1340 A.D. eruption of the Mono Craters, California: Constraints on degassing phenomena and initial volatile content. J. Volcanol. geotherm. Res. 35, 75-96.

Stolper, E. M., \& Epstein, S., 1986. Measurement of water in rhyolitic glasses: Calibration of an infrared spectroscopic technique. Am. Miner. 71, 1527-41.

Orlova, G. P., 1962. The solubility of water in albite melts. Int. Geol. Rev. 6, 254-8. 
Ostrovskiy, I. A., Orlova, G. P., \& Rudnitskaya, Y. S., 1964. Stoichiometry in the solution of water in alkalialuminosilicate melts. Dokl. Akad Nauk SSR 157, 149-51.

Paterson, M. S., 1982. The determination of hydroxyl by infrared absorption in quartz, silicate glasses and similar materials. Bull. Miner. 105, $20-9$.

Persikov, E. S., 1972. Experimental studies of solubility of water in granitic melt and kinetics of the melt-water equilibria at high pressures. Int. Geol. Rev. 16, 1062-7.

Pichavant, M., \& Ramboz, C., 1985. Premiere détermination experimentale des relations de phases dans le systeme haplogranitique en conditions de soussaturation en $\mathrm{H}_{2}$ O. C.R. Acad. Sci. Paris 301, Ser. II, 607-10.

Prigogine, I., \& Defay, R., 1954. Chemical Thermodynamics, Everett, D. H. (trans.). New York: Longmans Green and Co., $543 \mathrm{pp}$.

Remmele, R., Stanton, T., McMillan, P., \& Holloway, J., 1986. Raman spectra of hydrous glasses along the quartz-albite join. EOS 67, 1274.

Richet, P., Roux, J., \& Pineau, F., 1986. Hydrogen isotope fractionation in the system $\mathrm{H}_{2} \mathrm{O}$-liquid $\mathrm{NaAlSi}_{3} \mathrm{O}_{8}$ : New data and comments on $\mathbf{D} / \mathbf{H}$ fractionation in hydrothermal experiments. Earth planet. Sci. Lett. 78, 115-20.

Scholze, H., 1959. Der Einbau des Wassers in Gläsern. Glastech. Ber. 32, 81-8, 142-5, 278-81.

Seifert, F., Mysen, B. O., \& Virgo, D., 1981. Quantitative determination of proportions of anionic units in silicate melts. Yb. Carnegie Inst. Wash. 80, 301-2.

Shaw, H. R., 1964. Theoretical solubility of $\mathrm{H}_{2} \mathrm{O}$ in silicate melts: Quasi-crystalline models. J. Geol. 72, 601-17.

Silver, L. A., Ihinger, P. D., \& Stolper, E., 1989. The influence of bulk composition on the speciation of water in silicate glasses. Contr. Miner. Petrol. (in press).

- Stolper, E., 1985. A thermodynamic model for hydrous silicate melts. J. Geol. 93, 161-78.

Stolen, R. H., \& Walrafen, G. E., 1976. Water and its relation to broken bond defects in fused silica. J. Chem. Phys. 64, 2623-31.

Stolper, E. M., 1982a. Water in silicate glasses: An infrared spectroscopic study. Contr. Miner. Petrol. 81, 1-17. 1982b. The speciation of water in silicate melts. Geochim. Cosmochim. Acta 46, 2609-20.

- Fine, G., Johnson, T., \& Newman, S., 1987. The solubility of carbon dioxide in albitic melt. Am. Miner. 72 , 1071-85.

Silver, L. A., 1985. The speciation of water in silicate glasses: The influence of bulk composition. EOS 66, 1140.

Aines, R. D., 1983. The effects of quenching rate and temperature on the speciation of water in silicate glasses. Ibid. 64, 339.

Stone, J., \& Walrafen, G. E., 1982. Overtone vibrations of OH-groups in fused silica optical fibers. J. Chem. Phys. 76, $1712-22$.

Takata, M., Acocella, J., Tomozawa, M., \& Watson, E. B., 1981. Effect of water content on the electrical conductivity of $\mathrm{Na}_{2} \mathrm{O} \cdot 3 \mathrm{SiO}_{2}$ glass. J. Am. ceram. Soc. 64, 719-24.

Tuttle, O. F., \& Bowen, N. L., 1958. Origin of granite in light of experimental studies in the system $\mathrm{KAlSi}_{3} \mathrm{O}_{8}-\mathrm{NaAlSi}_{3} \mathrm{O}_{8}-\mathrm{SiO}_{2}-\mathrm{H}_{2} \mathrm{O}$. Geol. Soc. Am. Mem. 74, 153 pp.

Uys, J. M., \&.King, T. B., 1963. The effect of basicity on the solubility of water in silicate melts. Trans. met. Soc. AIME 227, 492-500.

Voigt, D. E., Bodnar, R. J., \& Blencoe, J. G., 1981. Water solubility in melts of alkali feldspar composition at $5 \mathrm{~kb}$, $950^{\circ} \mathrm{C} . \operatorname{EOS} 62,428$.

Wasserburg, G. J., 1957. The effect of $\mathrm{H}_{2} \mathrm{O}$ in silicate systems. J. Geol. 65, 15-23.

Watson, E. B., 1981. Diffusion in magmas of depth in the earth: The effects of pressure and dissolved $\mathrm{H}_{2} \mathrm{O}$. Earth planet. Sci. Lett. 52, 291-301.

Wu, C., 1980. Nature of incorporated water in hydrated silicate glasses. J. Amer. ceram. Soc. 63, 453-57. 